\title{
Uso de informação linguística \\ e análise de conceitos formais no aprendizado de ontologias
}

\author{
Carlos Eduardo Atencio Torres
}

\author{
DISSERTAÇÃO APRESENTADA \\ AO \\ Instituto de Matemática e Estatística \\ DA \\ Universidade DE SÃo PAUlo \\ PARA \\ OBTENÇÃO DO TÍTULO \\ $\mathrm{DE}$ \\ Mestre em CiÊnCIAS \\ Programa: Ciência da Computação \\ Orientador: Prof. Dra. Renata Wassermann
}

Durante o desenvolvimento deste trabalho o autor recebeu auxílio financeiro da CAPES

São Paulo, Setembro de 2012 


\title{
Uso de informação linguística e análise de conceitos formais no aprendizado de ontologias
}

\author{
Esta dissertação contém as correções e alterações \\ sugeridas pela Comissão Julgadora durante a defesa \\ realizada por Carlos Eduardo Atencio Torres em 08/10/2012. \\ O original encontra-se disponível no Instituto de \\ Matemática e Estatística da Universidade de São Paulo.
}

Comissão Julgadora:

- Profa. Dra. Renata Wassermann (orientadora) - IME-USP

- Prof. Dr. Fabio Gagliardi Cozman - POLI-USP

- Prof. Dr. Flávio Soares Corrêa da Silva - IME-USP 


\section{Agradecimentos}

Agradeço a Deus em primeiro lugar, sem Ele não teria alcançado nada.

A minha família que sempre me apoiou, enviando-me cartas de ânimo e de saudades. Agradeço especialmente a minha mãe e a meu pai que souberam me dar palavras de superação desde Peru e me ajudaram quando mais o precisava. Também a meus tios e os meus primos, em especial o meu primo Gustavo que foi o primeiro em me motivar em vir ao Brasil.

Agradeço aos meus amigos de laboratório que me fizeram sorrir sempre: Alexandre, Fábio, Esdras, Fabiano e Wesley. Os veteranos do laboratório que sempre me inspiravam: Ricardo, Lovato, Ellen e Marcio. E agradeço especialmente a Paulo e Viviane, os quais considero como meus verdadeiros irmãos, realmente devo tudo a vocês, as suas orientações, o seu carinho me animou muito.

Também meus amigos que ainda sem compartilhar a mesma vida acadêmica mas um mesmo ideal, me brindaram sua amizade nos momentos mais oportunos: Mariana, Daniboy, Camila, Fabrício, Gabriel, Carol, Fausto, Ana Elisa, Rafael, Adriana, Luciana, Joseline e todo o pessoal dos focolares.

Agradeço a Thiago, André, Scarlat, Talita, Rêgener, Nilberth, Marcelo e Elza, os quais me ajudaram a recuperar o meu relacionamento com Deus. Esta foi a minha experiência mais profunda na universidade.

Meus irmãos na igreja: Bruno, Adriana, Camila, Dilce, Aline e Raquel; com quem compartilhei problemas e alegrias. Nós oramos e Deus premiou.

Agradeço os meus compatriotas: Alvaro, Edith, Erika, Daniel, Chorri, Carlos, Rosario, Jorge e Leissi; e sobretudo ao pessoal de casa, chamados de chichos: Harry, Pantera, Chicho, Jorge, Juan Carlos, Javier, Alberto, Roberto e Geiser que me ajudaram a ter muitas gargalhadas em casa. Muito obrigado pelos bons momentos.

Agradeço também a minha orientadora Renata a quem devo muito. Agradeço pela paciência e por não ter desistido de mim. Você é uma pessoa admirável que a base de exemplo me ensinou muito na vida.

Finalmente, agradeço a CAPES pelo apoio financeiro durante o mestrado. 


\section{Resumo}

TORRES, C. E. A. Uso de informação linguística e análise de conceitos formais no aprendizado de ontologias. 2012. 87 f. Dissertação (Mestrado) - Instituto de Matemática e Estatística, Universidade de São Paulo, São Paulo, 2012.

$\mathrm{Na}$ atualidade, o interesse pelo uso de ontologias tem sido incrementado. No entanto, o processo de construção pode ser custoso em termos de tempo. Para uma ontologia ser construída, precisa-se de um especialista com conhecimentos de um editor de ontologias. Com a finalidade de reduzir tal processo de construção pelo especialista, analisamos e propomos um método para realizar aprendizado de ontologias (AO) de forma supervisionada.

O presente trabalho consiste em uma abordagem combinada de diferentes técnicas no AO. Primeiro, usamos uma técnica estatística chamada $\mathrm{C} / \mathrm{NC}$-values, acompanhada da ferramenta Cogroo, para extrair os termos mais representativos do texto. Esses termos são considerados por sua vez como conceitos. Projetamos também uma gramática de restrições (GR), com base na informação linguística do Português, com o objetivo de reconhecer e estabelecer relações entre conceitos. Para poder enriquecer a informação na ontologia, usamos a análise de conceitos formais (ACF) com o objetivo de identificar possíveis superconceitos entre dois conceitos. Finalmente, extraímos ontologias para os textos de três temas, submetendo-as à avaliação dos especialistas na área. Um web site foi feito para tornar o processo de avaliação mais amigável para os avaliadores e usamos o questionário de marcos de características proposto pelo método OntoMetrics. Os resultados mostram que nosso método provê um ponto de partida aceitável para a construção de ontologias.

Pa lavras-chave: Aprendizado de Ontologias, Extração de Termos, Descoberta de Relações, Análise Sintática, Gramática de Restrições, Análise de Conceitos Formais, Avaliação de Ontologias. 


\section{Abstract}

TORRES, C. E. A. Use of linguistic information and formal concept analysis for ontology learning. 2012. 87 f. Dissertação (Mestrado) - Instituto de Matemática e Estatística, Universidade de São Paulo, São Paulo, 2012.

Nowadays, the interest in the use of ontologies has increased, nevertheless, the process of ontology construction can be very time consuming. To build an ontology, we need a domain expert with knowledge in an ontology editor. In order to reduce the time needed by the expert, we propose and analyse a supervised ontology learning (OL) method.

The present work consists of a combined approach of different techniques in OL. First, we use a statistic technique called $\mathrm{C} / \mathrm{NC}$-values, with the help of the Cogroo tool, to extract the most significant terms. These terms are considered as concepts consequently. We also design a constraint grammar (CG) based in linguistic information of Portuguese to recognize relations between concepts. To enrich the ontology information, we use the formal concept analysis (FCA) in order to discover a parent for a set of concepts. In order to evaluate the method, we have extracted ontologies from text on three different domains and tested them with corresponding experts. A web site was built to make the evaluation process friendlier for the experts and we used an evaluation framework proposed in the OntoMetrics method. The results show that our method provides an acceptable starting point for the construction of ontologies.

Keywords: Ontology Learning, Term Extraction, Relation Discovery, Syntactic Analysis, Constraint Grammar, Formal Concept Analysis, Ontology Evaluation. 


\section{Sumário}

Lista de Abreviaturas $\quad$ xi

Lista de Símbolos $\quad$ xiii

Lista de Figuras $\quad$ xv

Lista de Tabelas $\quad$ xvii

1 Introdução 1

2 Aprendizado de Ontologias $\quad 3$

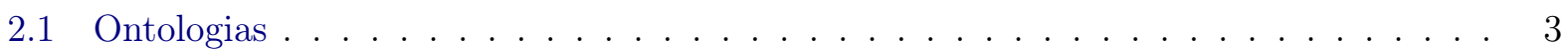

2.1 .1 Definição de Ontologias . . . . . . . . . . . . . . . . . . 3

2.1 .2 Tipos de ontologia . . . . . . . . . . . . . . . . . . 3

2.1 .3 Lógicas de Descrição . . . . . . . . . . . . . . . . . . . . . . . . . . . 4

2.1 .4 Raciocínio . . . . . . . . . . . . . . . . . . . 4

2.2 Aprendizado de Ontologias . . . . . . . . . . . . . . . . . . 6

2.2.1 Modelo de Camadas de Phillip Cimiano . . . . . . . . . . . . . . . 6

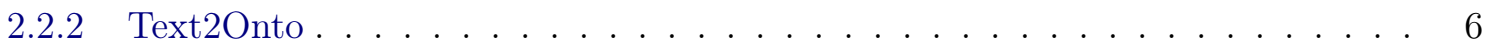

2.2 .3 Gramática Restritiva $(\mathrm{GR}) \quad \ldots \ldots \ldots \ldots \ldots \ldots$

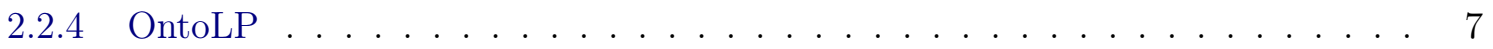

3 Análise de Conceitos Formais $\quad 9$

3.1 Exemplo do domínio de Turismo . . . . . . . . . . . . . . . . . . . 9

3.2 Forma Reduzida do Reticulado . . . . . . . . . . . . . . . . . . . . . . . 11

3.3 Aplicação nas Ontologias . . . . . . . . . . . . . . . . . . . . . . . . 11

3.4 Conceito Superior Comum . . . . . . . . . . . . . . . . . . . . . . . 12

4 Extração de Termos $\quad 15$

4.1 Métodos para extração de termos . . . . . . . . . . . . . . . . . . . 16

4.2 Ferramentas para a extração de termos . . . . . . . . . . . . . . . . . 16

4.3 Reconhecimento de sintagmas nominais e preposicionais . . . . . . . . . . . . 17

4.4 Extração de candidatos a termos com a métrica C-value/NC-value . . . . . . . . . . 17

4.4 .1 Calculando os C-values . . . . . . . . . . . . . . . . . 18

4.4 .2 Calculando os NC-values . . . . . . . . . . . . . . . . . . 19 
5 Descoberta de Relações $\quad 21$

5.1 Descoberta de Relações Taxonômicas . . . . . . . . . . . . . . . . . . . . . . . . 21

5.1 .1 Baseado em Similaridade . . . . . . . . . . . . . . . . . . 21

5.1 .2 Teoria de Conjuntos . . . . . . . . . . . . . . . . . . . 22

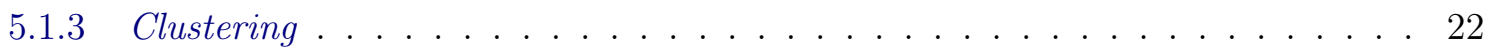

5.2 Descoberta de Relações Não Taxonômicas ． . . . . . . . . . . . . . . . . . . . . 22

5.3 Gramática de Restrições . . . . . . . . . . . . . . . . . . . . . . . . . . . 23

6 Análise Sintática $\quad 25$

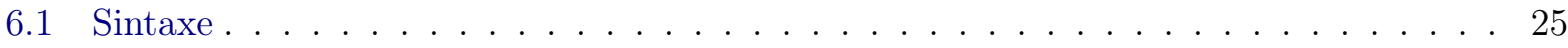

6.1 .1 Oração . . . . . . . . . . . . . . . . . . . . . . 25

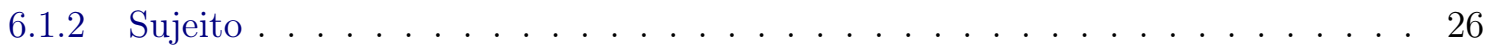

6.1 .3 Predicado . . . . . . . . . . . . . . . . . . . 27

6.2 Orações Complexas . . . . . . . . . . . . . . . . . . . . 28

6.2 .1 Orações subordinadas . . . . . . . . . . . . . . . . . . . 28

6.2 .2 Orações coordenadas . . . . . . . . . . . . . . . . . . . . . . . 29

6.3 Gramática Gerativa . . . . . . . . . . . . . . . . . . . . . . . 30

7 Experimentos e Resultados 33

7.1 Descrição dos textos . . . . . . . . . . . . . . . . . . . . . 33

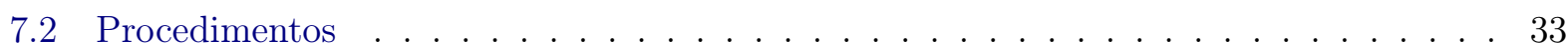

7.2 .1 Extração de Termos . . . . . . . . . . . . . . . . . . . . . 34

7.2 .2 Descoberta de Relações . . . . . . . . . . . . . . . . . . . . . . . 35

7.2 .3 Análise de Conceitos Formais . . . . . . . . . . . . . . . . . . . . 38

7.2 .4 Experimentando o uso da $\mathrm{ACF} \ldots \ldots \ldots \ldots \ldots$

8 Avaliação de Ontologias $\quad 41$

8.1 Introdução . . . . . . . . . . . . . . . . . . . . . . . . . . . 41

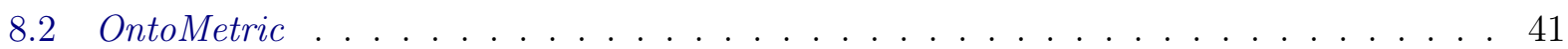

8.3 Avaliação com OntoMetrics . . . . . . . . . . . . . . . . . . . . . . . . 44

9 Conclusões $\quad 45$

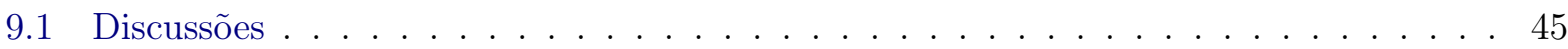

9.2 Considerações Finais . . . . . . . . . . . . . . . . . . . . . . . 47

9.3 Sugestões para Pesquisas Futuras ． . . . . . . . . . . . . . . . . . . 48

A Lista de Stop-Words $\quad 49$

B AOntoWEB $\quad 51$

C Questionário sobre o Marco de Características da Dimensão Conteúdo da Onto$\begin{array}{ll}\text { logia } & 55\end{array}$

$\begin{array}{ll}\text { D Ontologia de Branca de Neve } & 57\end{array}$

E Ferramenta para ajudar o usuário $\quad 59$ 
Referências Bibliográficas 


\title{
Lista de Abreviaturas
}

\author{
AO Aprendizado de Ontologias (Ontology Learning) \\ ACE Attempto Controlled English \\ ACF Análise de Conceitos Formais (Formal Concept Analysis) \\ CMS Content Management System \\ DL Description Logic \\ EMP Expressão Multi-Palavras \\ GR Gramática Restritiva (Constraint Grammar) \\ HNSCC Head and Neck Squamous Cell Carcinoma \\ INCA Instituto Nacional do Câncer \\ MAC Menor Ancestral Comum \\ SF Sintagma Flexional \\ SN Sintagma Nominal \\ SP Sintagma Preposicional \\ SV Sujeito-Verbo \\ SVO Sujeito-Verbo-Objeto \\ SUB Subjeito \\ OS Oração Subordinada \\ OSS Oração Subordinada Substantiva \\ OSSS Oração Subordinada Substantiva Subjetiva \\ OSSOD Oração Subordinada Substantiva Objetiva Direta \\ OSSOI Oração Subordinada Substantiva Objetiva Indireta \\ OSSP Oração Subordinada Substantiva Predicativa \\ OSSA Oração Subordinada Substantiva Apostiva \\ OSSCN Oração Subordinada Substantiva Completiva Nominal \\ OSA Oração Subordinada Adjetiva \\ OWL Ontology Web Language \\ W3C World Wide Web Consortium \\ XCES XML-based Encoding Standard for Linguistic Corpora
}




\section{Lista de Símbolos}

$\mathcal{A L}$ Linguagem de atributos (Attribute Language)

$\mathcal{I}$ Interpretação

$\mathcal{U}$ Operador de Disjunção

$\mathcal{C}$ Operador de Negação

$\mathcal{E} \quad$ Operador Existencial

$\forall \quad$ Operador lógico para todo

$\mathcal{N}$ Restrição numérica

$\mathcal{Q}$ Restrição numérica qualificada

$\mathcal{O}$ Operador de enumeração

$\mathcal{F}$ Operador de seleção 


\section{Lista de Figuras}

2.1 Conjunto de Camadas para AO de acordo com a metodologia de Philipp Cimiano . . 7

3.1 Reticulado de conceitos para o domínio de Viagens Turísticas. . . . . . . . . . . . 10

3.2 Taxonomia de conceitos para o domínio de Turismo . . . . . . . . . . . . . . . . 11

3.3 Exemplo de reticulado . . . . . . . . . . . . . . . . . . . . . . . 13

4.1 Árvore sintática retornada pelo Cogroo . . . . . . . . . . . . . . . . . . . . 18

6.1 Exemplo de indicador sintagmático . . . . . . . . . . . . . . . . . . 31

7.1 Árvore sintática da frase A Branca de Neve vagou pela floresta . . . . . . . . . . . . 34

7.2 Reticulado de conceitos para o tema de Métodos Ágeis . . . . . . . . . . . . . . 40

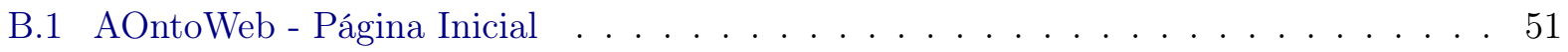

B.2 AOntoWeb - Introdução à avaliação da ontologia de Branca de Neve . . . . . . . . . 52

B.3 AOntoWeb - Branca de Neve - Termos . . . . . . . . . . . . . . . . . . . 52

B.4 AOntoWeb - Branca de Neve - Relações de Equivalência . . . . . . . . . . . . . . . 53

B.5 AOntoWeb - Branca de Neve - Relações Taxonómicas . . . . . . . . . . . . . . . . 53

B.6 AOntoWeb - Branca de Neve - Dominio é Imagem . . . . . . . . . . . . . . . . . . . . . . . . . . 54

B.7 AOntoWeb- Branca de Neve- Outras . . . . . . . . . . . . . . . . . . 54

E.1 Selecionando texto . . . . . . . . . . . . . . . . . . . . . . . . 59

E.2 Visualizar a árvore sintática que Cogroo retorna para cada sentencia . . . . . . . 60

E.3 Filtro de termos . . . . . . . . . . . . . . . . . . . . . . . 60

E.4 Filtro de relações . . . . . . . . . . . . . . . . . . . . . . . 61

E.5 Selecionar onde guardar a ontologia . . . . . . . . . . . . . . . . . . 61 


\section{Lista de Tabelas}

2.1 Alguns construtores que formam famílias de lógicas de descrição de $\mathcal{A L C ~} \quad \ldots$. . . 5

2.2 Comparação de Mecanismos de Inferência (Fonte: Wikipedia) . . . . . . . . . . . . 6

2.3 Exemplo do ACE, extraído do site de Attempto. . . . . . . . . . . . . . . . 8

3.1 Exemplo de verbos e objetos extraídos de um corpus textual sobre o domínio de Viagens Turísticas. . . . . . . . . . . . . . . . . . . . . . . 10

3.2 Domínio de Viagens Turísticas como um contexto formal. . . . . . . . . . . . . . 10

4.1 Lematização e informação morfológica . . . . . . . . . . . . . . . . . . . 18

5.1 Padrões de Hearst adaptados por Baségio. Em que NP: Noun Phrase (Sintagma Nominal) e SUB: Substantivo . . . . . . . . . . . . . . . . . . . . 22

7.1 Lista de termos para os nossos textos testes $\ldots \ldots \ldots \ldots$

8.1 Enfoques usados na avaliação de métodos de AO . . . . . . . . . . . . . . . 42

8.2 Características na dimensão conteúdo sem a avaliação do fator de axiomas. . . . . . . 43

8.3 Média dos resultados dos questionários sobre os fatores de conceito, relações e taxonomia. O valor mínimo era 1 e o máximo $5 . \ldots \ldots$. . . . . . . . . 44 


\section{Capítulo 1}

\section{Introdução}

O uso de ontologias formais no contexto da Web Semântica permite compartilhar conhecimento através de diferentes aplicações indo em direção ao sonho de Berners-Lee e Fischetti (1999). No entanto, a construção dessas ontologias é, geralmente, feita por um especialista (processo este que requer um investimento considerável de tempo e dinheiro). Portanto, é necessário desenvolver um método automático ou semiautomático de construção de ontologias. Esse processo é chamado de Aprendizado de Ontologia (AO).

Diferentes metodologias e aplicações que trataram o problema de $\mathrm{AO}$ foram detalhados nos estudos de Drumond e Girardi (2008) e Brank et al. (2005). A maioria dessas metodologias apresentou uma arquitetura dividida em: (i) extração de termos, (ii) extração de conceitos, (iii) construção de taxonomia de conceitos, (iv) descoberta de relações, e (v) extração de axiomas.

É importante notar que a maioria dos trabalhos foi feito para o idioma inglês, sendo o trabalho de Ribeiro-Junior (2008) o primeiro a realizar AO para textos em Português. Ele apresentou um plugin para o Protégé chamado OntoLP que recebe textos previamente transformados para o formato XCES (formato para representar a estrutura sintática do texto) e utiliza padrões sintáticos para adquirir as relações. Porém, um dos problemas dessa abordagem é que, devido à rigidez dos padrões sintáticos, muitos casos verdadeiros são omitidos na análise.

Um dos trabalhos para a língua inglesa é o projeto $\mathrm{ACE}^{1}$ que apresenta uma interessante proposta de tradução de sentenças escritas em linguagem natural a um formato de propriedades ontológicas. Tal processo usa uma gramática de restrições para restringir os elementos da linguagem que serão considerados para ser colocados na ontologia.

A Análise de Conceitos Formais (ACF), proposta por Wille (1982) é a forma mais simples de adquirir uma taxonomia de acordo com Cimiano et al. (2003). Cimiano mostrou que uma ontologia pode ser adquirida a partir de um reticulado de conceitos traduzido em uma taxonomia de conceitos.

Um grave problema nesse enfoque é observado no momento da etiquetação das propriedades. Já para Wang e He (2006), isso não representa problema, pois ele utiliza a linguagem SWRL (Semantic Web Rule Language) para representar regras em uma ontologia. Ainda assim, o ponto forte da ACF ainda é a taxonomia de conceitos.

No presente trabalho propomos um método de AO para o Português. Nosso objetivo não é construir um método totalmente autônomo mas que possa, com auxílio de um especialista, construir uma primeira ontologia sobre um determinado domínio. Este método consiste de diferentes etapas:

- Usamos o método C/NC-values para a extração de termos. Esse método utiliza a informação sintática das palavras, junto com a frequência delas e considera também a frequência em que uma palavra candidata a termo é parte de outra palavra candidata a termo. Uma ferramenta muito útil para a tarefa de conseguir a informação sintática é o corretor ortográfico Cogroo, o qual possui uma API para analisar textos.

- Projetamos uma GR para o Português, a qual foi testada com uma grande quantidade de construções sintáticas dessa língua.

\footnotetext{
${ }^{1}$ http://attempto.ifi.uzh.ch
} 
- Usamos a ferramenta Galicia, proposta por Godin et al. (1991), para construir um reticulado de conceitos a partir de uma tabela objeto-atributo. Usamos tal reticulado para identificar conceitos superiores comuns a dois ou mais conceitos e os adicionávamos na ontologia.

- Implementamos uma ferramenta em Java para extrair as ontologias a partir dos textos. Essa ferramenta possui uma opção de filtragem para cada etapa no AO.

- Usamos o marco de características do método OntoMetrics para avaliar a dimensão "conteúdo da ontologia"retornadas pela nossa ferramenta. Tal dimensão possui os fatores de Taxonomia, Conceitos, Relações e Axiomas. No entanto, o fator de Axiomas não foi considerado para o presente trabalho.

- Para a avaliação, levamos em consideração textos de três temas: (i) Métodos Ágeis, (ii) Branca de Neve e (iii) Câncer (Doença). Usamos a ferramenta e geramos ontologias para esses textos.

- Fizemos um site para mostrar amigavelmente tais ontologias para que especialistas as avaliem. As avaliações foram muito interessantes e as ontologias provaram ser idoneamente aceitáveis.

Os Capítulos 2 e 3 são introdutórios e apresentarão, de forma geral, os conceitos de AO e ACF respectivamente. Já no Capítulo 4, começaremos a descrever um sistema de $\mathrm{AO}$ e mencionaremos diferentes formas de extração de termos, ressaltando a técnica de C/NC-values. No Capítulo 5, descreveremos diferentes técnicas de descoberta de relações e discutiremos o problema da GR. No Capítulo 6, faremos um breve resumo da sintaxe da gramática portuguesa e descreveremos a gramática gerativa e a análise de constituintes. No Capítulo 7, relataremos nossas alegrias e frustrações nos experimentos. No Capítulo 8, introduziremos o conceito de avaliação de ontologias, detalhando o método de OntoMetrics e apresentaremos os resultados da avaliação pelos especialistas consultados. Finalmente, no Capítulo 9, relataremos as conclusões do trabalho. 


\section{Capítulo 2}

\section{Aprendizado de Ontologias}

Neste capítulo, revisaremos de forma geral os temas de ontologias, lógicas descritivas e aprendizado de ontologias $(\mathrm{AO})$.

\subsection{Ontologias}

\subsubsection{Definição de Ontologias}

De acordo com Gruber (1993), uma ontologia é a especificação de uma conceitualização compartilhada. De forma prática, Ivan Kostial (2003) indicou que o uso de uma ontologia permite definir conceitos e relações representando conhecimento a respeito de um documento, em particular em um domínio específico de termos.

O desenvolvimento de uma ontologia geralmente está sob a responsabilidade de um especialista com conhecimentos de um editor de ontologias. Tal processo segue um conjunto de boas práticas que vemos por exemplo em Mizoguchi (2003); Noy e Mcguinness (2001).

Uma ontologia possui os seguintes elementos:

1. Classes, também chamadas de conceitos;

2. Propriedades, também chamadas papéis em lógica de descrição; e

3. Indivíduos que são instâncias de classes definidas.

\subsubsection{Tipos de ontologia}

De acordo com a riqueza semântica, Mizoguchi (2003) definiu dois tipos de ontologias:

1. Ontologias pesadas: São desenvolvidas prestando-se muita atenção ao significado de cada conceito, assim como à ordem das relações. Dessa maneira, busca-se garantir a consistência e fidelidade do modelo.

2. Ontologias leves: São hierarquias de conceitos sem definições extensas. Elas melhoram as consultas, porém tornam-se dependentes do contexto.

Em 2004, o W3C recomendou OWL (Web Ontology Language) como linguagem para descrição de ontologias. OWL começou com três sublinguagens:

OWL-Lite: atende aqueles usuários que necessitam principalmente de uma classificação hierárquica e restrições simples. Permite um caminho de migração mais rápido de tesauros e outras taxonomias.

$\boldsymbol{O W L} \boldsymbol{W} \boldsymbol{D}$ : atende aqueles usuários que desejam a máxima expressividade, enquanto mantém a computabilidade e decibilidade, ou seja, garante-se que todas as conclusões sejam computáveis em tempo finito. 
$\boldsymbol{O W L}$-Full: é direcionada àqueles usuários que querem a máxima expressividade e a liberdade sintática do RDF sem garantir a decidibilidade computacional.

A partir de 2009, o W3C recomendou OWL 2 como linguagem padrão para expressar ontologias. OWL 2 substitui o antigo padrão recomendado em 2004 adicionando mais características. Este novo padrão introduz o conceito de perfil que é um fragmento de OWL 2 para negociar o poder expressivo pela eficiência de raciocínio. Existem três perfis:

OWL $2 \boldsymbol{E L}$ : fornece algoritmos de tempo polinomial para todas as tarefas padrão de raciocínio; é particularmente útil em aplicações empregando ontologias que contêm um grande número de propriedades e/ou classes. A sigla $E L$ reflete a base do perfil de família de lógicas de descrição $\mathcal{E L}$ (quantificação existencial).

$\boldsymbol{O W L} 2 \boldsymbol{Q L}$ : destina-se a aplicações que utilizam grandes volumes de instâncias de dados e nas quais a tarefa mais importante é devolver resultados para as consultas. A sigla $Q L$ reflete o fato que pergunta-resposta nesse perfil pode ser implementada reescrevendo perguntas em uma linguagem de consulta relacional padrão.

$O W L 2 R L$ : é destinada a aplicações que requerem raciocínio escalável sem sacrificar em excesso o poder expressivo. Sistemas de raciocínio OWL $2 R L$ podem ser implementados usando-se mecanismo de raciocínio baseado em regras. A sigla $R L$ reflete o fato que o raciocínio, neste perfil, pode ser implementado usando-se uma linguagem de regras padrão.

\subsubsection{Lógicas de Descrição}

Staab e Studer (2004) indicaram que as lógicas de descrição são uma família de linguagens de representação de conhecimento, podendo representar o conhecimento de um domínio de maneira formal e estruturada.

Cada lógica se diferencia entre si pelos construtores que possui, formando diferentes combinações a partir do $\mathcal{A L}^{1}$ de diversas extensões. A Tabela 2.1 apresenta as definições sintáticas e semânticas de diferentes construtores, respeitando a notação:

- A,C,D: são nomes de conceitos.

- R: relação.

- $\mathcal{I}$ : ou interpretação, é um par $\left\langle\Delta^{\mathcal{I}},{ }^{\mathcal{I}}\right\rangle$, em que :

$-\Delta^{\mathcal{I}}$ é o universo.

- I é uma função de mapeamento de:

* Conceitos para subconjuntos de $\Delta^{\mathcal{I}}$, e

* Papéis para subconjuntos de $\Delta^{\mathcal{I}} \times \Delta^{\mathcal{I}}$.

\subsubsection{Raciocínio}

Um mecanismo de inferência OWL é um mecanismo capaz de provar a consistência de uma ontologia e/ou inferir consequências lógicas a partir do conjunto de axiomas que a ontologia possui.

O trabalho do mecanismo de inferência consiste em:

- Encontrar relações de subordinação entre dois conceitos, por exemplo, $C \sqsubseteq D$ quer dizer que as interpretações de $C$ estão contidas em $D$, ou seja, $C^{\mathcal{I}} \subseteq D^{\mathcal{I}}$.

- Encontrar equivalência de conceitos $(C \equiv D)$.

\footnotetext{
${ }^{1}$ linguagem de atributos, em inglês attribute language
} 


\begin{tabular}{|l|c|l|}
\hline Construtor & Sintaxe & Semântica \\
\hline Nome de Conceito & $\mathrm{A}$ & $A^{\mathcal{I}} \subseteq \Delta^{\mathcal{I}}$ \\
\hline Top & $\top$ & $\Delta^{\mathcal{I}}$ \\
\hline Bottom & $\perp$ & 0 \\
\hline Conjunção & $C \sqcap D$ & $C^{\mathcal{I}}$ \\
\hline Disjunção $(\mathcal{U})$ & $C \sqcup D$ & $C^{\mathcal{I}} \cup D^{\mathcal{D}}$ \\
\hline Negação $(\mathcal{C})$ & $\neg C$ & $\Delta^{\mathcal{I}} \backslash C^{\mathcal{I}}$ \\
\hline Universal & $\forall R . C$ & $\left\{x \mid \forall y: R^{\mathcal{I}}(x, y) \rightarrow C^{\mathcal{I}}(y)\right\}$ \\
\hline Existencial $(\mathcal{E})$ & $\exists R . C$ & $\left\{x \mid \exists y: R^{\mathcal{I}}(x, y) C^{\mathcal{I}}(y)\right\}$ \\
\hline Restrição numérica $(\mathcal{N})$ & $\geq n . R$ & $\left\{x \mid \sharp\left\{y \mid R^{\mathcal{I}}(x, y) \geq n\right\}\right\}$ \\
\hline Restrição numérica qualificada $(\mathcal{Q})$ & $\geq n . R . C$ & $\left\{x \mid \sharp\left\{y \mid R^{\mathcal{I}}(x, y) \wedge C^{\mathcal{I}}(y)\right\}\right\}$ \\
\hline Enumeração $(\mathcal{O})$ & $\left\{a_{1}, \ldots a_{n}\right\}$ & $\left\{a_{1}^{\mathcal{I}}, \ldots, a_{n}{ }^{\mathcal{I}}\right\}$ \\
\hline Seleção $\mathcal{F}$ & $f: C$ & $\left\{x \in D o m\left(f^{\mathcal{I}}\right) \mid C^{\mathcal{I}}\left(f^{\mathcal{I}}(x)\right)\right\}$ \\
\hline
\end{tabular}

Tabela 2.1: Alguns construtores que formam famílias de lógicas de descrição de $\mathcal{A L C}$

- Verificar se a ontologia é consistente.

Na Tabela 2.2, foi comparado um conjunto de mecanismos, respeitando-se os seguintes critérios:

Lógicas de Descrição : A fim de evitar nomes extensos para lógicas de descrição, a abreviação $\mathcal{S}$ é usada para se referir a $\mathcal{A L C}_{R^{+}}$(estende $\mathcal{A L C}$ com papéis transitivos). Membros de $\mathcal{S}$ são $\mathcal{S H \mathcal { H F }}$ (estende $\mathcal{A L C}_{R^{+}}$com papéis hierárquicos, papéis inversos e número de restrições da forma $\leq 1 R$ ), $\mathcal{S H \mathcal { L }}$ (estende $\mathcal{A L C}_{R^{+}}$com papéis hierárquicos, papéis inversos e número de restrições avaliado) e outros que podem ser formados com ajuda da Tabela 2.1.

Algoritmo de Raciocínio : Algoritmos como Resolução, Tableaux, RETE (descrito em Forgy (1982)) e Datalog.

Verificação de Consistência : Verifica se a ontologia apresenta inconsistências.

Suporte de Regras : SWRL (Semantic Web Rule Language) é uma proposta para combinar as sublinguagens de OWL (OWL DL e Lite) com um conjunto de regras especificadas em RuleML (Rule Markup Language - Linguagem de marcação de regras).

Linguagem : Em que linguagem de programação foi feito.

O mercado oferece diferentes mecanismos de inferência que podem ser usados junto ao editor Protégé de ontologias, por exemplo o Pellet ${ }^{2}$, que é um mecanismo de código aberto, prático e usado em sistemas que trabalham com $O W L 2 D L$. Ele é completo e aceita OWL-DL, além disso, possui um desempenho similar aos dos outros mecanismos de inferência como o $\mathrm{FACT}++$ ou o RacerPRO (Sirin et al. (2007)).

A OWL API ${ }^{3}$ é uma API escrita em Java para manipular e criar ontologias. A última versão desta API foi projetada para trabalhar com OWL 2 .

O mecanismo de inferência mais atual é o HermiT que usa o algoritmo de hypertableau. Segundo Shearer et al. (2008), HermiT possui uma maior rapidez com respeito aos seus antagonistas: $\mathrm{FACT}++$ e Pellet.

HermiT é compatível com OWL API a partir da versão 3.1.0.

\footnotetext{
${ }^{2}$ http://clarkparsia.com/pellet

${ }^{3} \mathrm{http}: / /$ owlapi.sourceforge.net/
} 


\begin{tabular}{|l|l|l|l|l|l|l|}
\hline & Pellet & Kaon2 & RacerPro & Jena & FaCT++ & HermiT \\
\hline $\begin{array}{l}\text { Lógica de } \\
\text { Descrição }\end{array}$ & SROIQ(D) & SHIQ(D) & SHIQ(D-) & $\begin{array}{l}\text { Subconjunto } \\
\text { de SHIN(D) }\end{array}$ & SROIQ(D) & SHOIQ+ \\
\hline Algoritmo & Tableau & $\begin{array}{l}\text { Resolução } \\
\text { e Datalog }\end{array}$ & Tableau & $\begin{array}{l}\text { Basado em } \\
\text { Regras }\end{array}$ & Tableau & Hipertableau \\
\hline $\begin{array}{l}\text { Verificação } \\
\text { de Consis- } \\
\text { tência }\end{array}$ & Sim & - & Sim & $\begin{array}{l}\text { Incompleto } \\
\text { para OWL } \\
\text { DL Sim }\end{array}$ & Sim \\
\hline $\begin{array}{l}\text { Suporte } \\
\text { de Regras }\end{array}$ & $\begin{array}{l}\text { Sim } \\
\text { (SWRL) }\end{array}$ & $\begin{array}{l}\text { Sim } \\
\text { (SWRL) }\end{array}$ & $\begin{array}{l}\text { Sim não to- } \\
- \text { nand } \\
\text { talmente } \\
\text { suportado) } \\
\text { e regras } \\
\text { próprias }\end{array}$ & $\begin{array}{l}\text { Sim (Regras } \\
\text { próprias) }\end{array}$ & Não & $\begin{array}{l}\text { Sim } \\
\text { (SWRL- } \\
\text { DL) }\end{array}$ \\
\hline Linguagem & Java & Java & Java, Lisp & Java & C++ & Java \\
\hline
\end{tabular}

Tabela 2.2: Comparação de Mecanismos de Inferência (Fonte: Wikipedia)

\subsection{Aprendizado de Ontologias}

O termo Aprendizado de Ontologias (AO) foi originalmente usado por Maedche e Staab (2001) e foi descrito como a aquisição de um modelo de domínio a partir de uma fonte de dados. Segundo Drumond e Girardi (2008), os tipos de fontes de dados podem ser:

Dados estruturados : por exemplo os arquivos XML;

Dados semiestruturados : como alguns arquivos HTML que possuem conteúdo semântico (tags no cabeçalho).

Dados não estruturados : geralmente a maior parte da informação vem deste tipo de dados, e é o que chamamos de texto sem formatação.

Esta categorização se aplica de forma similar aos tipos de AO, existindo AO para dados estruturados, semiestruturados e nãoestruturados.

De acordo com Yang e Callan (2008), o AO é definido também como um problema de otimização em que se tenta minimizar as mudanças que se fazem a uma ontologia parcial no processo de adicionar novos conceitos.

$\mathrm{Na}$ literatura atual encontramos sempre metodologias com aprendizado semiautomático. Mesmo o trabalho de Blomqvist (2005) em cujo título declara ser um método totalmente automático, na realidade faz uso de padrões (que usuário insere previamente) para identificar padrões léxicosintático e padrões morfológicos consequentemente.

\subsubsection{Modelo de Camadas de Phillip Cimiano}

A metodologia de Cimiano (2006) é usada como padrão no AO. Consiste em um conjunto de camadas (ver Figura 2.1) em que primeiramente extraímos os termos de um texto, depois realizamos o aprendizado de conceitos, de relações e finalmente na parte superior da pilha, o aprendizado de axiomas.

\subsubsection{Text2Onto}

Originalmente tinha o nome de TextToOnto e foi uma ferramenta parte do projeto $\mathrm{KAON}^{4}$, que é um projeto de código aberto para o desenvolvimento de ontologias com fins empresariais.

\footnotetext{
${ }^{4}$ http://kaon.semanticweb.org/
} 


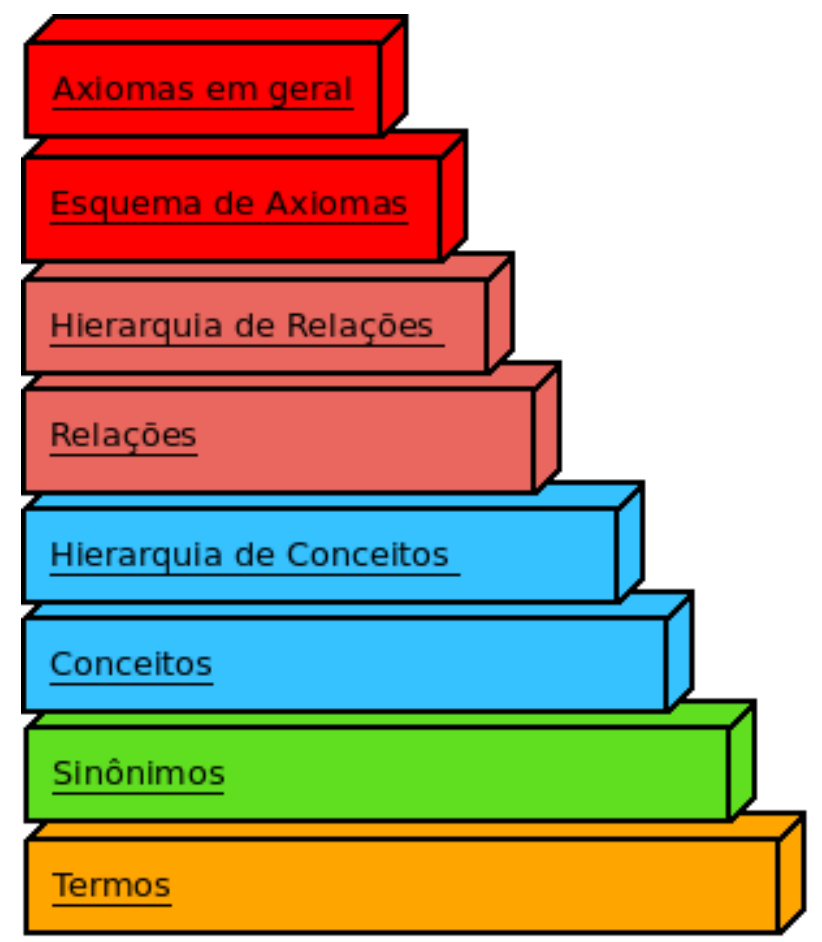

Figura 2.1: Conjunto de Camadas para AO de acordo com a metodologia de Philipp Cimiano

O Text2Onto ${ }^{5}$ adquiriu o seu atual nome a partir do trabalho de Cimiano e Volköer (2005), em que os autores apresentam três novas melhorias: (i) Um modelo ontológico probabilístico (MOP), (ii) uma interface de interação com o usuário, e (iii) uma estratégia de atualização das probabilidades no MOP.

\subsubsection{Gramática Restritiva (GR)}

É uma técnica que consiste em aplicar padrões léxico-sintáticos com informação contextual sobre textos a fim de adquirir apenas certa informação desejada.

Os sistemas baseados em GR são o foco de pesquisa do VISL ${ }^{6}$, que é um projeto importante de desenvolvimento de ferramentas baseadas em gramáticas online para fins acadêmicos. Entre algumas ferramentas que VISL oferece está o $\mathrm{ACE}^{7}$ (Attempto Controlled English) que tem por objetivo a construção da ontologia a partir de um texto recebido em linguagem natural com certas restrições.

$\mathrm{Na}$ Tabela 2.3 vemos diferentes construções em linguagem natural que o projeto ACE traduz para uma ontologia. Vale a pena ressaltar que: na construção 1, vemos que as classes man e human foram reconhecidas; na construção 3, os indivíduos John e Mary foram reconhecidos; na construção 7, vemos a definição da propriedade mary; e, na construção 8, vemos uma regra envolvendo duas propriedades like e love.

\subsubsection{OntoLP}

É um plugin feito para o Protégé como parte do trabalho de mestrado de Ribeiro-Junior (2008) que ressaltamos por ser o primeiro em projetar um sistema semiautomático de AO para o português. Ele usa técnicas híbridas entre estatística e padrões léxico-sintáticos para achar a lista de termos, além de aplicar padrões para identificar uma taxonomia de conceitos na ontologia.

Dentre as características mais importantes deste plugin estão:

\footnotetext{
${ }^{5}$ http://ontoware.org/projects/text2onto/

${ }^{6}$ http://beta.visl.sdu.dk/

${ }^{7}$ http://attempto.ifi.uzh.ch
} 


\begin{tabular}{|l|l|l|}
\hline & ACE & Linguagem Formal \\
\hline \hline 1 & Every man is a human. & man $\subseteq$ human \\
\hline 2 & Every human is a male or is a female. & human $\subseteq$ male $\bigcup$ female \\
\hline 3 & John is a student and Mary is a student. & $\{$ John, Mary $\subseteq \subseteq$ student. \\
\hline 4 & No dog is a cat. & dog $\subseteq$ not cat \\
\hline 5 & Every driver owns a car. & driver $\subseteq \exists$ own car \\
\hline 6 & Everything that a goat eats is some grass. & goat $\subseteq \forall$ eat gras $s$ \\
\hline 7 & John likes Mary. & $<J o h n, \operatorname{Mary}>\in l i k e$ \\
\hline 8 & Everybody who loves somebody likes him/her. & love $(\mathrm{X}, \mathrm{Y}) \Rightarrow$ like $(\mathrm{X}, \mathrm{Y})$ \\
\hline
\end{tabular}

Tabela 2.3: Exemplo do ACE, extraído do site de Attempto.

- A entrada são arquivos em formatação $\mathrm{XCES}^{8}$, que é uma representação em XML da anotação linguística de certos textos.

- A partir deste formato XCES, extraem-se facilmente os núcleos dos sintagmas nominais que serão considerados termos.

- Opcionalmente, realiza-se uma filtragem por grupos semânticos de acordo com a informação do analisador sintático PALAVRAS que foi desenvolvido por Bick (2000).

- Para calcular a relevância dos termos, foram usados três métodos: Frequência Relativa, $t f-i d f$ e $\mathrm{C} / \mathrm{NC}$ Value.

- Os termos simples são considerados subconceitos dos termos complexos, por exemplo: arquitetura é superconceito de arquitetura colonial, arquitetura eclesiástica e arquitetura moderna.

- Para a extração de taxonomias, usam-se os padrões léxico-sintáticos de Baségio.

Neste capítulo, revisamos conceitos básicos do tema de ontologias e lógicas de descrição. Estudamos também em que consiste um sistema de $\mathrm{AO}$ e tomamos como base o bolo de camadas de Philipp Cimiano. Mencionamos brevemente em que consiste a GR e o projeto ACE. Finalmente analisamos o OntoLP a maneira de exemplo de um sistema de AO. No próximo capítulo, descreveremos o método usado por Cimiano para tratar a taxonomia de conceitos: a análise de conceitos formais e descreveremos também os potenciais usos de tal método.

\footnotetext{
${ }^{8}$ XCES: XML-based Encoding Standard for Linguistic Corpora
} 


\section{Capítulo 3}

\section{Análise de Conceitos Formais}

A Análise de Conceitos Formais (ACF) é definida por Ganter e Wille (1999) como uma teoria de análise de dados que identifica estruturas de conceitos entre conjunto de dados.

Uma vez que definimos um mapeamento entre objetos e atributos, esta ferramenta conceitual se torna a forma mais simples de construir uma taxonomia usando o reticulado de conceitos.

Contexto Formal Consiste em uma tripla $\langle O, A, I\rangle$, em que $O$ é um conjunto de objetos, $A$ é um conjunto de atributos e $I \subseteq O \times A$ é uma relação binária.

\section{Conceito Formal}

- Consiste em uma tupla $<O^{\prime}, A^{\prime}>$ em que:

- $O^{\prime} \subseteq O$ e é também chamado extent

$-A^{\prime} \subseteq A$ e é também chamado intent

- Podem seguir uma ordem parcial respeitando a inclusão de elementos, assim:

$$
\begin{array}{lll}
<O^{\prime}, A^{\prime}>\leq<O^{\prime \prime}, A^{\prime \prime}> & \Leftrightarrow & O^{\prime} \subseteq O^{\prime \prime} \\
\text { e de forma equivalente: } & & \\
<O^{\prime}, A^{\prime}>\leq<O^{\prime \prime}, A^{\prime \prime}> & \Leftrightarrow & A^{\prime \prime} \subseteq A^{\prime}
\end{array}
$$

Isto significa que um conceito formal $<O_{1}, A_{1}>$ é menor do que outro $<O_{2}, A_{2}>$ se $O_{1}$ é um subconjunto de $O_{2}$ e ao mesmo tempo, o conjunto de atributos $A_{2}$ é um subconjunto de $A_{1}$.

- Devido a tal propriedade, o conceito formal minimal será aquele que possua apenas o elemento vazio no extent e possua todos os elementos de $A$ no intent. Em contraste, o conceito formal maximal será aquele que possua todos os elementos de $O$ no extent e apenas o conjunto vazio no intent.

\subsection{Exemplo do domínio de Turismo}

Este é um exemplo clássico apresentado por Cimiano (2006), e trata de um domínio de viagens turísticas em que a informação contextual é apresentada em uma lista de objetos associados a um determinado verbo, tal como pode ser visto na Tabela 3.1.

Tais verbos são adjetivados para serem tratados como atributos. Dessa forma, é construída uma tabela de associação objeto-atributo como pode ser visto na Tabela 3.2.

A seguir, aplica-se o algoritmo de Ganter (1984) resultando no reticulado de conceitos da Figura 3.1 .

O reticulado é uma estrutura que descreve uma ordem entre conceitos baseada no conjunto de atributos que cada conceito possui. Esta estrutura coloca no topo os conceitos mais gerais, ou seja, 


\begin{tabular}{|c|l|}
\hline verbo & objetos \\
\hline reservar & hotel, apartamento, carro, bicicleta, excursão, viagem \\
\hline alugar & apartamento, carro, bicicleta \\
\hline dirigir & carro, bicicleta \\
\hline montar & bicicleta \\
\hline acompanhar & excursão, viagem \\
\hline
\end{tabular}

Tabela 3.1: Exemplo de verbos e objetos extraídos de um corpus textual sobre o domínio de Viagens Turísticas.

\begin{tabular}{|l|c|c|c|c|c|}
\hline & reservável & alugável & dirigível & montável & acompanhável \\
\hline hotel & $\mathrm{X}$ & & & & \\
\hline apartamento & $\mathrm{X}$ & $\mathrm{X}$ & & & \\
\hline carro & $\mathrm{X}$ & $\mathrm{X}$ & $\mathrm{X}$ & & \\
\hline bicicleta & $\mathrm{X}$ & $\mathrm{X}$ & $\mathrm{X}$ & $\mathrm{X}$ & \\
\hline excursão & $\mathrm{X}$ & & & & $\mathrm{X}$ \\
\hline viagem & $\mathrm{X}$ & & & & $\mathrm{X}$ \\
\hline
\end{tabular}

Tabela 3.2: Domínio de Viagens Turísticas como um contexto formal.

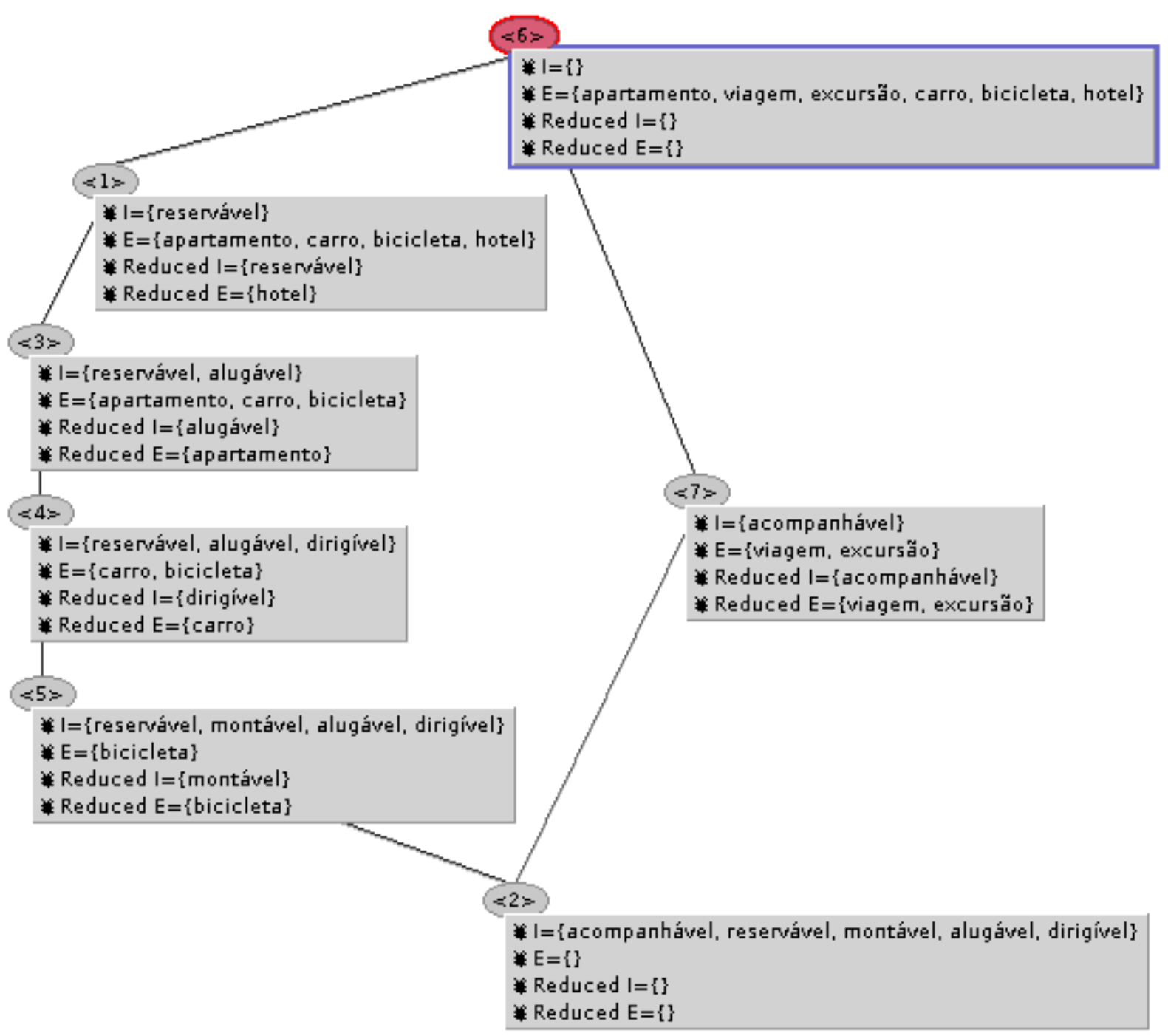

Figura 3.1: Reticulado de conceitos para o dominio de Viagens Turísticas. 
aqueles que possuem a menor quantidade de atributos, e em consequência, os conceitos com maior especificação ficarão na parte baixa do reticulado. Essa relação pode descrever uma taxonomia.

\subsection{Forma Reduzida do Reticulado}

No reticulado da Figura 3.1, encontramos informação redundante, por exemplo apartamento é repetido nos nós $<6>,<1>$ e $<3>$. Godin et al. (1991) apresentam uma forma de reduzir o reticulado com a ferramenta Galicia ${ }^{1}$.

A Figura 3.2 mostra a taxonomia sem a informação redundante.

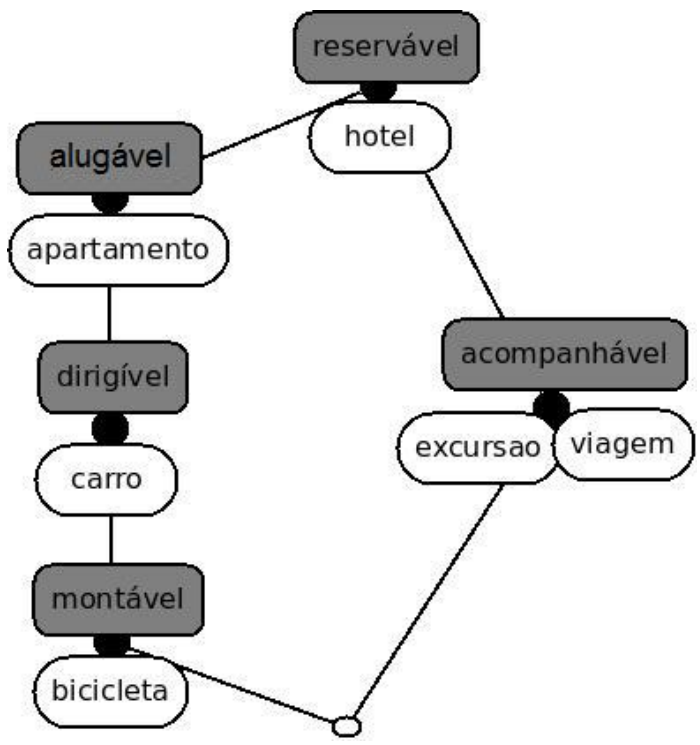

Figura 3.2: Taxonomia de conceitos para o dominio de Turismo

\subsection{Aplicação nas Ontologias}

Como foi bem apontado por Hitzler (2011), os usos de ACF na área de ontologias são:

- Construção de taxonomias.

- Melhoras na ontologia, por exemplo, a exploração de atributos.

- Enriquecimento semântico interativo.

- Alinhamento e Merging de Ontologias.

Alguns trabalhos descrevem o uso da ACF para auxiliar o especialista na construção de ontologias. Por exemplo, o trabalho de Peng e Zhao (2007) descreve uma metodologia incremental, auxiliada pela $\mathrm{ACF}$, para a construção de uma ontologia. Essa ontologia foi usada para recuperação de componentes de software.

Outros trabalhos aproveitam a ordem parcial entre conceitos no reticulado para construir uma taxonomia. Tomamos como exemplo o trabalho de Cimiano et al. (2003), que descreve os passos para realizar o AO a partir de textos usando ACF da seguinte forma:

- Realiza-se uma análise sintática do texto para extrair os pares verbo-objeto. Os objetos são tratados como os elementos do extent e para os verbos adiciona-se o sufixo -able a fim de serem tratados como elementos do intent.

\footnotetext{
${ }^{1}$ http://www.iro.umontreal.ca/ galicia/
} 
- Constrói-se o reticulado de forma reduzida, ou seja, de tal forma que cada objeto ou atributo é nomeado apenas uma vez no diagrama.

- Para cada conceito formal, cria-se um conceito na ontologia com a etiqueta formada pelos elementos do intent. E para cada elemento do extent criamos um subconceito de tal conceito novo criado.

Outro trabalho interessante é de Wang e He (2006), que propõe o uso de SWRL (Semantic Web Rule Language) para traduzir o reticulado em forma de um conjunto de cláusulas de Horn. Tal trabalho usa uma lógica modal específica para ontologias, como proposto no trabalho de Haav (2004).

\subsection{Conceito Superior Comum}

O problema de encontrar o menor ancestral comun (MAC) é estudado na teoria de grafos (Cormen et al. (2001)) e consiste em encontrar para dois nós $s$ e $t$ que pertencem a uma árvore, aquele nó $c$ que é ancestral comum a eles e cuja distancia com a raiz é máxima.

No caso de grafos, a definição muda pois não temos uma estrutura de árvore que tem uma raiz no topo. Nesse caso devemos indicar uma ordem parcial entre os nós para identificar, dado um nó qualquer, quais são os nós ancestrais e descendentes dele. Este é o mesmo caso que acontece no reticulado de conceitos que é um grafo dirigido com uma ordem parcial, por tanto, é possível encontrar um conceito superior comum para dois conceitos que pertençam ao reticulado.

Como podemos encontrar muitos caminhos a partir do nó superior do reticulado até os nós inferiores, procuramos o menor ancestral comum a partir dos filhos com a finalidade de diminuir o espaço de busca. Esta mudança muda também a definição de MAC no reticulado de conceitos:

$$
M A C(s, t)=\underset{c \in\{\text { ancestor }(s) \text { กancestor }(t)\}}{\arg \min }\{M A X(\text { distance }(c, s), \text { distance }(c, t))\}
$$

Nesta definição de MAC, queremos encontrar aquele nó $c$ que seja ancestral comum de $s$ e $t$, e cuja distancia máxima entre $c-t$ e $c-s$ seja mínima. A distancia neste caso será a quantidade de arcos entre os dois nós.

$\mathrm{Na}$ continuação, implementamos o algoritmo 1 para encontrar o MCA de dois conceitos no reticulado.

Por exemplo, na Figura 3.3, o MAC entre os nós $<5>$ e $<9>$ é o nó $<4>$ pois a maior distância dele aos nós filhos é 2 . E não pode ser $<2>$ por exemplo, pois a maior distância deste último aos filhos é 3 .

O principal uso de um conceito superior comum é a possibilidade de substituir para dois conceitos formais, outro conceito comum a eles (ancestral) e cuja distancia a eles for mínima. Para qualquer instância do problema, sempre existirá um conceito superior e no caso de uma ontologia, este será o conceito Thing.

Neste capítulo descrevemos a ACF, mencionamos algumas definições formais e descrevemos um exemplo clássico de Viagens Turísticas. Descrevemos também alguns usos de ACF no AO tais como a especificação de uma taxonomia a partir da forma reduzida. Finalmente descrevemos o uso de ACF para encontrar um conceito comum superior entre dois conceitos no reticulado. No próximo capítulo começamos a descrever a etapa inicial de todo sistema de AO: a extração de termos. 

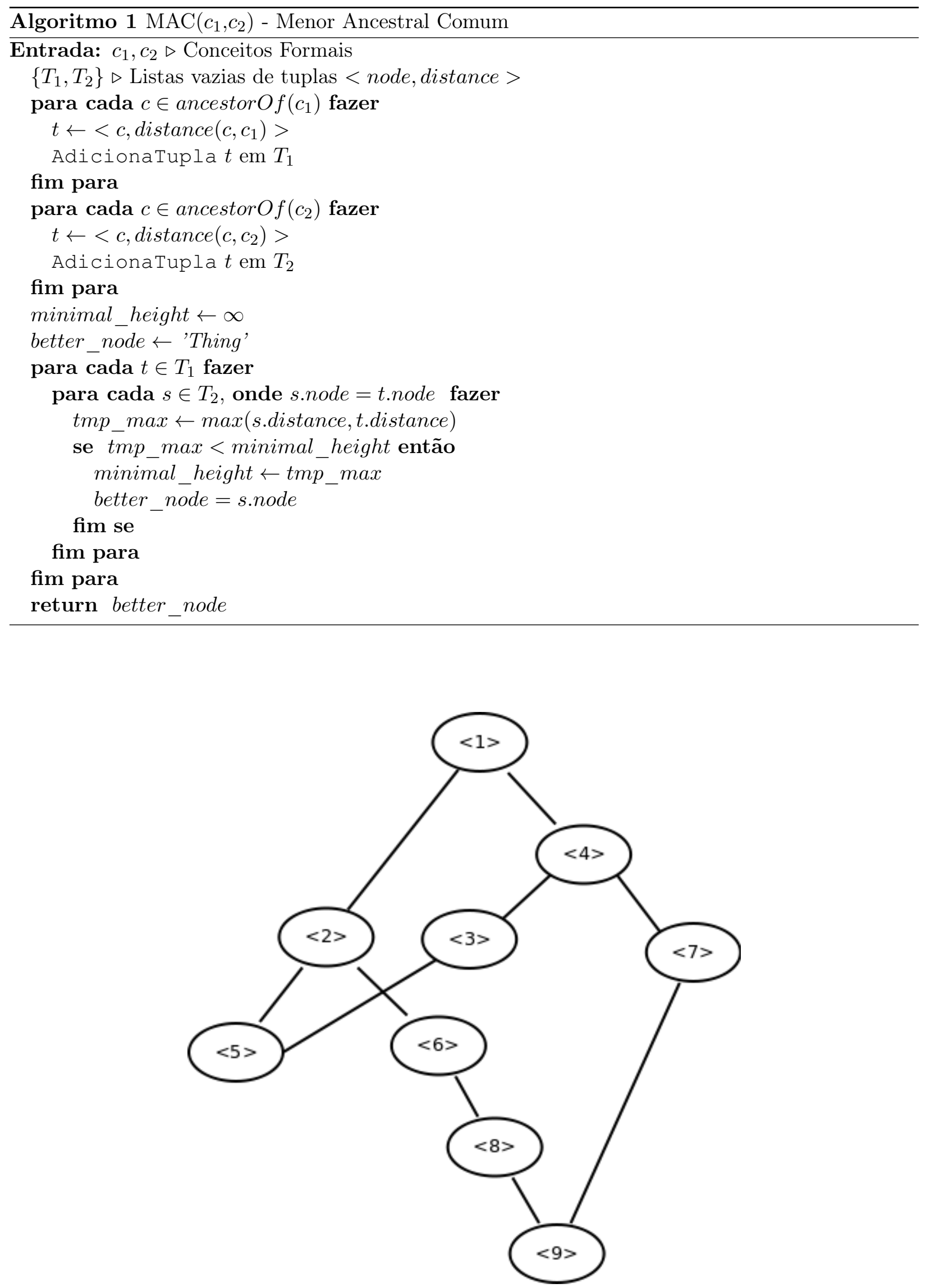

Figura 3.3: Exemplo de reticulado 


\section{Capítulo 4}

\section{Extração de Termos}

Segundo Cabré (1999) e Maria da Graça Krieger (2004), um termo é uma unidade léxica que possui um significado concreto dentro de um certo domínio. Ele pode ser considerado também como uma expressão multipalavra (EMP), definida por Sag et al. (2001) como um conjunto de palavras que possuem um significado próprio e cuja frequência em certo texto tem caráter idiossincrático.

Um sinônimo estabelecido por Wray (2002) a estas expressões multipalavras é o de sequências formulaic, que são definidas como: uma sequência, contínua ou descontínua, de palavras ou outros elementos, os quais são, ou parecem, pré-fabricados: isto é, armazenados e recuperados totalmente da memória no momento do uso, ao invés de serem sujeitos à generalização ou análise pela gramática da linguagem.

De acordo com Sag et al. (2001) existem dois tipos de EMP:

Frases léxicas - as quais possuem sintaxe ou semântica idiossincrática, ou contêm palavras que não ocorrem em isolamento. As expressões multipalavras deste tipo podem ser:

- Expressões idiomáticas, também chamadas expressões populares: Caracterizam-se por não ter um significado literal como por exemplo gírias: "show de bola".

- Compostos nominais: "centro estadual de educação tecnológica".

- Nomes próprios: "Instituto de Matemática e Estatística".

- Construções verbais: "dar é melhor que receber".

- Verbos de suporte: "Tomar banho" ou "Pôr em risco".

Frases institucionalizadas - são construções semânticas e sintáticas, mas estatisticamente idiossincráticas. Por exemplo em "banco de dados", as palavras "banco" e "dados" possuem significado próprio, mas juntas possuem outro significado próprio.

O trabalho de Duan et al. (2009) propôs um método híbrido para identificar EMPs a partir de documentos em inglês. Tal método usa processamento de linguagem natural para extrair a informação gramatical de cada palavra, e aplica uma técnica de alinhamento de sequências para obter aqueles segmentos mais similares entre todas elas.

Quando testamos esta técnica em um documento sobre métodos ágeis de desenvolvimento de software, obtivemos vários segmentos muito compridos, como o seguinte:

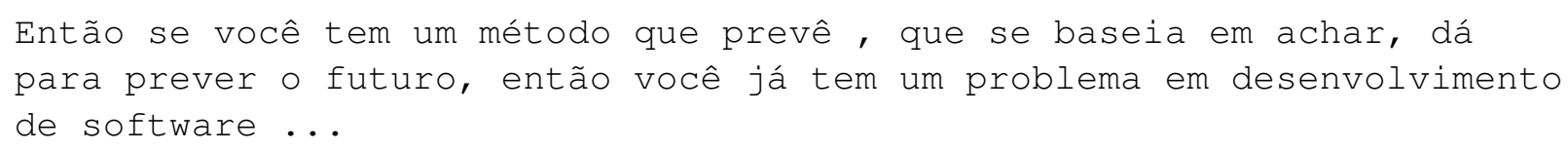

Segmentos como o anterior foram encontrados em todo o texto, e isso deveu-se ao fato de que muitas palavras, com pontuação elevada, estavam dentro de tais segmentos, por exemplo método, desenvolvimento e software. 
Para poder reduzir esses EMPs a uma lista de termos, precisaríamos incrementar a complexidade do sistema pois adicionaríamos um filtro a mais na etapa de reconhecimento de EMPs, por tanto, descartamos este método pois existem métodos mais diretos que procuram os termos sem focar no reconhecimento de EMPs.

\subsection{Métodos para extração de termos}

A maioria dos trabalhos usam técnicas estatísticas para extrair os termos. Por exemplo o trabalho de Pantel e Lin (2001) apresenta uma métrica híbrida baseada no valor de informação mútua junto à verossimilhança logarítmica.

O uso dessas duas métricas está fundamentado, já que a verossimilhança devolve valores altos para termos que acontecem como erros, como por exemplo "the the" no idioma inglês. Porém, a informação mútua diminui a possibilidade deste tipo de expressão ser escolhida como termo.

Para melhorar os resultados de Pantel e Lin, o trabalho de Tomokiyo e Hurst (2003) propôs o uso de uma fonte externa maior (background) para calcular as probabilidades com maior precisão que usando apenas o texto a ser analisado (foreground). Para cada fonte foi criado um modelo de linguagem, que é uma estrutura de dados que armazena probabilidades de ocorrências de uma palavra (unigram) ou de várias palavras (N-gram) aparecerem no texto.

Tomokiyo e Hurst usaram também o ponto de divergência $K L$ (Kullback-Leibler) para medir a ineficácia de assumir uma certa distribuição de probabilidade $p$ quando a verdadeira é $q$. A divergência KL é conhecida também como entropia relativa.

Finalmente, o trabalho de Deane (2005) compara diferentes métricas, a MutualRank entre elas, e explica que os métodos estatísticos não têm bons resultados devido à incorreta suposição da distribuição de probabilidade (como por exemplo distribuição normal ou de Poisson), mas que a distribuição Zipf é a mais apropriada porque ela se amolda melhor em distribuições assimétricas (skewed distribution em inglês), as quais são mais comuns em ocorrências de palavras.

A conclusão de Deane com respeito à incorreta suposição da distribuição de probabilidade também é defendida pelo trabalho de Duan et al. (2009), que usou o alinhamento de sequências na extração de termos.

\subsection{Ferramentas para a extração de termos}

A seguir apresentamos uma lista de ferramentas disponíveis na Internet, dedicadas à extração de termos:

- ExatoLP é uma ferramenta desenvolvida na Universidade de Rio Grande do Sul para extrair termos a partir de textos escritos em Português.

- KEA é um extrator de palavras chave para documentos, portanto, devolve poucas palavraschave para um texto. O trabalho de Lacerda-Dias (2004) adaptou este sistema para o Português.

- TOPIA é parte da biblioteca ZOPE, que é uma biblioteca de aplicações escrita em Python. De código simples, compete contra a ferramenta online do Yahoo. Usa um léxico em Inglês com muitas anotações sintáticas. Ele usa a métrica $\mathrm{C} / \mathrm{NC}$-Values.

- Text-NSP (Ngram Statistic Package) é uma biblioteca Perl de utilidades para a análise estatística em textos. É uma ferramenta muito usada para trabalhos em linguística que analisam palavras.

- AlchemyAPI é uma biblioteca com outras utilidades interessantes para aplicação em sites, tais como extração de entidades nomeadas, marcações de conceitos, análise de sentimentos em textos, entre outras. Existe a versão da biblioteca para Android OS (Mobile SDK), Java, 
Perl, Ruby, Python, PHP, C ++ e C\#. Não é livre e precisa se registrar para obter um API Key.

- MAUI é uma ferramenta cujo objetivo é etiquetar um texto com os termos que definem tal texto. Ele tem suporte em Espanhol, Francês e Alemão. Esta ferramenta consulta a web para adquirir informação contextual.

Existem também sistemas online que realizam a tarefa de extração de termos. Vemo-los na continuação:

- Five Filter Term Extraction suporta Inglês e usa a ferramenta TOPIA.

- ZEMANTA é um serviço web. Uma versão cliente pode ser baixada para realizar consultas em informações contextuais com relação aos textos que o usuário ingressa.

- Yahoo's Term Extraction é um dos melhores. A quantidade de consultas são restritas por dia.

- Translated.net, Terminology Extraction suporta os idiomas Inglês, Italiano e Francês.

- TermMine suporta apenas o idioma Inglês. Possui uma versão para baixar e usar com o Protégé. Usa a métrica C/NC-i. Como lematizador usa o TreeTagger (comercial) e o Genia Tagger.

- OpenCalais ${ }^{1}$ é uma ferramenta similar a MAUI, porém, mais completa pois ela faz marcações semânticas para um determinado texto. É usado em Drupal e outros CMS (Content Management System ).

\subsection{Reconhecimento de sintagmas nominais e preposicionais}

O Cogroo, apresentado em Kinoshita et al. (2007), é um projeto de código livre para correção gramatical de textos em língua portuguesa. Ele possui uma API que pode ser usada para realizar a lematização ${ }^{2}$ do corpus.

O projeto Cogroo usou o corpus da Floresta Sintática ${ }^{3}$ para treinar e gerar modelos gramaticais. Tal corpus foi gerado pelo PALAVRAS, que é uma ferramenta comercial para a análise gramatical.

Uma vantagem de usar o Cogroo é a desambiguação de frases. Por exemplo na sentença Quem casa quer casa, ele identifica positivamente que a primeira ocorrência de casa refere-se a um verbo e a segunda ocorrência refere-se a um substantivo.

O Cogroo usa um shallow parser para construir uma árvore sintática simples. A partir dessa árvore, pode-se obter uma lista de tokens, cada um contendo a informação sintática (NP,SUB,etc) e/ou morfológica (Noun, third person, etc) das unidades gramaticais da oração.

Por exemplo, na frase Os métodos ágeis são importantes no desenvolvimento de software, o Cogroo realizou uma análise sintática, obtendo uma lista de tokens e uma árvore sintática que apreciamos na Tabela 4.1 e na Figura 4.1 respectivamente.

\subsection{Extração de candidatos a termos com a métrica C-value/NC- value}

A métrica $\mathrm{C} / \mathrm{NC}$-value é prática, pois precisa das frequências das palavras, e também confiável, já que vários sistemas a usam, como o Copia, o Term Extractor e OntoLP (plugin desenvolvido no trabalho de Ribeiro-Junior (2008)).

\footnotetext{
${ }^{1}$ http://www.opencalais.com/

${ }^{2} \mathrm{~A}$ lematização é o processo de extrair as palavras sem inflexões de tempo, gênero e número, chamando elas de lemas

${ }^{3}$ Floresta Sintática http://www.linguateca.pt/floresta/corpus.html
} 


\begin{tabular}{|l|l|l|}
\hline Token & Lema & Tag Morfológico \\
\hline Os & o & determiner, male,plural \\
\hline métodos & método & noun,male,plural \\
\hline ágeis & ágil & adjective, male,plural \\
\hline são & ser & verb,plural,third,present, indicative,finite \\
\hline importantes & importante & adjective,male,plural \\
\hline no & em & preposition \\
\hline no & o & determiner,male,singular \\
\hline desenvolvimento & desenvolvimento & noun,male,singular \\
\hline de & de & preposition \\
\hline software & software & noun,male,singular \\
\hline
\end{tabular}

Tabela 4.1: Lematização e informação morfológica

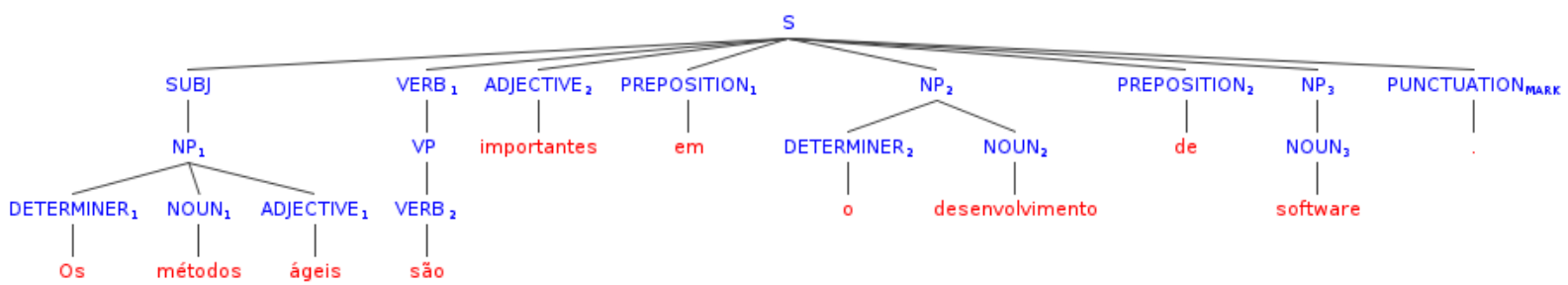

Figura 4.1: Árvore sintática retornada pelo Cogroo

Esta métrica foi introduzida no trabalho de Frantzi et al. (1998) e combina informação linguística e estatística. O processo divide-se em duas etapas: (i) Calcular os C-values, e (ii) Calcular os NC-values.

\subsubsection{Calculando os C-values}

Aqui calculamos um valor de ranking para os candidatos de termos usando apenas a frequência das palavras no texto. Consiste em duas partes:

1. Parte Linguística:

(a) Realiza-se um processo de lematização em todo o texto.

(b) Aplica-se um filtro linguístico para conseguir os sintagmas nominais e preposicionais.

(c) Remove-se os stop-words.

2. Na parte estatística, retorna-se um valor para uma cadeia candidata a termo usando:

(a) A frequência total de ocorrências da cadeia candidata no corpus.

(b) A frequência da cadeia candidata como parte de outros candidatos a termos maiores.

(c) O número desses candidatos maiores.

(d) O tamanho dos candidatos (quantidade de palavras).

Finalmente a métrica C-value fica explícita da seguinte forma:

$$
C-\text { value }(a)=\left\{\begin{array}{l}
\log _{2}|a| \times f(a), \text { se } a \text { estiver isolado } \\
\log _{2}|a| \times\left(f(a)-\frac{1}{P\left(T_{a}\right)} \sum_{b \in T_{a}} f(b)\right), \text { caso contrário }
\end{array}\right.
$$

em que:

$a$ é o candidato a termo,

$f($.$) é a frequência de ocorrência no corpus,$ 
$T_{a}$ é o conjunto de candidato a termos extraídos que contém $a$,

$P\left(T_{a}\right)$ é o número desses candidatos a termos.

\subsubsection{Calculando os NC-values}

Uma vez calculado os C-values, a informação contextual é usada para ajudar na identificação dos termos corretos. O fundamento de usar tal recurso se deve a que normalmente podemos identificar o significado de uma palavra analisando o contexto em que ela aparece.

Os tipos de palavras contextuais podem ser adjetivos, substantivos ou verbos que estão próximos a um candidato a termo. A relevância de uma palavra contextual weight(.):

em que :

$$
\operatorname{weight}(w)=\frac{t(w)}{n}
$$

$w$ é a palavra contextual (substantivo, verbo ou adjetivo)

$t(w)$ é o número de termos em que a palavra $w$ aparece adjacente.

$n$ número total de termos considerados

Finalmente, temos:

$$
N C-\operatorname{value}(a)=0.8 \times C-\operatorname{value}(a)+0.2 \times \sum_{b \in C_{a}} f_{a}(b) \text { weight }(b)
$$

em que:

$a$ é o termo candidato,

$C_{a}$ é o conjunto de diferentes palavras contextuais de $a$

$b$ é uma palavra de $C_{a}$,

$f_{a}(b)$ é a frequência de $b$ como uma palavra de contexto de $a$

Neste capítulo primeiro descrevemos as expressões multipalavras que são segmentos de texto com carácter idôneo, porém, os termos que estamos procurando são segmentos mais simples que esses EMPs. Vimos como a estatística desempenha um rol importante na extração de termos e mencionamos também algumas ferramentas usadas na extração de termos. Descrevemos a ferramenta Cogroo que possui uma API para realizar análise gramatical em textos. Finalmente, detalhamos a métrica $\mathrm{C} / \mathrm{NC}$-value para a extração de termos com ajuda na estatística e a informação gramatical. No próximo capítulo continuamos descrevendo um sistema de AO detalhando a descoberta de relações. 


\section{Capítulo 5}

\section{Descoberta de Relações}

De acordo com Shamsfard e Abdollahzadeh Barforoush (2003), existem dois tipos de relações conceituais:

1. Taxonômicas : representam relações de generalização ou especialização. Pertencem a este tipo as relações de hiponímia e/ou hiperonímia. De acordo com Sánchez (2009) existem dois métodos para a descoberta de relações deste tipo: (i) usando padrões léxico-sintáticos como os padrões de Hearst; e (ii) encontrando padrões do tipo [[ADJETIVO*]SUBSTANTIVO], esse último enfoque foi abordado por Grefenstette (1997).

2. Não Taxonômicas : são as demais relações, por exemplo sinonímia (mesmo significado), meronímia (parte de), antonímia, possessão, e outras relações que são obtidas de forma automática por algum sistema de aprendizado, e que podem possuir uma representação própria como R1, R2 ou R $(1,2)$; ou uma representação em linguagem natural como gostar_de, andar_com, etc.

\subsection{Descoberta de Relações Taxonômicas}

De acordo com Cimiano (2006), existem três métodos para adquirir uma hierarquia de conceitos.

1. Baseado em similaridades,

2. Teoria de Conjuntos, e

3. Clustering

\subsubsection{Baseado em Similaridade}

O trabalho de Hearst (1992) propõe seis padrões léxico-sintáticos para serem procurados nos textos de língua inglesa. Mais tarde, Baségio (2006) fez a adaptação deles para a língua portuguesa (ver Tabela 5.1).

Por exemplo na sentença "Agar is a substance prepared from a mixture of red algae, such as Gelidium, for laboratory or industrial use", depois de aplicar o padrão $h 1$ extraímos a relação: hiponímia("Gelidium", "red algae") que indica que "red algae" tem como subconceito "Gelidium".

Para a sentença "... works by such authors as Herrick, Goldsmith and Shakespare", depois de aplicar o padrão $h 2$, extraímos as relações:

• hiponímia("author","Herrick");

- hiponímia("author","Goldsmith”); e

- hiponímia("author", "Shakespeare”).

que indica que "Herrick", "Goldsmith" e "Shakespeare" são subconceitos de "author". 


\begin{tabular}{|c|c|c|}
\hline & Padrão Original & Adaptação \\
\hline$h 1$ & $\mathrm{NP}$ such as $\{\mathrm{NP},\}^{*}\{($ and $\mid$ or $)\} \mathrm{NP}$ & SUB tal(is) como $\left\{(\mathrm{SUB})^{*}(\mathrm{ou}-\mathrm{e})\right\}$ SUB \\
\hline$h 2$ & such $\mathrm{NP}$ as $\{\mathrm{NP},\}^{*}\{($ and $\mid$ or $)\} \mathrm{NP}$ & SUB tal(is) como $\{(\mathrm{SUB}) *($ ou-e $)\}$ SUB \\
\hline$h 3$ & $\mathrm{NP}, \mathrm{NP}^{*}\{$,$\} or other \mathrm{NP}$ & tal(is) SUB como $\left\{(\mathrm{SUB})^{*}(\mathrm{ou}-\mathrm{e})\right\}$ SUB \\
\hline$h 4$ & $\mathrm{NP}, \mathrm{NP}^{*}\{$,$\} and other \mathrm{NP}$ & SUB $\{, \text { SUB }\}^{*}\{$,$\} ou outro(s) SUB$ \\
\hline$h 5$ & $\begin{array}{l}\mathrm{NP} \text { including }\{\mathrm{NP},\}^{*} \mathrm{NP}\{(\text { and } \mid \text { or })\} \\
\mathrm{NP}\end{array}$ & SUB $\{, \text { SUB }\}^{*}\{$,$\} e outro(s) SUB$ \\
\hline$h 6$ & $\mathrm{NP}$ especially $\{\mathrm{NP},\}^{*}\{($ and $\mid$ or $)\} \mathrm{NP}$ & $\begin{array}{l}\text { - } \mathrm{SUB}, \text { especialmente } \mathrm{SUB},{ }^{*} \text { ou-e SUB } \\
\text { - } \mathrm{SUB}, \text { principalmente } \mathrm{SUB},{ }^{*} \text { ou-e SUB } \\
\text { - } \mathrm{SUB}, \text { particularmente SUB },{ }^{*} \text { ou-e SUB } \\
\text { - } \mathrm{SUB}, \text { em especial SUB, }{ }^{*} \text { ou-e SUB } \\
\text { - } \mathrm{SUB}, \text { em particular SUB, }{ }^{*} \text { ou-e SUB } \\
\text { - } \mathrm{SUB}, \text { de maneira especial SUB, }{ }^{*} \text { ou-e SUB } \\
\text { - } \mathrm{SUB}, \text { sobretudo SUB },{ }^{*} \text { ou-e SUB }\end{array}$ \\
\hline
\end{tabular}

Tabela 5.1: Padrões de Hearst adaptados por Baségio. Em que NP: Noun Phrase (Sintagma Nominal) e SUB: Substantivo

\subsubsection{Teoria de Conjuntos}

Neste tópico, Cimiano propõe a Análise de Conceitos Formais como a técnica mais simples para obter uma taxonomia de conceitos. Esta metodologia indica que uma taxonomia pode ser construída estabelecendo-se relações de similaridade entre conceitos contando com a quantidade de especificações em comum que eles possuam.

\subsubsection{Clustering}

Os trabalhos que usam técnicas de clustering estão baseados na hipótese da distribuição de Harris (1968), que simplesmente indica que palavras similares aparecem em contextos similares.

Usando um enfoque linguístico-computacional, a distribuição de Harris consiste em estabelecer relações entre termos que possuam elementos sintáticos contextuais comuns. Para o estabelecimento de relações de taxonomia entre termos, devemos estabelecer primeiro a que cluster o termo pertence e depois consultar a ordem dele. A quantidade de relações associadas a um cluster pode definir tal ordem.

\subsection{Descoberta de Relações Não Taxonômicas}

Sánchez (2009) indica que a descoberta de relações deve se ocupar de duas tarefas: (i) encontrar os conceitos relacionados entre si e estabelecer uma relação entre eles, e (ii) etiquetar tal relação.

Sánchez também indica alguns trabalhos que usaram um conjunto fechado de relações genéricas, por exemplo: parte-de, qualia, causation.

O trabalho de Botero e Ricarte (2008) propôs um algoritmo de clustering para achar relações semânticas. Um problema desse trabalho é o estabelecimento de conceitos compostos como algorithm_genetic pois o trabalho agrupava dois grupos diferentes de conceitos: (i) aqueles relacionados a algorithm, e (ii) conceitos relacionados a genetic, mas que não necessariamente representavam fielmente o conceito de genetic_algorithm. Entre as conclusões, Botero deixa aberto como 
trabalho futuro a otimização do algoritmo com ajuste de certas variáveis.

O trabalho de Schutz e Buitelaar (2005) estabelece verbos como relações entre conceitos. Ele analisa um determinado texto e fornece uma lista com as triplas relevantes (pares de conceitos, conectados por um verbo) sobre outra ontologia de conceitos existente.

\subsection{Gramática de Restrições}

De acordo com Karlsson (1995), a Gramática de Restrições é um paradigma no Processamento de Linguagem Natural. Ela consiste na compilação de um conjunto de regras em uma gramática. Cada regra mantém um contexto e determina um comportamento diferente para um componente analisado na sentença.

\section{Problemas de GR no Português}

A informação em qualquer texto não aparece em uma forma ideal em que podemos aplicar simples padrões. Por exemplo:

- A Branca de Neve, bonita como nenhuma, cantava alegremente no bosque.

Se quisermos encontrar a estrutura SVO (sujeito-verbo-objeto) na sentença anterior, uma simples análise não ajudaria, pois temos a seguinte ordem:
$\underbrace{\text { A Branca de Neve }}_{\text {sujeito }}$,
$\underbrace{\text { bonita como nenhuma }}_{\text {aposto }}, \underbrace{\text { cantava }}_{\text {verbo }}$
C. Circunstancial
$\underbrace{\text { no bosque }}_{\text {C. Indireto }}$

Notamos que o aposto é um elemento que dificulta a análise, mas que é importante pois faz parte da semântica da oração. Ele indica que Branca de Neve é bonita como nenhuma.

Também notamos que a frase não possui apenas um mas dois objetos ou complementos: alegremente (circunstancial) no bosque (indireto).

A complexidade é acrescentada quando analisamos frases de período composto, por exemplo:

- Branca de Neve crescia e ficava bonita.

Podemos obter duas expressões nucleares, ou orações de período simples:

- Branca de Neve crescia

- Branca de Neve ficava bonita

Ainda parece trivial, mas a complexidade cresce conforme vamos analisando orações mais extensas, por exemplo:

- Branca de Neve despediu-se dos sete anões e partiu junto com o príncipe para um castelo distante onde se casaram e foram felizes para sempre.

Uma análise ótima poderia obter as seguintes frases de período simples:

- Branca de Neve despediu-se dos sete anões

- Branca de Neve partiu junto com o príncipe

- Branca de Neve partiu para um castelo distante

- Branca de Neve e o príncipe casaram

- Branca de Neve e o príncipe foram felizes para sempre 
Existe também uma frase que não está de forma explícita:

- O príncipe partiu junto com a Branca de Neve para um castelo distante

Aparentemente, uma pessoa pode extrair tal informação de uma forma natural. Porém, o trabalho para um programa de computador é desafiador.

Até aqui, nós detalhamos mais uma etapa no AO que é a Descoberta de Relações. Detalhamos alguns métodos para extrair relações taxonômicas e não taxonômicas. Vimos também o desafiante que seria a implementação de uma GR para textos escritos em Português e agora no próximo capítulo estudaremos alguns conceitos básicos de gramática e linguística a fim de projetar uma GR. 


\section{Capítulo 6}

\section{Análise Sintática}

Neste capítulo faremos uma revisão da sintaxe da língua portuguesa em que, além de conceitos básicos, detalharemos também a análise de constituintes. Para isso, tomamos como livro base Bechara (2009) e também o livro de sintaxe e cognição de Lagunilla e Rebollo (2004).

\subsection{Sintaxe}

A sintaxe é uma parte da gramática que estuda a ordem dos constituintes em uma oração.

A oração encerra a menor unidade de sentido do discurso com propósitos definidos (Bechara (2009)). Ela pode estar constituída por um ou mais vocábulos, por exemplo:

- Atenção!

- Vamos embora!

- Claro que sim!

- Margaret viaja com Bruno na terça à noite

Quando uma mensagem é completa de acordo com o contexto, e delimitada por um silêncio precedente e uma pausa final (sinais de pontuação), chama-se de período, existindo período simples e período composto quando a sentença possui uma ou mais orações respectivamente.

\subsubsection{Oração}

Existem diferentes tipos de oração:

- Declarativas, por exemplo:

- A biblioteca abriu ontem.

- Miguel está falando pelo telefone.

- Ainda não sei.

- Interrogativas, por exemplo:

- Quantos anos você tem?

- Tudo bem?

- Imperativas, por exemplo:

- Vá comer!

- Seja forte!

- Exclamativa, por exemplo: 
- Oh, meu Deus!

- Que interessante!

Os termos essências da oração são o sujeito e o predicado. A omissão de um deles é chamada de elipse:

- $\underbrace{\text { Marcos }}_{\text {Sujeito }} \underbrace{\text { estuda muito }}_{\text {Predicado }}$.

- $\underbrace{\text { Maia! }}_{\text {Sujeito }} \underbrace{}_{\text {Predicado }}$, elipse por ausência do predicado.

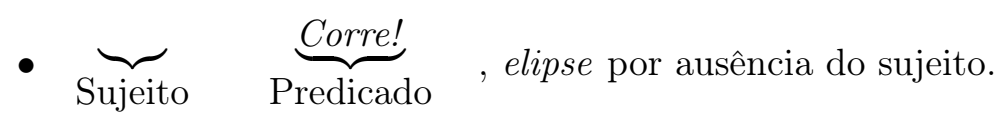

\subsubsection{Sujeito}

De acordo com Bechara, o sujeito indica a pessoa ou coisa de que afirmamos ou negamos uma ação ou qualidade, enquanto que o predicado é tudo o que se declara na oração, ordinariamente em referência ao sujeito.

O núcleo do sujeito (NS) é o substantivo, que geralmente está rodeado de determinantes. Em geral, tais determinantes podem ser artigos, adjetivos, pronomes e quantificadores.
- $\underbrace{O}_{\text {artigo }} \underbrace{\text { livro }}_{\mathrm{NS}}$
- $\underbrace{\text { Os }}_{\text {artigo }} \underbrace{\text { livros }}_{\mathrm{NS}} \underbrace{\text { bons }}_{\text {adjetivo }}$
- $\underbrace{\text { Aqueles }}_{\begin{array}{l}\text { Pronome } \\ \text { demonstrativo }\end{array}} \underbrace{\text { livros }}_{\begin{array}{c}\text { quantificador } \\ \text { NS }\end{array}} \underbrace{\text { seus }}_{\begin{array}{l}\text { pronome } \\ \text { possessivo }\end{array}}$

Existem também, a um nível sintático-semântico, os chamados termos nucleares que estão intimamente ligados à relação predicativa. Por exemplo:

- Tim Berner's Lee propôs a Web Semântica como meio de comunicação entre máquinas.

Além de [Tim Berner's Lee] e [propôs], existem as frases [Web Semântica] e [meio de comunicação entre máquinas] que são chamados nucleares porque:

- A oração fala da [Web Semântica], e

- menciona também que esta Web Semântica foi proposta como [meio de comunicação entre máquinas].

Quando existe um elemento que não está referido nem ao sujeito nem ao predicado, mas a toda a oração, então pode ser deslocado a qualquer posição, por exemplo:

- Certamente, Tim Berner's Lee propôs a Web Semântica como meio de comunicação entre máquinas.

- Tim Berner's Lee, certamente, propôs a Web Semântica como meio de comunicação entre máquinas.

- Tim Berner's Lee propôs a Web Semântica como meio de comunicação entre máquinas, certamente. 


\subsubsection{Predicado}

O núcleo do predicado é o verbo. Quando o verbo é intransitivo, o predicado é chamado simples, pois possui um significado concreto.

Quando o predicado é extenso, possui delimitações chamadas de argumentos ou complementos verbais. Tais complementos podem ser:

\section{Complemento direto ou objeto direto}

São aqueles que completam o significado dos verbos transitivos diretos, por exemplo:

- O estudante leu um livro.

- Eu estudei vários temas.

\section{Complemento indireto ou objeto indireto}

Aqueles que estão ao lado dos verbos transitivos indiretos. Estes complementos caraterizam-se por estar junto a uma preposição, por exemplo:

- Os professores gostam da pesquisa.

- O aluno enviou seu trabalho ao professor.

- Os dois enviaram artigos para o congresso.

\section{Complemento adverbiais}

Os adjuntos adverbiais podem ser

- de lugar (respondem a perguntas como onde?, por onde?, etc.):

Adriana trabalha na Embratel. (onde)

Passamos por várias cidades do interior. (por onde?)

Thiago viaja para Recife. (aonde?)

- temporais (responde a perguntas como quando?, desde quando?, etc.):

Limpamos a casa no domingo. (quando?)

Não paramos desde as quatro até as oito. (desde quando?, até quando?)

- modais (responde a perguntas como como?, de que maneira?):

Bruno está ajudando bem. (como?)

Pâmela ficou muito cansada. (de que maneira?)

- de fim, de causa, de instrumento e de companhia:

Timóteo estudou matemática para seu trabalho. (fim)

Choravam de emoção. (causa)

Chutou a bola com a perna esquerda. (instrumento)

Saiu com Ellen. (companhia)

- de quantidade:

Talita trabalha muito mais nos domingos.

Peru acabou o jogo com dois gols contra. 
- de distribuição:

Os biscoitos foram entregues para cada vizinho.

- de inclinação e oposição:

Sempre esteve a favor dos mais necessitados.

Ela sempre foi contra o aborto.

- de substituição, troca ou equivalência:

Estou brincando no lugar de estudar.

Sirley trocou a casa por mais carros.

- de campo ou aspecto:

O novo estagiário é um especialista em base de dados.

Ele conseguirá nos ajudar com seus conhecimentos atualizados.

- de assunto ou matéria tratada

O programa de hoje tratou $\left\{\begin{array}{c}\frac{\text { das doenças do corpo }}{\text { sobre a segurança nas ruas }} \\ \underline{\text { a respeito da crise financeira }}\end{array}\right.$

\subsection{Orações Complexas}

Na gramática tradicional identificavam-se dois tipos de orações de acordo com a função sintática: independente e dependente, em que a oração principal era definida como aquela que pede uma dependente, ou seja, aquela que a que as dependentes se ligam, por exemplo:

$\underbrace{\text { A Branca de Neve dormiu }}_{\text {Oração Principal }} \underbrace{\text { porque comeu a maçã envenenada }}_{\text {Oração Dependente }}$.

Ora, a atual gramática comporta dois tipos de orações: subordinada e coordenada, as quais veremos na continuação.

\subsubsection{Orações subordinadas}

A partir do exemplo anterior, observamos que a oração comeu a maçã é independente de Branca de Neve dormiu, mas passou a exercer uma função de adjunto adverbial de causa já que porque comeu a maçã envenenada é a oração subordinada.

\section{Oração Subordinada Substantiva}

A Oração Subordinada Substantiva (O.S.S.) exerce a função de substantivo e está precedida da conjunção que. Há seis tipos:

- Subjetiva (O.S.S.S): É preciso que os alunos estudem.

- Objetiva Direta (O.S.S.O.D): O cliente disse que fizemos um bom trabalho.

- Objetiva Indireta (O.S.S.O.I): Precisamos de que os provedores agilizem os processos.

- Predicativa (O.S.S.P): O motivo foi que o outro time não conseguiu.

- Completiva Nominal (O.S.S.C.N): Tenho esperança que o artigo seja aceito.

- Apositiva (O.S.S.A.): Algo é fato que a gente trabalhou muito para isto. 


\section{Oração Subordinada Adjetiva}

É aquela que modifica um substantivo. A ligação é feita com ajuda de um pronome relativo, que, por exemplo:

- O projeto que era mais difícil acabou nesta semana.

- O teste que tinha menos erros falhou no último momento.

Também pode haver uma preposição ao lado do pronome relativo, por exemplo:

- O lugar a que vamos ainda está longe.

- O celular de que gostas chegou no país.

Essas orações também podem vir entre pausas, por exemplo:

- O cavalo,que ganhou a última corrida, saiu nas capas das revistas.

\section{Oração Subordinada Adverbial}

Pode exercer função de advérbio ou mesmo de locução adverbial:

- O prazo foi adiado para ter mais tempo.

Podem ser também:

- Causais: Acabei o mestrado porque me esforcei.

- Comparativas: Os comentários de Marcelo foram tão bons como os de Flávio.

\subsubsection{Orações coordenadas}

São orações independentes que formam uma sequência. Por exemplo:

- Branca de Neve crescia e ficava mais bonita.

Aqui temos duas orações:

- Branca de Neve crescia

- e ficava mais bonita

Quando as orações coordenadas possuem um travessão (-) como conector, chamam-se intercaladas. Por exemplo:

- Uma mordida nesta maçã fará Branca de Neve dormir para sempre - disse a bruxa.

Caso contrário, as orações coordenadas com conetivos chamam-se conectivas. Estas últimas podem ser de diferentes tipos:

- aditivas:

Faremos nossos trabalhos neste fim de semana e também seremos rápidos.

Não sou sábio nem pretendo sê-lo.

- adversativas:

Jogaram bem, mas perderam como sempre.

Ora você sai com os amigos, ora você fica em casa. 
- alternativas:

Ou é verdadeira ou é falsa.

Pode ir para a esquerda ou para a direita.

- conclusivas:

Eu não estudei pra prova, logo, tirei baixa nota.

Me esforcei muito, portanto espero uma grande recompensa.

- explicativas:

Os humanos não voam porque não são aves.

A comida está gostosa, pois eu que fiz.

Todas estas estruturas são analisadas por linguístas usando a análise de constituintes. Tal análise pode ser feita de forma mais profunda na gramática gerativa, que detalharemos na continuação.

\subsection{Gramática Gerativa}

Um dos principais fundadores desta teoria foi Chomsky (1957) que indicou que o verdadeiro objetivo da linguística deveria ser a formulação de uma gramática que, por meio de um número finito de regras, fosse capaz de gerar todas as frases de um idioma, do mesmo modo que um falante pode formar um número infinito de frases em sua língua, mesmo quando nunca as tenha ouvido ou pronunciado.

De acordo com Ruwet (1975), uma gramática gerativa é uma gramática explícita, que enumera explicitamente todas e não mais que as frases gramaticais de uma língua, assim como suas descrições estruturais.

Para Lagunilla e Rebollo (2004), uma gramática explícita consiste em um modelo de descrição sistemática da competência dos falantes de uma certa língua. O termo competência de acordo com Perini (1976), designa o conjunto de normas ou regras que nos permite emitir, receber e julgar enunciados em uma certa língua.

Na linguística existem três níveis de representação, os quais foram bem introduzidos por Costa-Campos e Xavier (1991):

- O nível 1, que é inacessível pelo linguista, possui os mecanismos e as representações abstratas das atividades da linguagem. Este nível é adquirido desde a infância com o mundo que nos rodeia. Aqui são geradas sequências linguísticas, que podem ser observadas no nível 2.

- A partir do nível 2, o linguista tem acesso ao nível 1 e sobre ele formula hipóteses. Aqui podemos falar de formas linguísticas, por exemplo casa dá a ideia de um imóvel onde podem morar pessoas. Uma frase com casa daria a ideia da interação dela com outros objetos.

- No nível 3, é construído um sistema de representação metalinguístico para responder pela relação entre as sequências do nível 2 e os mecanismos ou representação do nível 1. Por exemplo, quando realizamos uma análise gramatical de uma oração: casa - substantivo.

A seguir estudaremos uma ferramenta para a análise de frases.

\section{Análise de Constituintes}

De acordo com Silva e Koch (2001), sintagma é um conjunto de elementos com valores significativos dentro da oração e que mantêm entre si uma relação de dependência e de ordem. Existem diferentes tipos:

- Sintagma Nominal (SN), cujo núcleo é o substantivo. 
- Sintagma Verbal (SV), cujo núcleo é o verbo.

- Sintagma Adjetival (SA), cujo núcleo é um adjetivo.

- Sintagma Preposicional (SP), que é um SN acompanhado de uma preposição.

A estrutura sintática é uma configuração formada por unidades sintáticas, chamadas categorias, de diferentes classes (nome, verbo, adjetivo, preposição, flexão, sintagma nominal, sintagma verbal, etc.), entre as quais, estabelecem-se dois tipos de relações fundamentais: domínio e precedência.

Quando uma frase é analisada, o linguista constrói um indicador sintagmático, que não é mais que um gráfico em forma de árvore que representa a estrutura sintática da frase. Podemos ver, na Figura 6.1, o indicador sintagmático da frase A formiga comeu a folha.

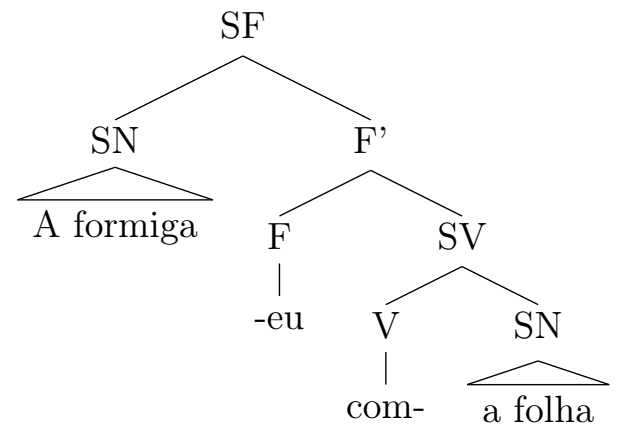

Figura 6.1: Exemplo de indicador sintagmático

Notemos que no topo desta árvore, encontra-se o sintagma flexional - SF - e a flexão verbal eu, afixo do pretérito de comer, encontra-se deslocada à esquerda do verbo e é anterior ao sintagma verbal. Tal flexão possui um nível a mais para indicar o tempo em que acontece o SV.

O conjunto de regras para obter uma estrutura superficial, que seja mais simples, chama-se transformação. Aplicando tais transformações, podemos obter:

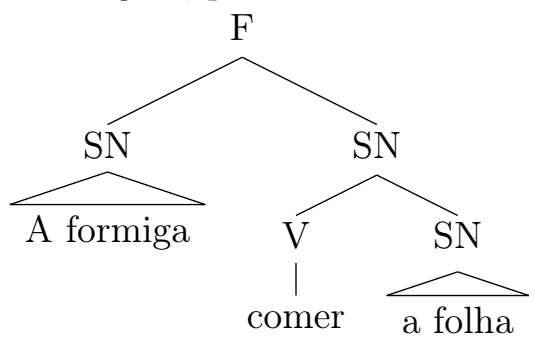

A transformação mais simples é a supressão de sujeito idêntico (SSI), relatada por Perini (1976), que consiste em suprimir o sujeito de uma oração subordinada quando este for idêntico a qualquer outro SN presente na oração. Na frase:

- [Antônio querer [Antônio sambar com a Portela]]

Com a SSI, a frase ficaria simplificada em:

- [Antônio quer sambar com a Portela]

Neste capítulo, revisamos conceitos da gramática portuguesa. Vimos que as orações podem pertencer a períodos simples e compostos. Também estudamos brevemente a Gramática Gerativa e vimos como a Análise de Constituintes nos permitiu apreciar a riqueza sintática contida em uma simples oração. No próximo capítulo descreveremos os experimentos e concretizaremos dentro de uma GR um conjunto de regras que usa a informação gramatical e as estruturas sintáticas estudadas neste capítulo. 


\section{Capítulo 7}

\section{Experimentos e Resultados}

Para poder avaliar nosso trabalho, escolhemos textos sobre três temas nos domínios de: engenharia de software, conto de fadas e biologia. As ontologias foram aprendidas e submetidas à avaliação usando o modelo de características de conteúdo proposta no método OntoMetrics.

\subsection{Descrição dos textos}

\section{Engenharia de Software: Métodos Ágeis de Desenvolvimento de Software}

Consiste na transcrição de um conjunto de palestras sobre métodos ágeis, ministradas e registradas pelo grupo AgilCoop ${ }^{1}$ na Universidade de São Paulo desde 2007. O texto final com a união de todas as transcrições possuia 11098 palavras.

\section{Conto de Fadas: Branca de Neve e os Sete Anões}

A versão usada é a adaptação popular em Português do conto dos irmãos Grimm ${ }^{2}$. O texto possui apenas 837 palavras.

\section{Biologia: Câncer (Doença)}

Usamos dois textos:

- O primeiro é uma publicação feita pelo Instituto Nacional do Câncer - INCA, que trata do carcinoma de células escamosas da cabeça e pescoço (HNSCC), que é o quinto tipo de câncer mais comum mundialmente. Tal artigo foi publicado na Revista Brasileira de Cancerologia em Colombo e Rahal (2009). Esse texto possui 6263 palavras.

- O segundo texto é um artigo do Wikipédia ${ }^{3}$ em que são descritos, de forma geral, os aspectos básicos do cancro (Português europeu) ou câncer (Português brasileiro). O texto possui 7374 palavras.

\subsection{Procedimentos}

A seguir, descreveremos os passos realizados e as experiências em cada um deles.

\footnotetext{
${ }^{1}$ http://ccsl.ime.usp.br/agilcoop/agilvideo

${ }^{2}$ http://www.educacional.com.br/projetos/efla4/contosdefadas/brancadeneve.html

${ }^{3} \mathrm{http}: / /$ pt.wikipedia.org/wiki/Cancro
} 


\subsubsection{Extração de Termos}

Usamos o Cogroo para lidar com a informação linguística dos textos e experimentamos o seguinte:

- Antes da versão 3, a forma de usar o Cogroo se dava através de uma interface UIMA. Tal interface padronizava o Cogroo para poder ser utilizado por diferentes ferramentas. Isso possibilitava que, com o mesmo código, pudéssemos trocar de Português para Inglês ou outras línguas.

- O Cogroo UIMA era um projeto ambicioso, porém, percebemos que apareciam alguns erros na rotulação, ou seja, alguns elementos gramaticais não eram corretamente estabelecidos. Portanto decidimos re-projetar nossa arquitetura para trabalhar com o Cogroo diretamente sem usar o UIMA.

- Como qualquer sistema, o Cogroo às vezes não é preciso no reconhecimento de elementos gramaticais. Por exemplo, em certas ocasiões, o advérbio ai é marcado como um substantivo. A palavra que também é interpretada de diferentes formas, às vezes como um especificador, às vezes como um substantivo e às vezes como um pronome.

- O Cogroo 3 possui um shallow parser que retorna uma árvore sintática com sintagmas nominais, por exemplo, vemos na Figura 7.1 a árvore sintática da frase $A$ Branca de Neve vagou pela floresta.

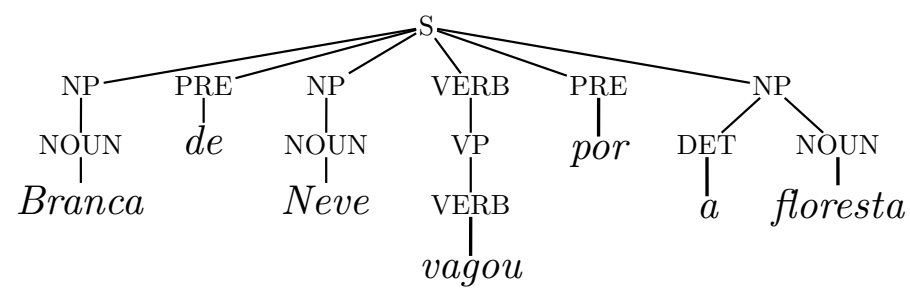

Figura 7.1: Árvore sintática da frase A Branca de Neve vagou pela floresta

Nós usamos a métrica C/NC-Value, detalhada na Seção 4.4, com as seguintes características:

- Usamos o Cogroo para realizar a lematização das palavras. Também o usamos como filtro linguístico para obter os sintagmas nominais e consequentemente os sintagmas preposicionais:

- Como vimos na Figura 7.1, o Cogroo reconhece positivamente quais são os sintagmas nominais, mas para reconhecer os sintagmas preposicionais localizamos dois sintagmas nominais que possuam uma preposição entre eles, tais como:

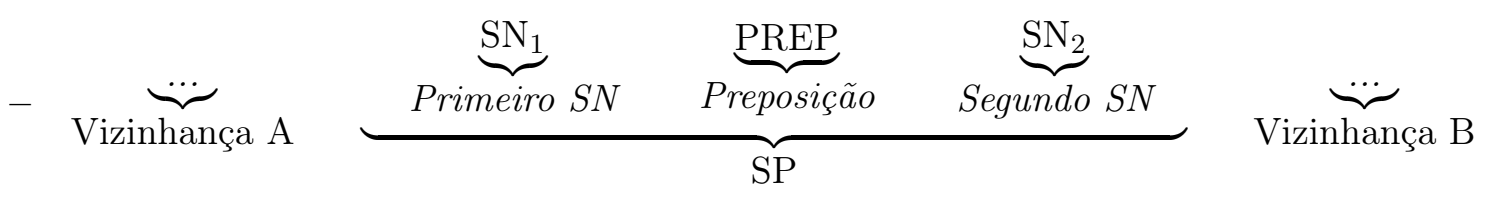

- Para cada SP, removemos os stop-words que estiverem no começo e no final, por exemplo a frase cada sintoma na lista acima ficaria reduzida a sintoma na lista.

- As palavras contextuais do $\mathrm{SN}_{1}$ são a última palavra da vizinhança $A$ e a primeira palavra do $\mathrm{SN}_{2}$. Similarmente, as palavras contextuais do $\mathrm{SN}_{2}$ são a última palavra do $\mathrm{SN}_{1}$ e a primeira palavra da vizinhança $B$. Finalmente, as palavras das vizinhanças são as palavras contextuais do SP. 
- Em relação aos stop-words, nós consideramos uma lista de 150 palavras, entre símbolos de pontuação, adjetivos de posição, interjeições, conjunções, artigos, conectivos, etc. Vemos tal lista no Apêndice A.

Finalmente, a Tabela 7.1 mostra os primeiros quinze elementos escolhidos como termos para cada texto.

\subsubsection{Descoberta de Relações}

No desenvolvimento do presente trabalho, tentamos aplicar a estratégia do trabalho de Ribeiro-Junior (2008), ou seja, aplicamos os padrões de Baségio (adaptação de Hearst) nos textos mas não encontramos resultados positivos, apenas uma ou até três relações reconhecidas em cada um. Esse resultado frustrante deveu-se ao fato de que os padrões eram muito rígidos, por exemplo, no seguinte texto:

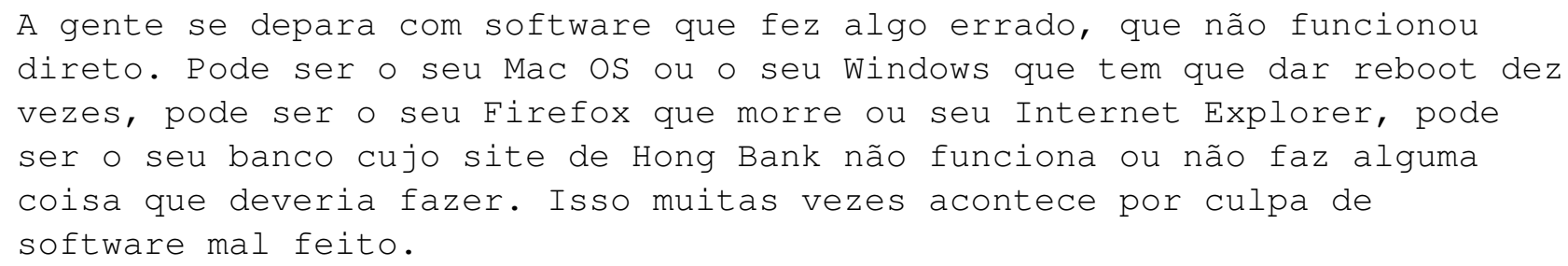

Nenhum padrão é reconhecido, porém, os termos Mac OS e Windows compartilham a mesma natureza, e deveriam ser reconhecidos como equivalentes, de forma similar, Firefox e Internet Explorer.

Com o uso da GR, conseguimos identificar as seguintes relações:

- Mac dar reboot_dez_vezes.

- Windows dar reboot_dez_vezes.

- Gente deparar software.

- Software faz errado.

- Software not_funcionar direto.

A estratégia adotada é parecida a RelText (mencionado na Seção 5.2), já que estabelecemos verbos como relações enquanto que o domínio e a imagem são o sujeito e predicado da oração em que o verbo aparece. Na continuação propomos uma lista de regras para poder analisar os textos em português.

\section{Regras para uma GR na Língua Portuguesa}

Como vimos no final do capítulo anterior, o gerativista ${ }^{4}$ realiza uma análise de constituintes de forma mais profunda para descobrir a origem da estrutura a fim de simplificá-la. De forma similar, realizamos tal processo da seguinte forma:

Visitamos cada elemento de uma sentença e tentamos identificar a estrutura sujeito-verbo-objeto (SVO), em que o sujeito e o objeto serão de tipo Lista, e o verbo será apenas de tipo String.

1. Quando encontramos um sintagma nominal (SN), consideramos a alternativa deste ser parte de uma sequência de SNs e/ou Sintagmas Preposicionais (SPs), como por exemplo:

- O SCRUM, o XP e o Desenvolvimento Guiado por Funcionalidades são metodologias ágeis. 


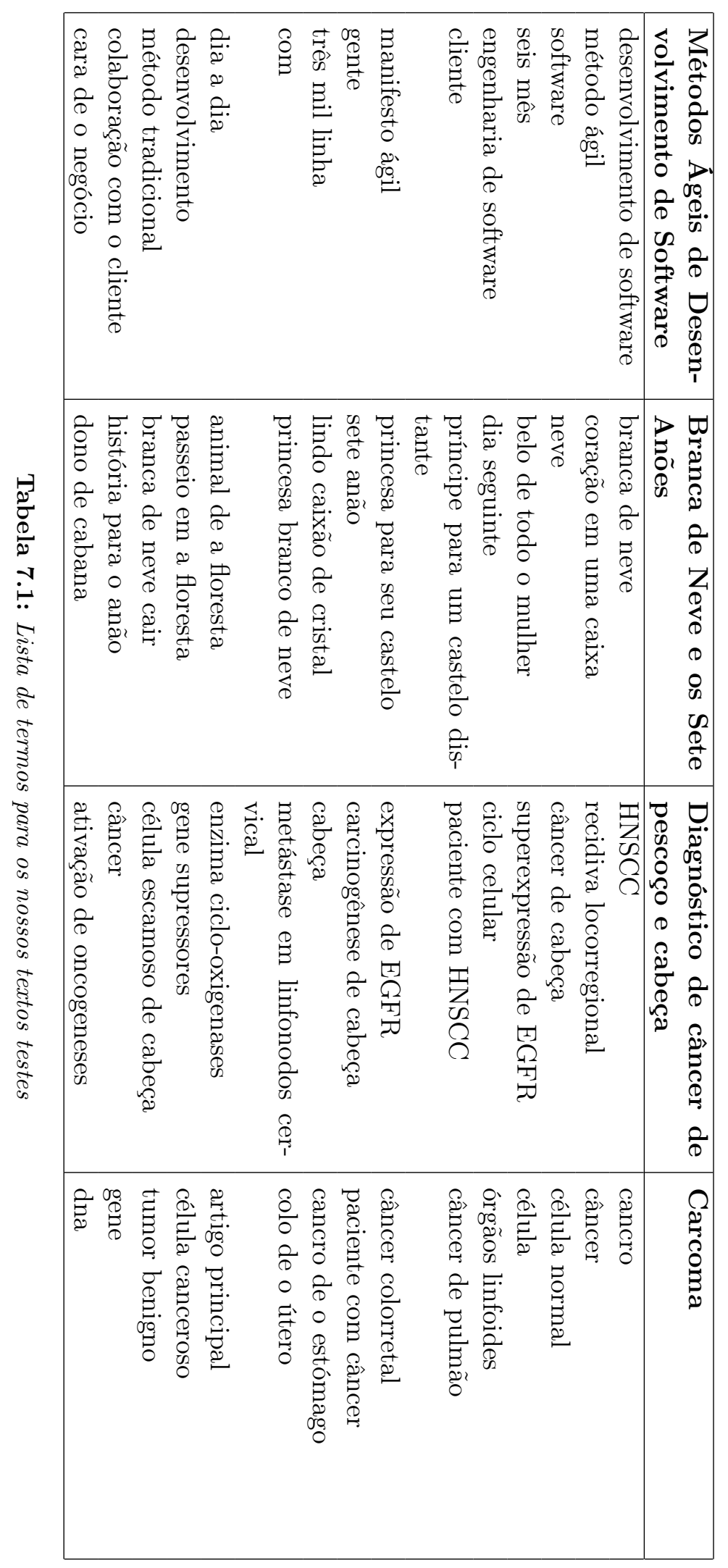


Neste exemplo, os sintagmas nominais SCRUM e XP são reconhecidos; e de igual maneira o SP Desenvolvimento Guiado por Funcionalidades.

Finalmente, dependendo se o verbo já foi encontrado, será colocado na lista de sujeitos (antes do verbo) ou na lista de objetos (depois do verbo).

2. Se encontrarmos um verbo, primeiro verificamos se o verbo principal já foi inicializado. E se ainda não foi, simplesmente estabelecemos o verbo encontrado como o principal da atual sentença; caso contrário, supomos que seja uma oração de período composto e chamamos ao processo de análise recursiva, passando como parâmetro o primeiro elemento não vazio entre:

(a) o último objeto do predicado,

(b) o sujeito da sentença atual, ou

(c) o sujeito recebido de uma sentença anterior analisada.

3. No caso de um advérbio, analisamos se ele é de negação como não, nunca, jamais, nem, tampouco, e se ele está do lado do verbo. Exemplo:

- O analista não pode falhar

Se não for de negação, consideramos a possibilidade da frase ser de período composto verificando se tal advérbio é de causa (porque, consequentemente); ou de exclusão (apenas, exclusivamente, salvo, senão, simplesmente, só, somente, unicamente); ou de inclusão (ainda, até, inclusivamente, mesmo, nomeadamente, também), de lugar (ai, aonde, onde); ou de modo (aliás). Exemplo:

- Deve-se entregar no prazo porque o cliente está exigindo.

Se não for algum dos tipos anteriores de advérbio, simplesmente o ignoramos.

4. Para o caso de uma preposição, verificamos se estamos lidando com um um verbo composto como por exemplo: Eu "gosto de viajar" para o estrangeiro.

5. Se encontrarmos um adjetivo, ele é considerado como um SN, e o tratamos como na primeira regra.

6. Se encontrarmos um especificador, como por exemplo "que", então estamos frente a uma frase subordinada, e chamamos recursivamente o algoritmo para tal frase.

7. Se encontramos uma conjunção, estamos frente a um caso de oração coordenada, porém, o tratamento será o mesmo da regra anterior.

8. Se encontramos uma vírgula, então, pode ser o caso de outra frase e tratamos similarmente aos casos anteriores.

9. Qualquer outro caso é simplesmente ignorado.

\section{Exemplos da análise com GR}

Por exemplo, na frase:

Branca de Neve crescia e ficava cada vez mais bonita,

cada elemento é analisado da seguinte forma:

1. Branca de Neve: sintagma preposicional, estabelecemos ele como o sujeito da frase atual.

2. crescia: verbo, estabelecemos ele como verbo principal da frase. 
3. $e$ : conjunção, por tanto analisamos o resto da sentença passando como sujeito Branca de Neve.

3.1. ficava: verbo, estabelecemos ele como verbo principal da sub-frase atual.

3.2. cada: pronome, simplesmente ignoramos.

3.3. vez: substantivo, consideramos ele como objeto do predicado.

3.4. mais: adverbio, simplesmente ignoramos.

3.5. bonita: adjetivo, consideramos ele como objeto do predicado.

3.6. Salvamos a tupla:

- < Branca de Neve, ficar $>$

3.7. Salvamos as triplas:

- <Branca de Neve, ficar, vez>

- <Branca de Neve, ficar, bonita $>$

4. Salvamos a tupla:

- <Branca de Neve, cresce>

Embora a GR tenha sido projetada para aceitar vários casos, alguns casos não deverm ser aceitos, por exemplo $<$ Branca de Neve, ficar, vez $>$. Por isso é necessário um usuário para filtrar tais resultados.

O conjunto de regras também aceita sequencias, por exemplo:

Java, Python e PHP são linguagens interpretadas.

1. Java: sintagma nominal, por tanto verificamos se ele pode ser uma sequencia de sintagmas. Isto nos retorna: $\{$ Java, Python, $P H P\}$.

2. $s \tilde{a} \boldsymbol{o}$ : verbo, estabelecemos ele como verbo principal da frase principal.

3. linguagens interpretadas: substantivo e adjetivo, estabelecemos eles como objeto do verbo.

4. Estabelecemos as tuplas:

- <Java,ser $>$

- $<$ Python,ser $>$

- $<P H P$, ser $>$

5. Salvamos as triplas:

- $<$ Java, ser, linguagem_interpretada $>$

- <Python, ser, linguagem_interpretada $>$

- $<$ PHP, ser, linguagem_interpretada $>$

\subsubsection{Análise de Conceitos Formais}

Testamos três diferentes formas de introduzir a ACF dentro do processo de construção da ontologia:

1. Construção de uma ontologia considerando os termos como objetos e os verbos como atributos

2. Com a mesma estratégia anterior, porém, usando rótulos reduzidos.

3. Estabelecendo superconceitos em nossa ontologia já aprendida com nosso método de análise sintática. 


\subsubsection{Experimentando o uso da ACF}

Além de usar a ACF para obter um superconceito a partir do reticulado, implementamos também uma forma de traduzir um reticulado a uma ontologia e experimentamos usar uma técnica de redução de etiquetas para conceitos formais.

Basicamente, nosso roteiro foi o seguinte:

1. Identificamos o termos principais e os adicionamos ao conjunto de objetos.

2. Reconhecemos os verbos que estavam juntos a estes termos e construímos um Contexto Formal. Por exemplo:

$$
\text { - } \underbrace{\text { Branca de Neve }}_{\text {primeiro termo }} \underbrace{\text { dormiu }}_{\text {verbo }} \text { na } \underbrace{\text { floresta }}_{\text {segundo termo }} \text {. }
$$

O atributo dormir é mapeado ao termo Branca de Neve, e o atributo está_dormido é relacionado com o termo floresta. A regra para trocar a terminação AR e ER/IR do verbo por um sufixo ANDO ou INDO nem sempre é correta, por exemplo para o verbo ir, nossa regra geraria o atributo esta_indo, no entanto, o correto seria usar outro verbo mais adequado, de acordo com o contexto em que se fala. Por exemplo, se o sujeito está indo a outra cidade, então essa cidade recebe os objetos que possuem o atributo: está_chegando.

3. Usamos o Galicia para construir o reticulado de conceitos e o traduzimos para um formato de ontologia. Todos os conceitos formais foram traduzidos em classes da ontologia, tendo como etiquetas os números dos nós. Visualmente o resultado é difícil de compreender, por exemplo apreciamos na Figura 7.2 o reticulado de conceitos para o tema de Métodos Ágeis. Esse reticulado teve 155 conceitos sem redução de etiquetas.

4. Estabelecemos as relações tomando como domínio as extensões, e, como imagem, as intensões. A etiqueta recebeu uma palavra genérica (active) junto a um número, por exemplo a active12 possui como domínio Desenvolvimento e como imagem está_dividido, está_melhorado e terminar.

O principal problema com o estabelecimento de relações é que alguns conceitos possuíam uma enorme quantidade de objetos ou de atributos, por exemplo o active11 possuia apenas 1 domínio, mas 27 elementos na imagem.

A expressividade indicava que a ontologia estava escrita na família de lógica de descrição $\mathcal{A L U}$ e $\mathcal{A L C}$.

Devido à inviabilidade da avaliação com outros métodos, bem como ao fato de ter um menor poder de expressividade, esta técnica foi descartada e nos concentramos na análise sintática e no uso da ACF como ferramenta para estabelecer um conceito superior comum para dois ou mais conceitos.

Neste capítulo detalhamos os passos seguidos na realização das experiências. Descrevemos primeiro os textos analisados e depois detalhamos como foi realizada a extração de termos, depois a aplicação da GR e finalmente o uso do análise de conceitos. No próximo capítulo, descrevemos o método usado para a avaliação das ontologias aprendidas. 


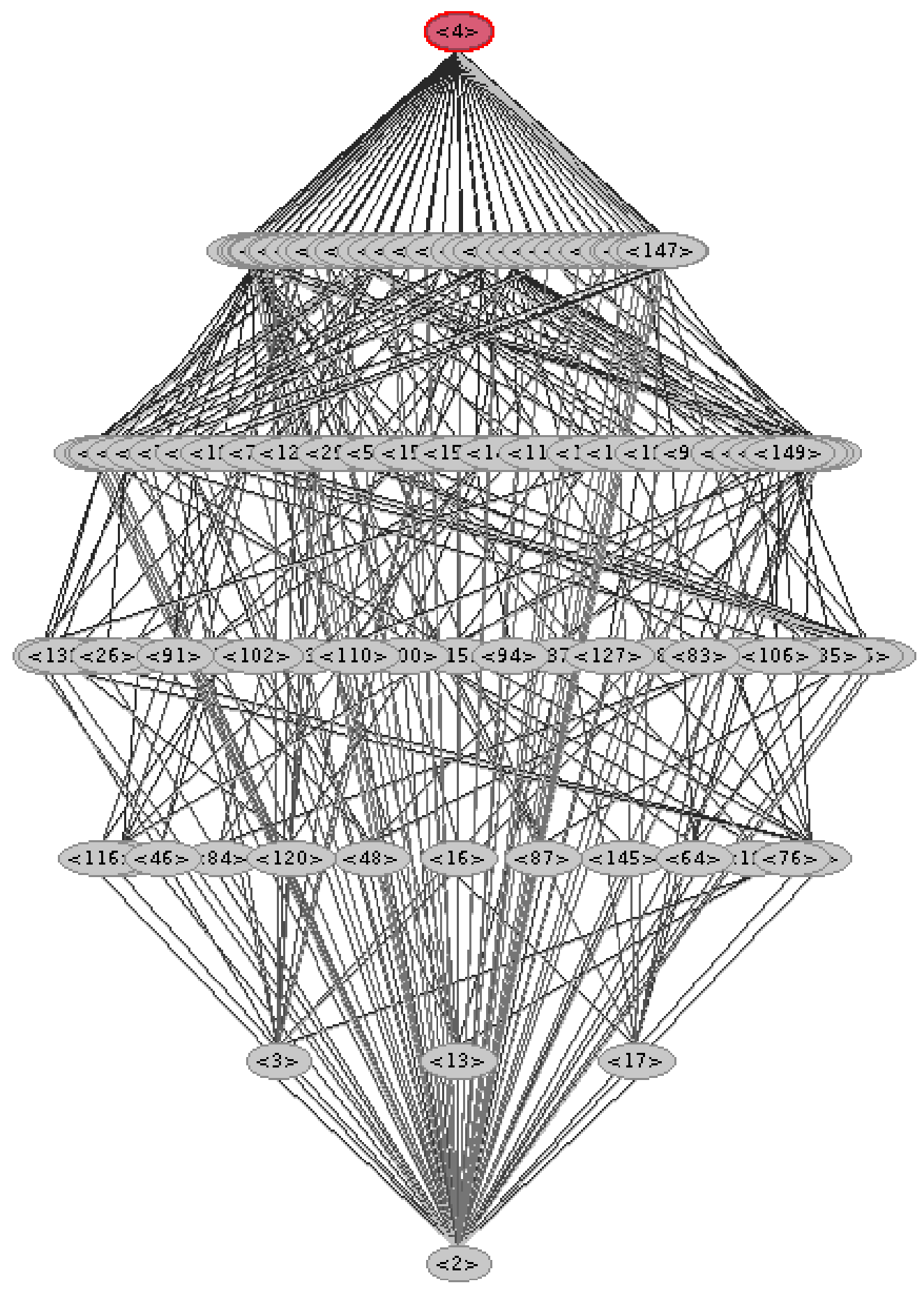

Figura 7.2: Reticulado de conceitos para o tema de Métodos Ágeis 


\section{Capítulo 8}

\section{Avaliação de Ontologias}

Este capítulo foi dividido em três partes: (i) introdução aos métodos de avaliação de ontologias, (ii) detalhamento do método OntoMetrics e (iii) apresentação dos resultados originados por ele.

\subsection{Introdução}

É difícil definir o que é uma "boa ontologia", mas para alguns autores, como Freitas (2007), uma boa ontologia é apenas aquela que cumpre com os requisitos do sistema onde queremos aplicá-la.

Outra definição interessante também é a de Vrandečić (2010) que indica que a uma boa ontologia é aquela que tem a intenção de ser amplamente reutilizável e ser capaz de colaborar com outras aplicações.

Ante a preocupação por obter uma ontologia que represente da maneira mais fiel um certo domínio de conhecimento, os investigadores propuseram durante os últimos anos diferentes formas de avaliar tais ontologias. De acordo com o trabalho de Brank et al. (2005), existem as seguintes formas de avaliação de ontologias:

(i) baseando-se em uma referência dourada, em que a referência dourada é uma ontologia fruto da síntese de outras ontologias de referência, e da discussão com um especialista do domínio;

(ii) usando a ontologia em uma aplicação, em que respondemos as perguntas: "Satisfazemos as restrições do sistema?", "Resolve as consultas que os usuários precisam?";

(iii) comparando com uma fonte de dados, isto é, se a ontologia possui termos para conceitos e relações congruentes com o domínio estudado.

(iv) feita por um humano, que na verdade é feita por um especialista que determina se a ontologia representa realmente o domínio de estudo.

Devemos levar em consideração também que as ontologias desenvolvidas manualmente são diferentes daquelas que foram obtidas através de um método de aprendizado semi ou completamente automático e requerem outra forma de avaliação. O trabalho de Dellschaft e Staab (2008) analisa justamente diferentes enfoques para a avaliação de ontologias fruto de algum método de aprendizado. Podemos ver tal análise na Tabela 8.1.

\subsection{OntoMetric}

Lozano-Tello (2002), propôs em sua tese de doutorado o método OntoMetric para reconhecer que ontologia, dentre outras, deve ser usada para um certo domínio.

Esse método usou a metodologia METHONTOLOGY (Lopez et al., 1997) para construir as ontologias de referência e descreveu também, um marco multinível de características onde 160 itens foram agrupados em 5 dimensões para avaliar a idoneidade de uma ontologia: 


\begin{tabular}{|l|l|}
\hline Enfoques & Características \\
\hline Baseado em tarefas & - Diferentes métricas de recuperação de informação são usadas. \\
& $\begin{array}{l}\text { - A tendência deles é indicar o que falta, o que sobra e o que deve ser } \\
\text { mudado na ontologia, no entanto, não existe uma só forma certa } \\
\text { de avaliar tais coisas. }\end{array}$ \\
\hline Baseado em corpus & $\begin{array}{l}\text { - Úteis para avaliar se uma ontologia cobre efetivamente um certo } \\
\text { domínio. }\end{array}$ \\
& $\begin{array}{l}\text { - Parcialmente úteis pois as ontologias retornadas por estes métodos } \\
\text { podem ser usadas como benchmark para avaliar as ontologias fruto } \\
\text { de outras técnicas de AO. }\end{array}$ \\
\hline Baseado em critérios & $\begin{array}{l}\text { - Uma grande variedade de medições podem ser estabelecidas. } \\
\text { Pluralidade de avaliações. Cada uma pode dar uma diferente on- } \\
\text { tologia ganhadora. }\end{array}$ \\
\hline
\end{tabular}

Tabela 8.1: Enfoques usados na avaliação de métodos de AO

- conteúdo,

- linguagem de implementação,

- metodologia de desenvolvimento,

- ambientes de desenvolvimento, e

- custos de uso

As características da dimensão conteúdo, avaliam os elementos internos da ontologia. Possui os seguintes fatores:

- Conceitos.

- Relações.

- Taxonomia.

- Axiomas.

As características da dimensão linguagem englobam aspectos mais formais sobre lógica, atributos, instâncias, inferências e outras particularidades.

As características relacionadas com à dimensão "metodologia de desenvolvimento"possuem fatores como:

- Precisão da Metodologia, em que se detalha as partes técnicas no planejamento do projeto de desenvolvimento da ontologia.

- Usabilidade da Metodologia, em que se verifica a clareza das instruções do projeto.

- Maturidade da Metodologia, para medir a magnitude do projeto. 
As características relacionadas à dimensão "ambiente de desenvolvimento"possuem os seguintes fatores:

- Prestações do Ambiente.

- Aspectos de Visualização.

- Aspectos de Edição.

- Aspectos de Interação.

- Aspectos Metodológicos.

- Aspectos Cooperativos.

- Aspectos de Tradução.

- Aspectos de Integração de Ontologias.

Finalmente, as características relacionadas à dimensão "custos de uso"são destinadas a fins comerciais.

No presente trabalho estamos interessados apenas na idoneidade do conteúdo da ontologia, porém, a parte de axiomas não será considerada, pois nosso método não considerou tais elementos. Vemos na Tabela 8.2 as características da dimensão conteúdo.

\begin{tabular}{|l|l|}
\hline Código & Característica \\
\hline \hline \multicolumn{2}{|c|}{ Fatores de Conceitos } \\
\hline C11 & Os conceitos essenciais para o projeto encontram-se na ontologia \\
\hline C12 & $\begin{array}{l}\text { Os conceitos essenciais para o projeto estão em níveis superiores da on- } \\
\text { tologia }\end{array}$ \\
\hline C13 & Os conceitos estão descritos adequadamente em linguagem natural \\
\hline C14 & $\begin{array}{l}\text { A especificação formal dos conceitos coincide com a descrição em lingua- } \\
\text { gem natural }\end{array}$ \\
\hline C15 & Os atributos descrevem de forma precisa os conceitos \\
\hline C16 & O número de conceitos é adequado para representar a ontologia \\
\hline \multicolumn{2}{|c|}{ Fatores de Relações } \\
\hline C21 & As relações essenciais para o projeto estão na ontologia \\
\hline C22 & Os conceitos encontram-se relacionados corretamente \\
\hline C23 & As relações estão descritas adequadamente em linguagem natural \\
\hline C24 & As aridades das relações são adequadas para o projeto \\
\hline C25 & As relações têm especificadas suas propriedades formais \\
\hline C26 & O número de relações é adequado para representar a ontologia \\
\hline \multicolumn{2}{|c|}{ Fatores de Taxonomia } \\
\hline C31 & Classificação dos conceitos de várias perspectivas \\
\hline C32 & As relações Not-Subclass-Of são apropriadas \\
\hline C33 & As relações de partição disjunta são usadas apropriadamente \\
\hline C34 & As relações de partição exaustiva são usadas apropriadamente \\
\hline C35 & Profundidade máxima adequada \\
\hline C36 & A média de filhos por conceito é adequada \\
\hline
\end{tabular}

Tabela 8.2: Características na dimensão conteúdo sem a avaliação do fator de axiomas. 


\begin{tabular}{|c|c|c|c|}
\hline Fator & Métodos Ágeis & Branca de Neve & Doença do Câncer \\
\hline \multicolumn{3}{|c|}{ Fatores de Conceito } \\
\hline C11 & 4,3 & 4,7 & 4,4 \\
\hline C12 & 4,3 & 4 & 4 \\
\hline C13 & 4 & 4,7 & 3,7 \\
\hline C14 & 4,3 & 4,7 & 3,4 \\
\hline C16 & 4 & 4,7 & 4 \\
\hline \multicolumn{3}{|c|}{ Fatores de Relações } \\
\hline C21 & 4 & 5 & 3,4 \\
\hline C22 & 4 & 4 & 3,2 \\
\hline C23 & 4,3 & 5 & 3,4 \\
\hline C24 & 3,7 & 4,3 & 3,4 \\
\hline C25 & 4,3 & 5 & 3,5 \\
\hline C26 & 4,3 & 4,7 & 4,1 \\
\hline \multicolumn{3}{|c|}{ Fatores de Taxonomia } \\
\hline C31 & 4,3 & 5 & 3,7 \\
\hline C33 & 4,7 & 4,7 & 4,4 \\
\hline C35 & 4 & 3,7 & 3,4 \\
\hline C36 & 3 & 3,3 & 3 \\
\hline
\end{tabular}

Tabela 8.3: Média dos resultados dos questionários sobre os fatores de conceito, relações e taxonomia. O valor mínimo era 1 e o máximo 5.

\subsection{Avaliação com OntoMetrics}

As ontologias geradas com nosso método de análise sintático e ACF foram colocadas em formato web e um pequeno site foi feito para que outras pessoas as avaliem. Podemos ver algumas imagens no Apêndice B. Neste site foi incorporado um questionário para medir os Fatores de Conceitos, Relações e Taxonomia. Vemos um exemplo do questionário no Apêndice C.

Ressaltamos que a notação usou os lemas das palavras. Portanto, os nomes das relações são verbos no infinitivo. Aqueles SN com adjetivos estarão no singular e no gênero masculino. Quando uma negação for encontrada, um prefixo "not_" é adicionado e quando uma forma passiva é reconhecida, o prefixo "can_be" é adicionado ao verbo.

- As pessoas que avaliaram a ontologia de Métodos Ágeis foram os membros do laboratório de métodos ágeis da USP, os mesmos que formaram AgilCoop.

- A ontologia da Doença de Câncer foi avaliada por estudantes de medicina cursando o terceiro ano e também por membros do grupo de pesquisa no Hospital do Câncer A.C. Camargo.

- Finalmente, a ontologia do conto de fada Branca de Neve foi avaliada pelo público em geral.

As respostas dos questionários estavam no intervalo de 1 a 5, e encontram-se na Tabela 8.3.

\section{Observações}

- O fator C15 (os atributos descrevem de forma precisa os conceitos) não foi considerado pois não existiu um aprendizado de atributos para os conceitos.

- Os fatores C32 e C34 (relação Not-SubClasse e partição exaustiva respectivamente), não foram considerados. 


\section{Capítulo 9}

\section{Conclusões}

Neste trabalho foi apresentado uma proposta para realizar AO em textos escritos em português, em que:

- A extração de termos usa a métrica C/NC-values com ajuda da API do Cogroo, como vimos na Seção 4.4.

- A descoberta de relações usa uma gramática de restrições que projetamos para a língua portuguesa.

- Analisamos sequencialmente cada elemento da frase aplicando as regras que vimos na Seção 7.2.2. O produto desta análise é um conjunto de triplas SVO.

- As relações taxonômicas são estabelecidas baixo os seguintes critérios:

- Se na tripla SVO o verbo for o verbo SER, então uma propriedade de subsunção é estabelecida entre o sujeito e o objeto. Por exemplo:

* Branca de Neve é bonita

* Branca_de_Neve $\sqsubseteq$ bonita

- Caso contrário, estabelecemos uma relação de subsunção entre o sujeito é o objeto acompanhado do verbo que será a propriedade. Por exemplo:

* A rainha ficou doente

* Rainha $\sqsubseteq$ fica Doente

- Para aquelas propriedades cujo número de elementos no domínio ou na imagem for maior de dois, procuramos o conceito comum superior a eles com ajuda do reticulado Apresentamos um algoritmo na Seção 3.4.

- Foi implementada uma ferramenta para ajudar ao usuário na construção da ontologia, permitindo ele filtrar a lista de termos e a lista de relações. Algumas imagens da ferramenta podem ser vistas no apêndice E.

\subsection{Discussões}

Nesta seção, discutimos as ontologias que obtivemos através da nossa proposta.

\section{Sobre Métodos Ágeis}

Dois exemplos ótimos encontrado foram de Cliente e Programador 


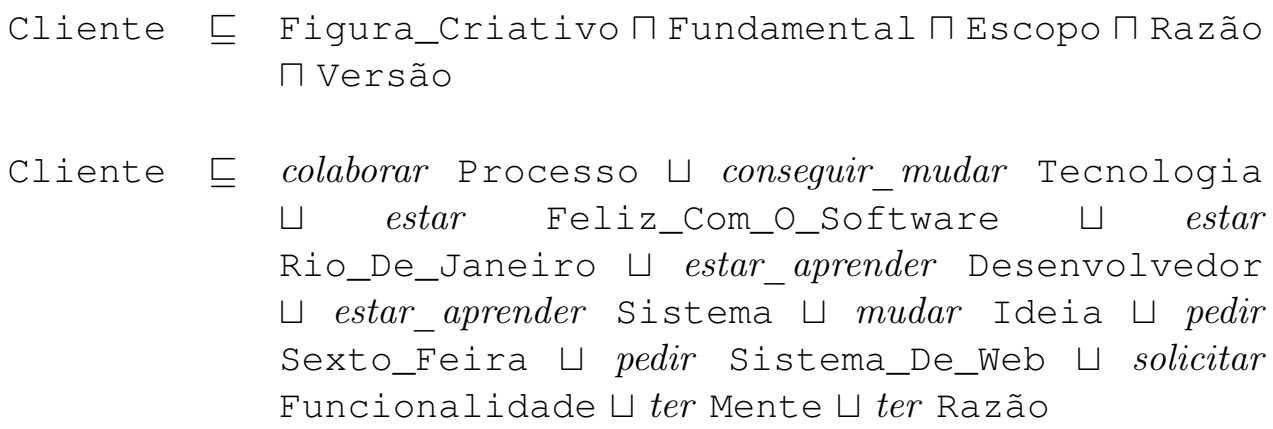

Programador $\sqsubseteq$ acreditar Método_Ágil

Programador $\neq$ entender Pessoal $\sqcap$ entender Regra_De_Negócio

- Ressaltamos estes dois exemplos pois na verdade, o foco das palestras era explicar o papel das pessoas (clientes e programadores) no processo de desenvolvimento.

- Na primeira linha apreciamos a relação de subsunção entre Cliente e outros elementos. Os primeiros parecem corretos, porém Razão não parece. No entanto, é possível que uma empresa suponha corretamente que "a razão da empresa é o cliente" e isso validaria a subsunção. Finalmente Escopo e Versão não parecem ser similares ao conceito de Cliente.

- Algumas relações taxonômicas só são verdade para casos específicos, por exemplo, estar Feliz_Com_O_Software e estar Rio_De_Janeiro. Outras relações só fazem sentido em um determinado contexto, por exemplo, ter Mente só faz sentido na sentença "o cliente tem em mente uma ideia do que quer", mas mesmo assim, tal frase não justifica a necesidade de estabelecer essa relação.

\section{Sobre Branca de Neve}

Um conceito interessante para analisar é a Pele, a qual possui as seguintes equivalências:

$$
\text { Pele } \sqsubseteq \text { Cabelo_Preto } \sqcap \text { Lábio_Vermelho } \sqcap \text { Neve }
$$

Tais equivalências foram encontradas a partir da frase:

Sua pele era branca como a neve, os lábios vermelhos como o sangue e os cabelos pretos como o ébano.

$\mathrm{Na}$ frase, Pele foi reconhecido como sujeito, era como verbo, e o predicado foi considerado como uma sequência de conceitos, estabelecendo uma relação de equivalência com o sujeito.

\section{Sobre Doença do Câncer}

Encontramos comentários muito interessantes de um especialista, que comentou algumas relações:

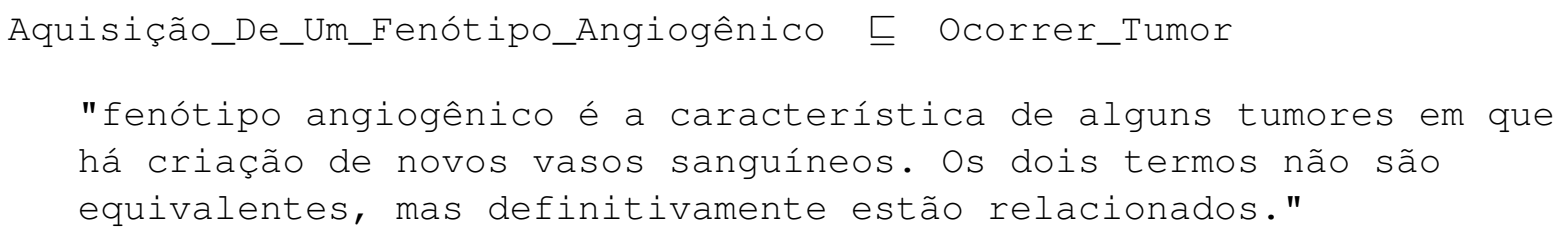




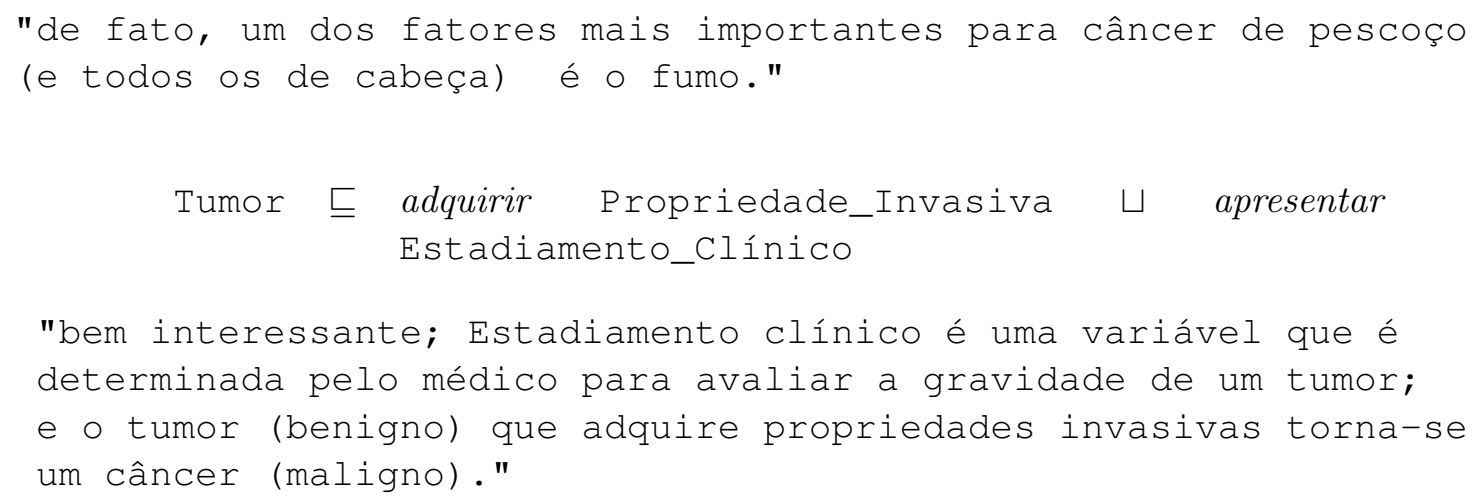

\subsection{Considerações Finais}

- No princípio da pesquisa, investimos muito esforço em procurar um método preciso para a extração de termos. A precisão, porém, não representou um fator importante no desenvolvimento do trabalho porque por exemplo, era impossível criar uma ontologia de métodos ágeis com apenas 10 termos embora importantes. Ainda eram precisos mais termos, por isso apresentamos ao usuário todos os termos com a possibilidade de filtrar os que considerava mais importantes.

- De forma similar ao trabalho de Jean-Pierre et al. (1997), a imprecisão dos resultados deve-se a diferentes fontes de erros:

- Erros por causa do Cogroo, por exemplo:

* Um erro muito comum era a identificação do advérbio aí como substantivo. Porém, tal erro era correto em frases como: Deixarei a nota aí.

* Outro erro frequente era a identificação da palavra pode como conjugação do verbo podar, enquanto o verbo correto deveria ser poder.

- Erros por causa da fonte:

* O texto de Métodos Ágeis possui muitas estruturas informais por serem parte de uma palestra, o que dificulta o processo de aprendizado. Como por exemplo: " $A$, isso que eu chamo colaborar". "Vamos tocar o barco".

- Reforçamos o problema de não ter tido ferramentas prontas para a extração de termos, reconhecimentos de relações, etc.

- Os resultados que apreciamos na Tabela 8.3 mostram que as ontologias retornadas por nosso método foram avaliadas positivamente pelos especialistas. As duas ontologias para a doença do Câncer obtiveram os valores mais baixos, porém os comentários dos especialistas indicaram que houve propriedades na ontologia que relatavam fatos verdadeiros sobre o tema e que davam valor a nossos resultados.

- O desafio inicial foi atingido, que consistia em propor um método que conseguisse extrair uma ontologia de um texto não de forma automática e soberana, mas sim de forma supervisionada e dependente de um especialista. O resultado foi uma ontologia inicial sem instâncias que, de forma simples, descreve certas características do domínio analisado. 


\subsection{Sugestões para Pesquisas Futuras}

Acreditamos que a descoberta de relações requer uma maior atenção. Os recursos linguísticos são muito extensos, existem diferentes gramáticas e diferentes formalismos. Um melhor estudo dessa informação de um ponto de vista prático seria necessário. Assim como o tema de ontologias foi revivido em 2004 a partir de conceitos filosóficos muito anteriores à época, acreditamos que a representação de conhecimento poderia ser muito mais enriquecida se aplicássemos mais a teoria linguística.

Também pensamos que uma fonte de informação semântica seria muito útil, mas não apenas um dicionário como o Amazonas, se não um léxico. Um léxico poderia abrir muito mais os caminhos das pesquisas relacionadas com a representação de conhecimento.

Finalmente, a tradução do reticulado a uma forma de ontologia não foi estudada apropriadamente, ela requer ainda um estudo mais profundo. Vimos que com diferentes critérios, podemos criar diferentes ontologias. 


\section{Apêndice A}

\section{Lista de Stop-Words}

Total de 150 palavras:

\begin{tabular}{|c|c|c|c|c|}
\hline & bem & esses & não & sob \\
\hline , & boa & em & nome & sobre \\
\hline & bom & embaixo & nosso & somente \\
\hline / & cada & enquanto & novo & tem \\
\hline- & cima & então & o & tal \\
\hline * & com & este & onde & também \\
\hline+ & como & estes & os & têm \\
\hline , & comprido & eu & $\mathrm{ou}$ & tempo \\
\hline $\mathrm{a}$ & conhecido & fim & outra & tenho \\
\hline ai & corrente & horas & outras & teu \\
\hline as & da & isso & outro & tipo \\
\hline à & dai & ista & outros & todo \\
\hline às & das & iste & para & todos \\
\hline acima & de & isto & parte & tu \\
\hline acerca & debaixo & ligado & pela & tudo \\
\hline agora & dentro & maioria & pelas & um \\
\hline algum & desde & maiorias & pelo & uma \\
\hline alguma & desligado & mais & pelos & umas \\
\hline algumas & deve & mas & por & uns \\
\hline alguns & devem & mesmo & porque & valor \\
\hline ali & deverá & meu & que & veja \\
\hline ambos & direita & minha & qual & verdade \\
\hline antes & dois & minhas & qualquer & verdadeiro \\
\hline aquela & dos & muita & quando & vós \\
\hline aquelas & e & muitas & quem & você \\
\hline aquele & ela & muito & quito & vocês \\
\hline aqueles & ele & muitos & se & \\
\hline aqui & eles & no & sem & \\
\hline assim & essa & nosso & seu & \\
\hline atrás & essas & nossos & seus & \\
\hline & esse & nós & $\operatorname{sim}$ & \\
\hline
\end{tabular}


APÊNDICE A 


\section{Apêndice B}

\section{AOntoWEB}

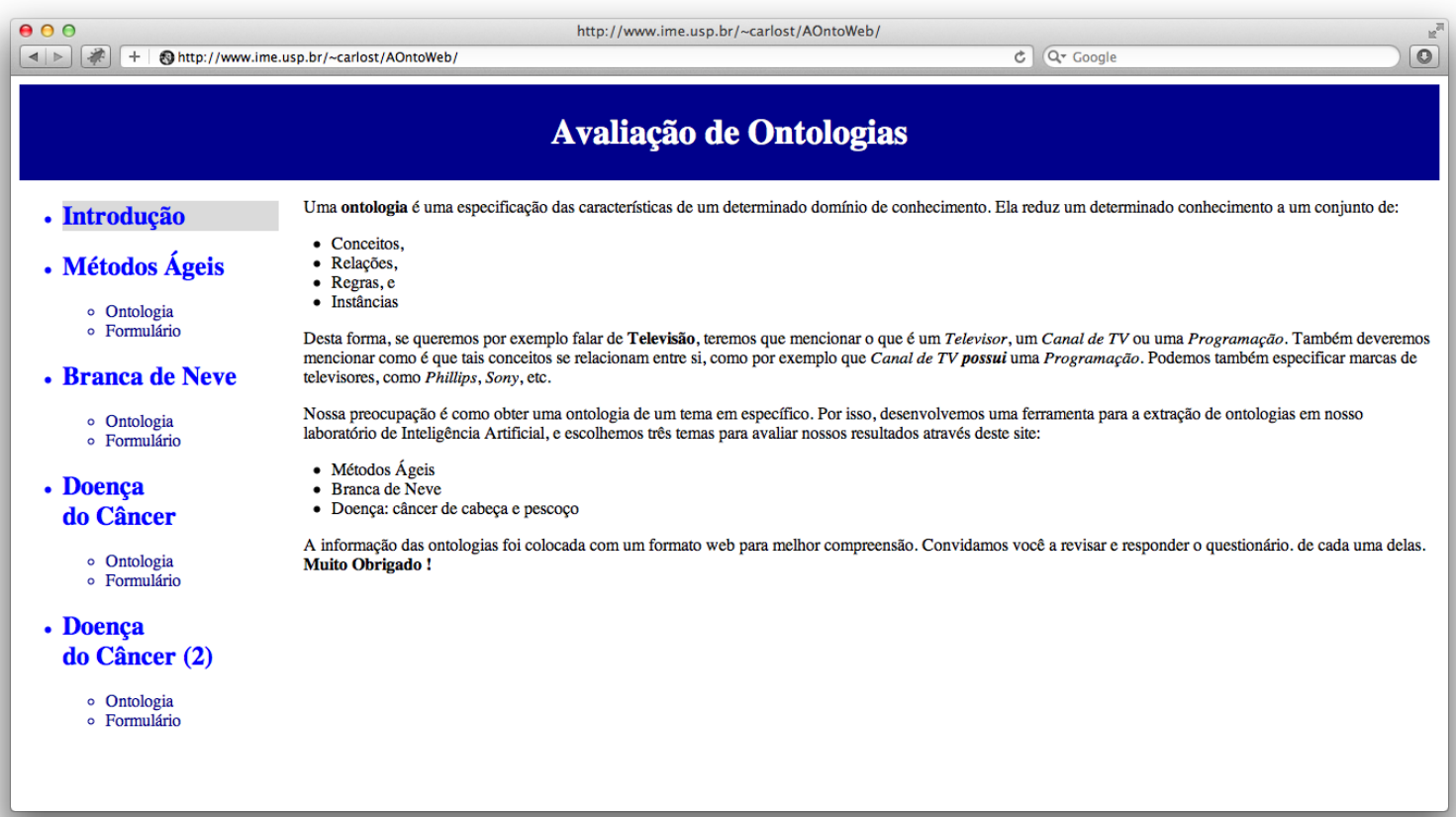

Figura B.1: AOntoWeb - Página Inicial 
http://wnw.ime.usp.br/ carlost/AOntoWeb/

C Q. Google

0

Avaliação de Ontologias

- Introdução

\section{Branca de Neve}

- Métodos Ágeis

Branca de Neve é um clássico conto de fadas. A versão usada no presente projeto é a adaptação no português do conto dos irmãos Grimm (Veja-se neste link).

- Ontologia

Pedimos que consulte primeiro nossa ontologia aqui:

Branca de Neve

- Ontologia de Branca de Neve

- Branca de Neve

- Doença

do Câncer

- Ontologia
- Formulário

- Doença

do Câncer (2)

- Ontologia

Figura B.2: AOntoWeb - Introdução à avaliação da ontologia de Branca de Neve

$\theta 00$

http://wnw.ime.usp.br/ carlost/AOntoWeb/

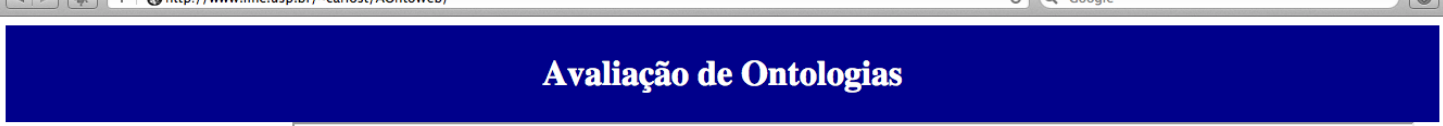

- Introdução

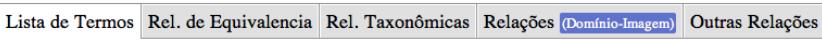

- Métodos Ágeis

- Ontologia
- Formulário

- Branca de Neve

- Ontologia

- Doença

do Câncer

- Ontologia
- Formulário

Doença

do Câncer (2)

- Ontologia

- branca de neve

- coração em uma caixః

Dica: Lista de termos

- neve

- neve dia seguinte

- dia seguinte

- príncipe de o reino vizinho

- lindo caixão de cristal

- princesa branco de neve

- princesa branco de net

- história para o anão

dono de a cabana

- dono de a cabana

- velhino maltrapilha

- rainha

- corpo de a princesa

- corpo de a princesa

- Medaco demacã

Figura B.3: AOntoWeb - Branca de Neve - Termos 


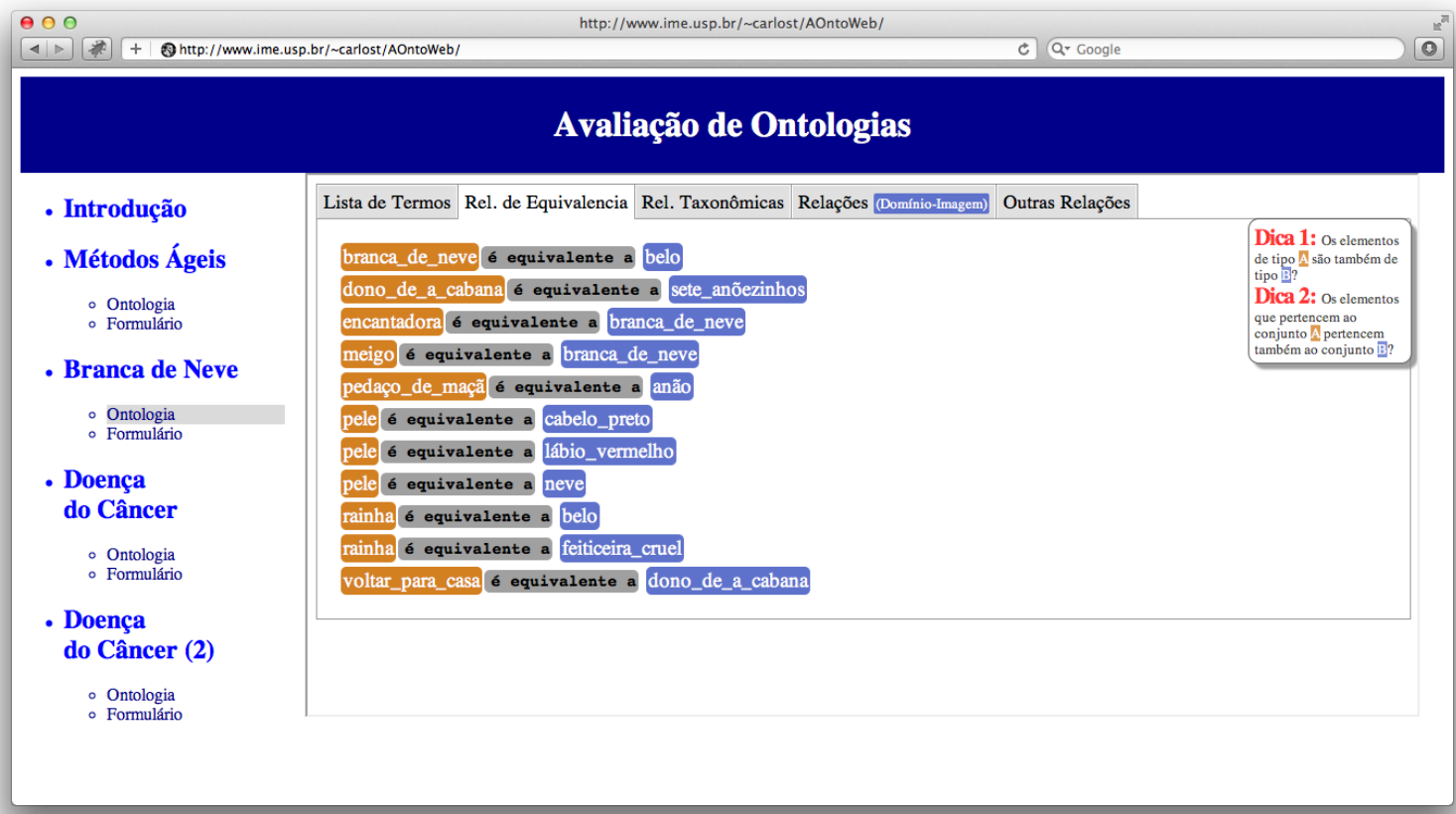

Figura B.4: AOntoWeb - Branca de Neve - Relações de Equivalência

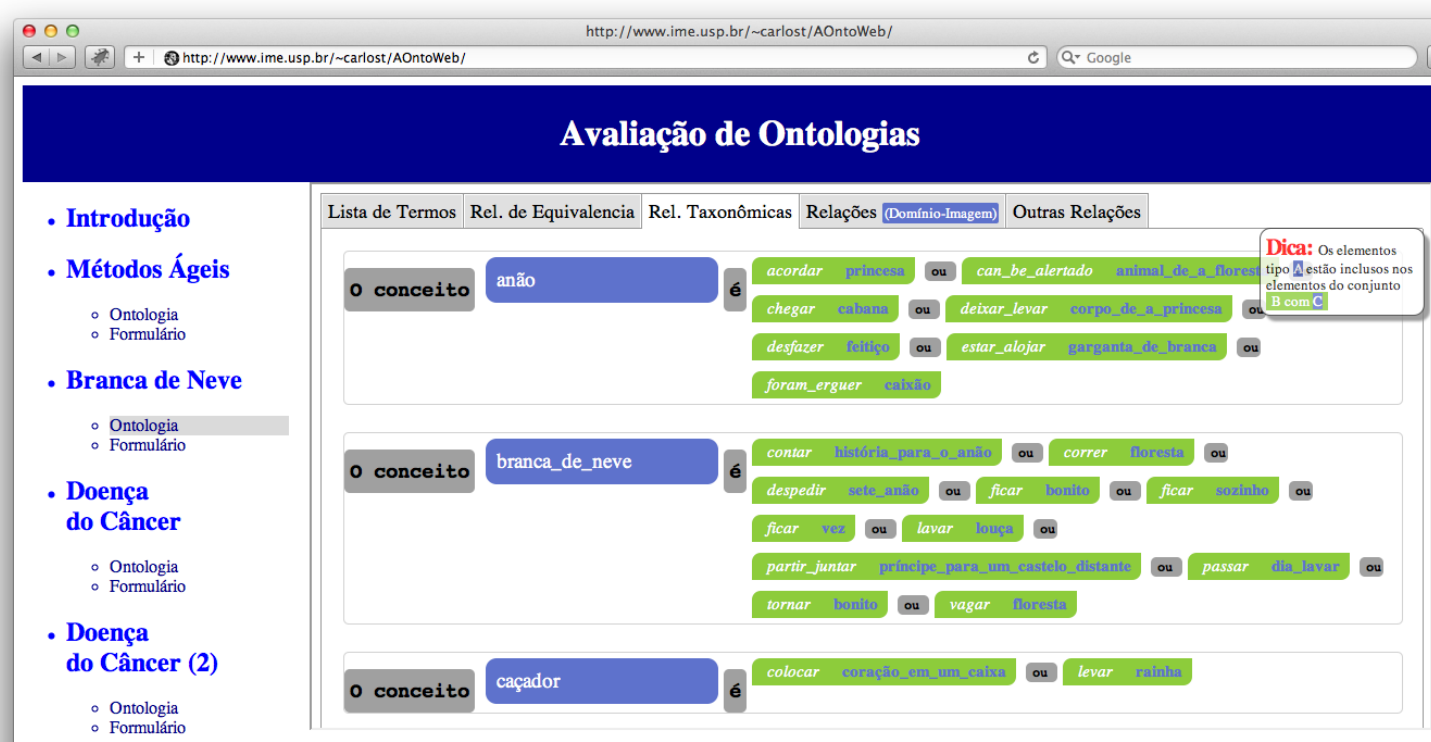

Figura B.5: AOntoWeb - Branca de Neve - Relações Taxonómicas 
$\theta 00$

http: //www.ime.usp.br/ carlost/AOntoWeb/

C Q. Google

(

Avaliação de Ontologias

- Introdução

- Métodos Ágeis

- Ontologia

- Branca de Neve

- Ontologia

Doença

do Câncer

- Ontologia

- Doença

do Câncer (2)

- Ontologia

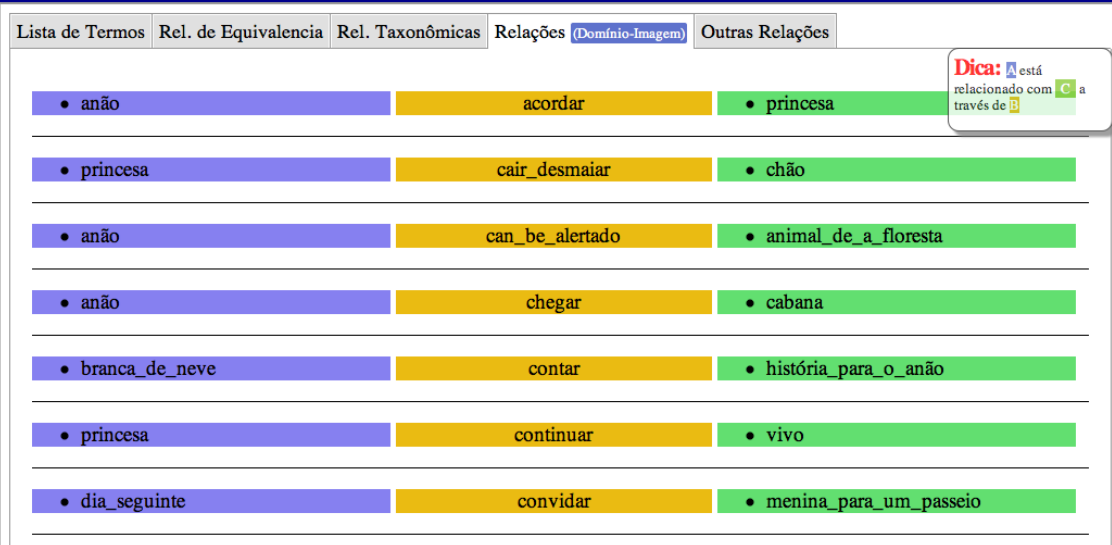

Figura B.6: AOntoWeb - Branca de Neve - Dominio é Imagem

$\theta 00$

http://wnww.ime.usp.br/ carlost/AOntoWeb/

\section{Avaliação de Ontologias}

- Introdução

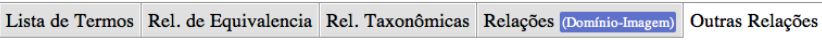

- Métodos Ágeis

- Ontologia

Branca de Neve

- Ontologia
- Formulário

- Doença

do Câncer

- Ontologia
- Formulário

Doença

do Câncer (2)

- Ontologia

\begin{tabular}{|c|c|c|}
\hline Lista de Termos Rel. de Equivalencia & Rel. Taxonômicas Relações (Domínio-Imagem) & Outras Relações \\
\hline \multirow{2}{*}{$\begin{array}{l}\text { - caçador } \\
\text { - poção_venenoso }\end{array}$} & & 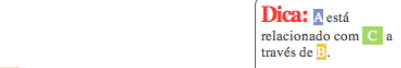 \\
\hline & colocar & Talvez $\underline{\Lambda}$ ou $\mathrm{C}$ faltem \\
\hline \multicolumn{3}{|l|}{ - ser } \\
\hline - ficar & ficar & \\
\hline
\end{tabular}

Figura B.7: AOntoWeb - Branca de Neve - Outras 


\section{Apêndice C}

\section{Questionário sobre o Marco de Características da Dimensão Conteúdo da Ontologia}

\section{Exemplo de Branca de Neve}

1. Lembre que este é um questionário para avaliar a idoneidade da ontologia gerada pelo nosso sistema.

2. Valores baixos indicam um retorno pobre

3. Valores altos indicam uma grande riqueza de informação

C11 Os conceitos essenciais se encontram presentes na ontologia?

(quando falamos de conceitos, nos referimos a lista de termos)

\begin{tabular}{lllllll} 
& 1 & 2 & 3 & 4 & 5 & \\
\hline Muito baixo & $\bigcirc$ & $\bigcirc$ & $\bigcirc$ & $\bigcirc$ & $\bigcirc$ & Muito alto
\end{tabular}

C12 Os conceitos essenciais estão nos níveis superiores da ontologia?

(os conceitos mais relevantes apareceram entre os primeiros elementos da lista de termos)

\begin{tabular}{lllllll} 
& 1 & 2 & 3 & 4 & 5 & \\
\hline Muito baixo & $\bigcirc$ & $\bigcirc$ & $\bigcirc$ & $\bigcirc$ & $\bigcirc$ & Muito alto
\end{tabular}

C13 Os conceitos encontram-se descritos em linguagem natural?

(os nomes dos termos ficaram claros?)

\begin{tabular}{lllllll} 
& 1 & 2 & 3 & 4 & 5 & \\
\hline Muito baixo & $\bigcirc$ & $\bigcirc$ & $\bigcirc$ & $\bigcirc$ & $\bigcirc$ & Muito alto
\end{tabular}

C14 A especificação formal dos conceitos casa com a descrição em linguagem natural? (a forma em que os conceitos apareceram nas relações foi correto?)

\begin{tabular}{lcccccc} 
& 1 & 2 & 3 & 4 & 5 & \\
\hline Muito baixo & $\bigcirc$ & $\bigcirc$ & $\bigcirc$ & $\bigcirc$ & $\bigcirc$ & Muito alto
\end{tabular}

C16 O número de conceitos é adequado?

(a quantidade de termos foi boa?)

\begin{tabular}{lllllll} 
& 1 & 2 & 3 & 4 & 5 & \\
\hline Muito baixo & $\bigcirc$ & $\bigcirc$ & $\bigcirc$ & $\bigcirc$ & $\bigcirc$ & Muito alto
\end{tabular}

C21 As relações essenciais estão na ontologia?

(as relações entre conceitos foram suficientes para falar de Branca de Neve? ) 
C22 Os conceitos estão correctamente relacionados?

\begin{tabular}{ccccccc} 
& 1 & 2 & 3 & 4 & 5 & \\
\hline Muito baixo & $\bigcirc$ & $\bigcirc$ & $\bigcirc$ & $\bigcirc$ & $\bigcirc$ & Muito alto
\end{tabular}

C23 As relações estão escritas convenientemente em linguagem natural?

(conseguiu entender os nomes das relações?)

\begin{tabular}{lcccccc} 
& 1 & 2 & 3 & 4 & 5 & \\
\hline Muito baixo & $\bigcirc$ & $\bigcirc$ & $\bigcirc$ & $\bigcirc$ & $\bigcirc$ & Muito alto
\end{tabular}

C24 ariedade das relações são apropriadas para o projecto?

( Padre $=>\mathrm{n}$-Tem $=>$ Hijos $)$ - Opcional

\begin{tabular}{lcccccc} 
& 1 & 2 & 3 & 4 & 5 & \\
\hline Muito baixo & $\bigcirc$ & $\bigcirc$ & $\bigcirc$ & $\bigcirc$ & $\bigcirc$ & Muito alto
\end{tabular}

C25 As relações possuem suas propriedades formais especificadas?

(O domínio e a imagem está correctamente definida?)

\begin{tabular}{lcccccc} 
& 1 & 2 & 3 & 4 & 5 & \\
\hline Muito baixo & $\bigcirc$ & $\bigcirc$ & $\bigcirc$ & $\bigcirc$ & $\bigcirc$ & Muito alto
\end{tabular}

C26 O número de relações é adequado para o projecto?

\begin{tabular}{lllllll} 
& 1 & 2 & 3 & 4 & 5 & \\
\hline Muito baixo & $\bigcirc$ & $\bigcirc$ & $\bigcirc$ & $\bigcirc$ & $\bigcirc$ & Muito alto
\end{tabular}

C31 A classificação dos conceitos desde várias perspectivas é a correta?

(A taxonomia está correta?)

\begin{tabular}{lllllll} 
& 1 & 2 & 3 & 4 & 5 & \\
\hline Muito baixo & $\bigcirc$ & $\bigcirc$ & $\bigcirc$ & $\bigcirc$ & $\bigcirc$ & Muito alto
\end{tabular}

C33 A relação de disjunção é usada convenientemente para as necessidades do sistema? (As relações de "não é"estavam corretas?)

\begin{tabular}{lllllll} 
& 1 & 2 & 3 & 4 & 5 & \\
\hline Muito baixo & $\bigcirc$ & $\bigcirc$ & $\bigcirc$ & $\bigcirc$ & $\bigcirc$ & Muito alto
\end{tabular}

C35 A profundidade máxima na hierarquia de conceitos é a adequada?

Opcional

\begin{tabular}{ccccccc} 
& 1 & 2 & 3 & 4 & 5 & \\
\hline Muito baixo & $\bigcirc$ & $\bigcirc$ & $\bigcirc$ & $\bigcirc$ & $\bigcirc$ & Muito alto
\end{tabular}

C36 A média de filhos por conceitos é a adequada?

(algumas relações taxonômicas possuem mais de um elemento, a média deles é adequada?)

\begin{tabular}{lllllll} 
& 1 & 2 & 3 & 4 & 5 & \\
\hline Muito baixo & $\bigcirc$ & $\bigcirc$ & $\bigcirc$ & $\bigcirc$ & $\bigcirc$ & Muito alto
\end{tabular}




\section{Apêndice D}

\section{Ontologia de Branca de Neve}

\section{Termos}

branca de neve

coração em uma caixa neve

dia seguinte

príncipe de o reino vizinho

lindo caixão de cristal

princesa branco de neve

animal de a floresta

história para o anão

dono de a cabana velhino maltrapilha

trabalhar em a limpeza

rainha

corpo de a princesa

mordida em esta maçã

pedaço de maçã

reino distante

reino vizinho

princesa

feticeira cruel lábio vermelho sete anõezinhos poção venenoso espelho mágico cabelo preto lindo jovem copo d'agua anão

\section{Relações de Equivalência}

- Branca_de_Neve $\sqsubseteq$ Belo

- Dono_De_A_Cabana $\sqsubseteq$ Sete_Anõezinhos

- Encantadora $\sqsubseteq$ Branca_De_Neve

- Meigo $\sqsubseteq$ Branca_De_Neve

- Pedaço_de_maçã $\sqsubseteq$ Maçã

- Pele $\sqsubseteq$ Cabelo_Preto

- Pele $\sqsubseteq$ Lábio_Vermelho

- Pele $\sqsubseteq$ Neve

- Rainha $\sqsubseteq$ Belo

- Rainha $\sqsubseteq$ Feiticeira_Cruel

- Voltar_Para_Casa $\sqsubseteq$ Dono_De_A_Cabeça

\section{Relações Taxonômicas}

- Anão $\sqsubseteq$ acordar Princesa $\sqcup$ can_be_alertado Anima_De_A_Floresta $\sqcup$ chegar Cabana $\sqcup$ deixar_levar Corpo_De_A_Princesa sqcup desfazer Feitiço $\sqcup$ estar_alojar Garganta_De_Branca $\sqcup$ foram_erquer Caixão 
- Branca_De_Neve $\sqsubseteq$ contar Historia_Para_O_Anão $\sqcup$ correr Floresta $\sqcup$ despedir Sete_Anão $\sqcup$ ficar Bonito $\sqcup$ ficar Sozinho $\sqcup$ ficar Vez $\sqcup$ lavar Louça $\sqcup$ partir_juntar Príncipe_Para_Um_Castelo_Distante $\sqcup$ passar Dia_Lavar $\sqcup$ torar Bonito $\sqcup$ vagar Floresta

- Caçador $\sqsubseteq$ colocar Coração_Em_Um_Caixo ப levar Rainha

- Certo_Dia $\sqsubseteq$ ver Branca_De_Neve

- Dia_Seguinte $\sqsubseteq$ convidar Menino_Para_Um_Passeio

- Mordida_Em_Esta_Maçã $\sqsubseteq$ fazer Branco_De_Neve_Dormir

- Poção_Venenoso $\sqsubseteq$ colocar Maçã

- Princesa $\sqsubseteq$ continuar Vivo $\sqcup$ continuar Vivo $\sqcup$ oferecer Copo_D'_Agua $\sqcup$ vestir Arrumação $\sqcup$ vestir Castelo $\sqcup$ vestir Trabalhar_Em_A_Limpeza $\sqcup$ vestir Trapo

- Rainha $\sqsubseteq$ ficar Doente $\sqcup$ ficar Curioso $\sqcup$ perguntar Espelho $\sqcup$ resolver_consultar Espelho

\section{Conceitos Superiores Encontrados}

- Colocar

- Domínio: Caçador $\sqcap$ Poção_Venenosa

- Imagem: -

- Ficar

- Dominio: Ser $\sqcap$ Ficar

- Imagem: 


\section{Apêndice E}

\section{Ferramenta para ajudar o usuário}

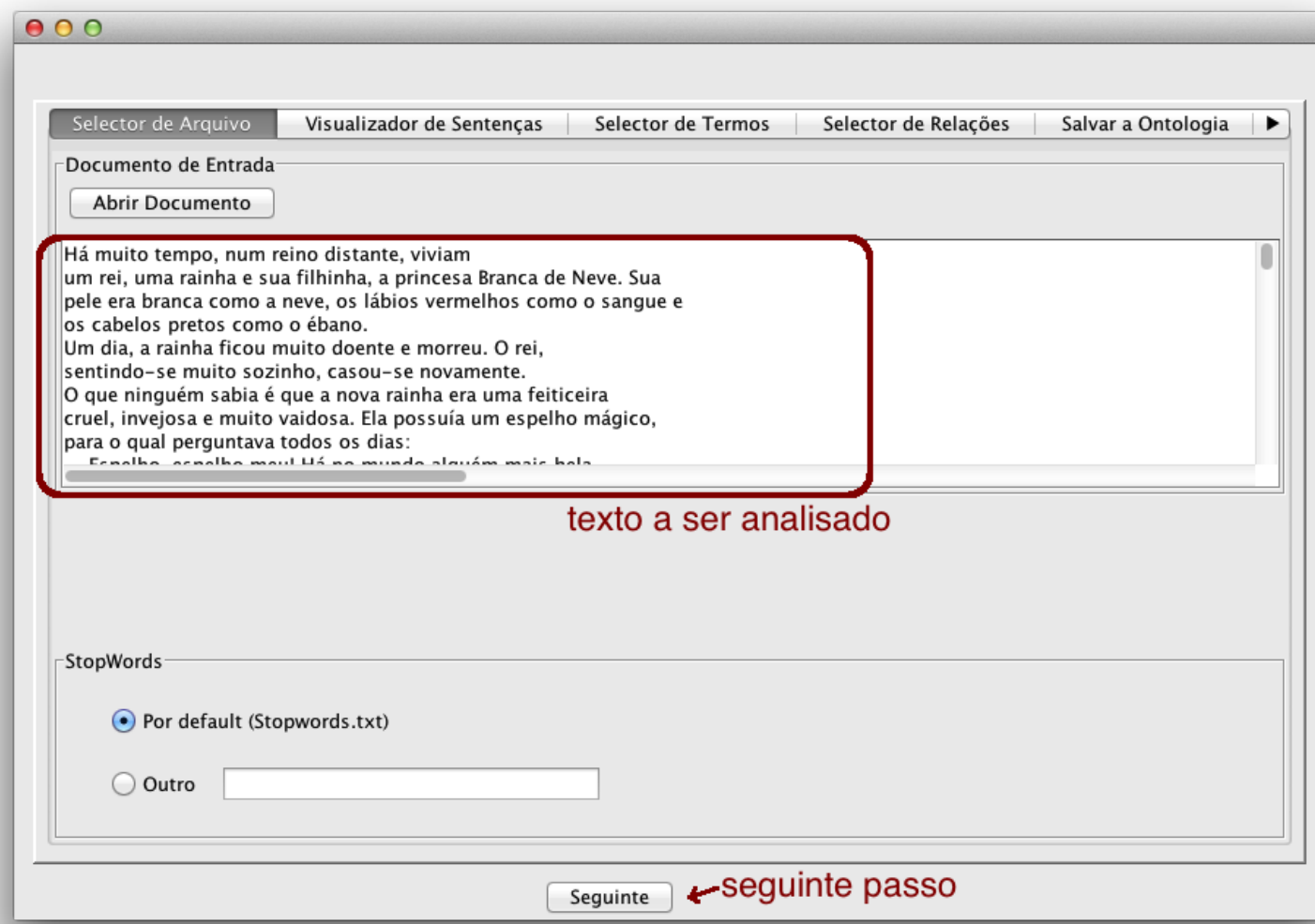

Figura E.1: Selecionando texto 


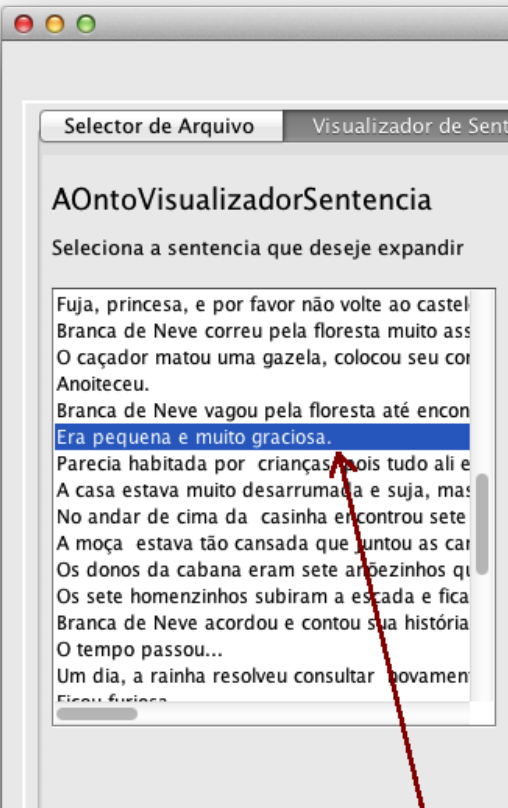

ao selecionar a sentença, a árvore sintática aparece na direita

Figura E.2: Visualizar a árvore sintática que Cogroo retorna para cada sentencia

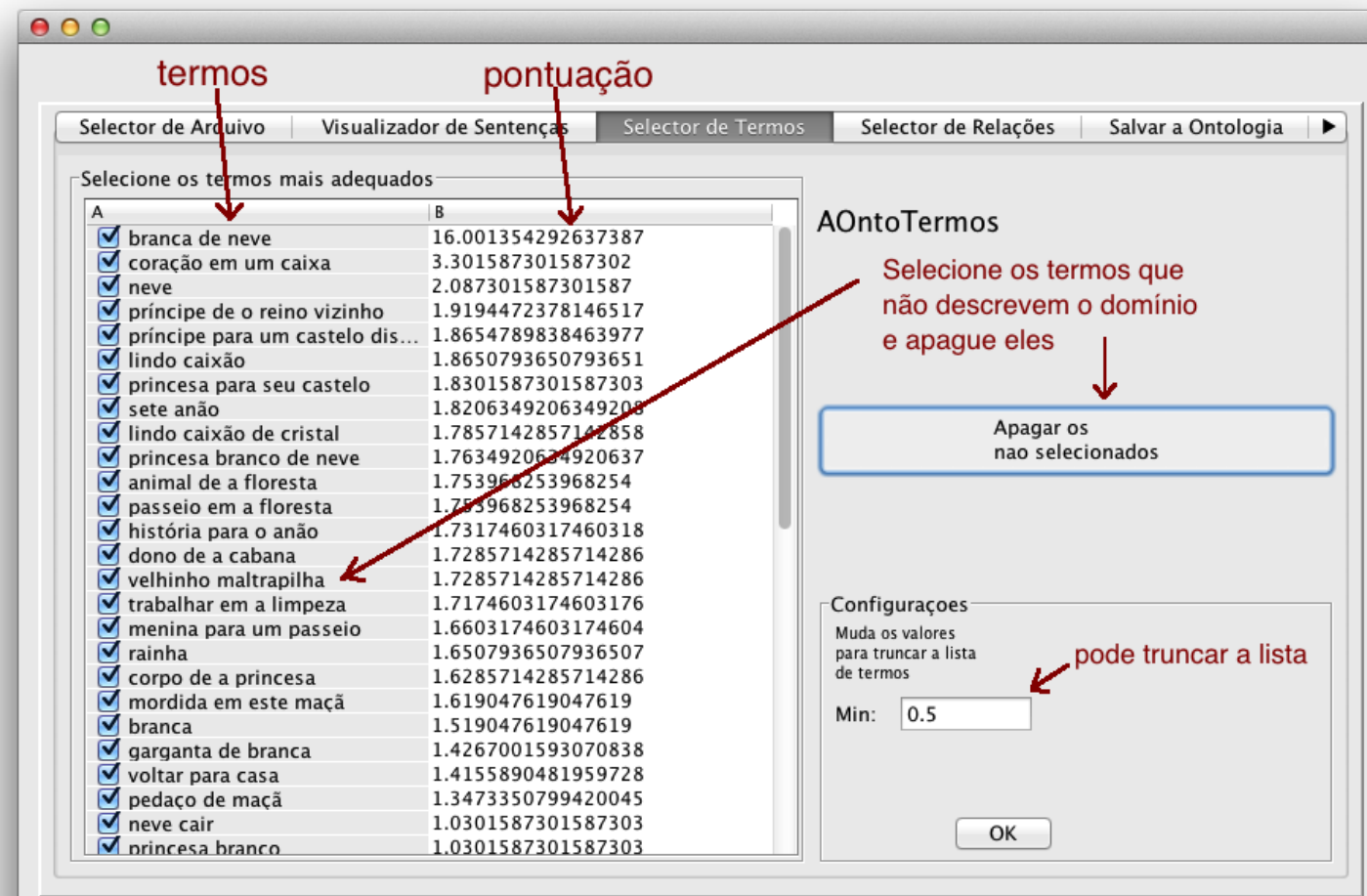




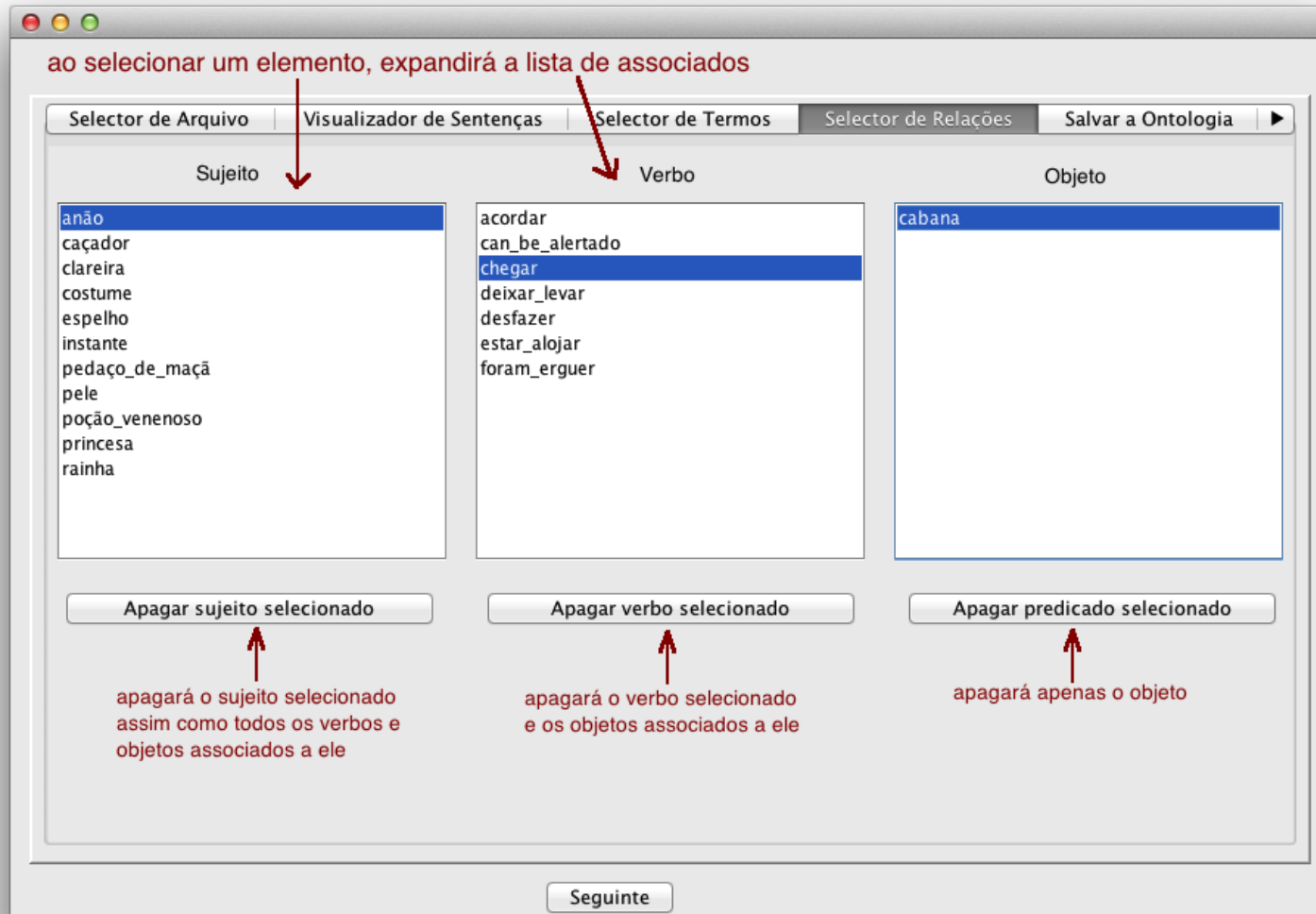

Figura E.4: Filtro de relações

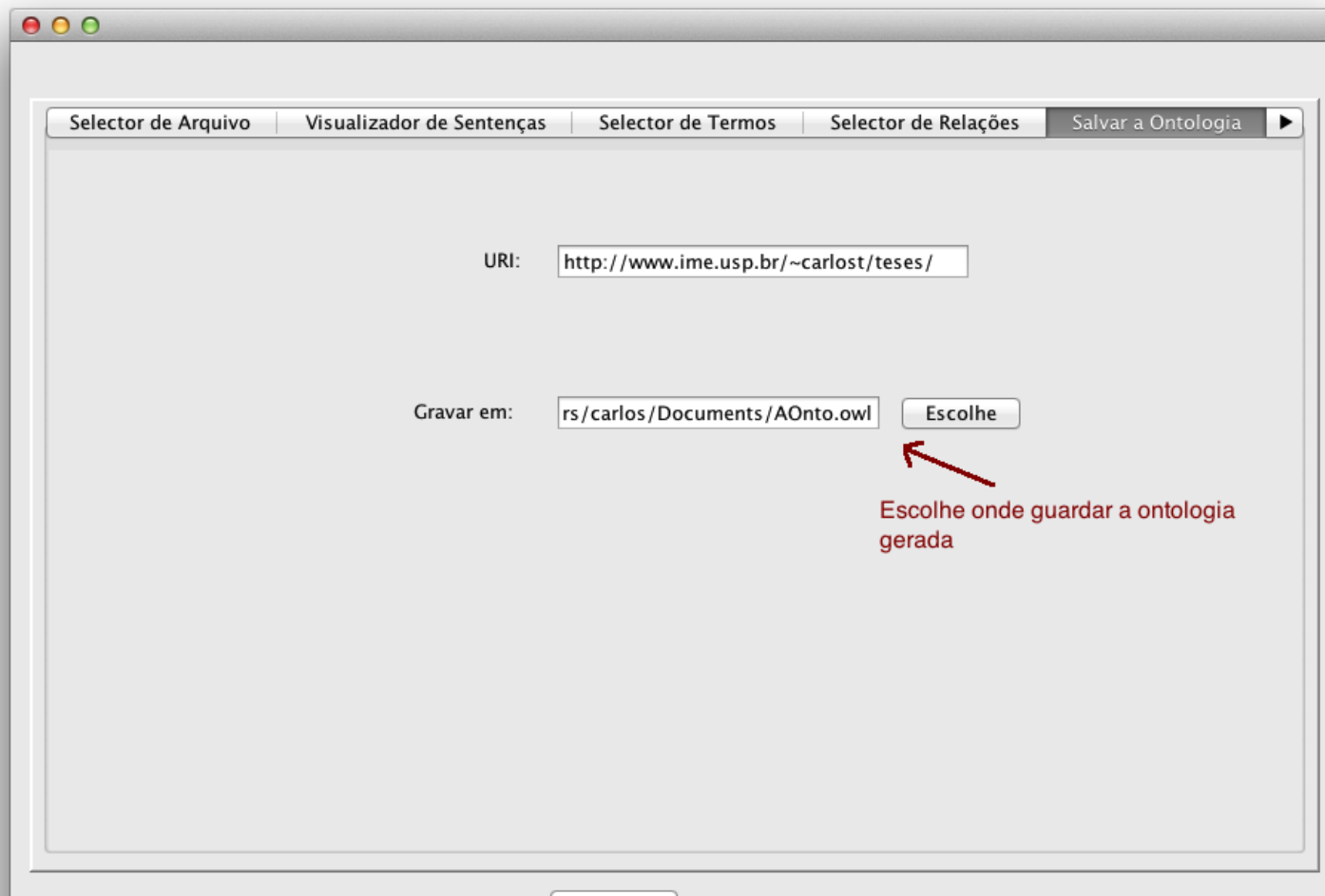


APÊNDICE E 


\section{Referências Bibliográficas}

Baségio(2006) Túlio Lima Baségio. Uma Abordagem Semi-automática para Identificação de Estruturas Ontológicas a partir de Textos na Língua Portuguesa do Brasil. Dissertação de Mestrado, Pontificia Universidade Católica do Rio Grande do Sul, Rio Grande do Sul. Citado na pág. 21

Bechara(2009) Evanildo Bechara. Moderna Gramática Portuguesa, Atualizada pelo Novo Acordo Ortográfico. 37 edição. Citado na pág. 25

Berners-Lee e Fischetti(1999) Tim Berners-Lee e Mark Fischetti. Weaving the Web : The Original Design and Ultimate Destiny of the World Wide Web by its Inventor. Harper San Francisco. ISBN 0062515861. URL http://www.amazon.com/exec/obidos/redirect?tag= citeulike07-20\&path=ASIN/0062515861. Citado na pág. 1

Bick(2000) E. Bick. The Parsing System"Palavras": Automatic Grammatical Analysis of Portuguese in a Constraint Grammar Framework. Aarhus University Press. Citado na pág. 8

Blomqvist(2005) Eva Blomqvist. Fully automatic construction of enterprise ontologies using design patterns: Initial method and first experiences. Em OTM Conferences (2), páginas 13141329. Citado na pág. 6

Botero e Ricarte(2008) Sergio William Botero e Ivan L. M. Ricarte. Extração de relações semânticas via análise de correlação de termos em documentos. Em Brazilian Symposium in Information and Human Language Technology - STIL. Citado na pág. 22

Brank et al.(2005) Janez Brank, Marko Grobelnik e Dunja Mladenic. A survey of ontology evaluation techniques. Em In In Proceedings of the Conference on Data Mining and Data Warehouses (SiKDD 2005. Citado na pág. 1, 41

Cabré(1999) M. T. Cabré. La Terminologia: Representación y Comunicación, volume 1a ed. Citado na pág. 15

Chomsky(1957) N. Chomsky. Syntactic Structures. Janua linguarum: Series minor. Mouton. URL http://books.google.com.br/books?id=55YaAAAAIAAJ. Citado na pág. 30

Cimiano(2006) Philipp Cimiano. Ontology Learning and Population from Text: Algorithms, Evaluation and Applications. Springer-Verlag New York, Inc., Secaucus, NJ, USA. ISBN 0387306323. Citado na pág. 6, 9, 21

Cimiano e Volköer(2005) Philipp Cimiano e Johanna Volköer. Text2onto - a framework for ontology learning and data-driven change discovery, 2005. Citado na pág. 7

Cimiano et al.(2003) Philipp Cimiano, Steffen Staab e Julien Tane. Automatic acquisition of taxonomies from text: Fca meets nlp. Em Proceedings of the ECML / PKDD Workshop on Adaptive Text Extraction and Mining, páginas 10-17, Cavtat-Dubrovnik, Croatia. URL http: //www.dcs.shef.ac.uk/ fabio/ATEM03/cimiano-ecml03-atem.pdf. Citado na pág. 1, 11

Colombo e Rahal(2009) Jucimara Colombo e Paula Rahal. Alterações genéticas em câncer de cabeça e pescoço. Revista Brasileira de Cancerologia, páginas 165-174. Citado na pág. 33 
Cormen et al.(2001) Thomas H. Cormen, Clifford Stein, Ronald L. Rivest e Charles E. Leiserson. Introduction to Algorithms, chapter 21. McGraw-Hill Higher Education, 2nd edição. ISBN 0070131511. Citado na pág. 12

Costa-Campos e Xavier(1991) Maria Henriqueta Costa-Campos e Maria Francisca Xavier. Sintaxe e Semântica do Português. Universidade Aberta. Citado na pág. 30

Deane(2005) Paul Deane. A nonparametric method for extraction of candidate phrasal terms. Em ACL '05: Proceedings of the 43rd Annual Meeting on Association for Computational Linguistics, páginas 605-613, Morristown, NJ, USA. Association for Computational Linguistics. doi: http: //dx.doi.org/10.3115/1219840.1219915. Citado na pág. 16

Dellschaft e Staab(2008) Klaas Dellschaft e Steffen Staab. Strategies for the evaluation of ontology learning. Em Proceedings of the 2008 conference on Ontology Learning and Population: Bridging the Gap between Text and Knowledge, páginas 253-272, Amsterdam, The Netherlands, The Netherlands. IOS Press. ISBN 978-1-58603-818-2. URL http://dl.acm.org/citation.cfm?id= 1563823.1563842. Citado na pág. 41

Drumond e Girardi(2008) Lucas Drumond e Rosario Girardi. A survey of ontology learning procedures. Em WONTO. Citado na pág. 1, 6

Duan et al.(2009) Jianyong Duan, Ru Li e Yi Hu. A bio-inspired application of natural language processing: A case study in extracting multiword expression. Expert Syst. Appl., 36(3):4876-4883. ISSN 0957-4174. doi: http://dx.doi.org/10.1016/j.eswa.2008.05.046. Citado na pág. 15, 16

Forgy(1982) Charles Forgy. Rete: A fast algorithm for the many pattern/many object pattern match problem. Artificial Intelligence, 19(1):17-37. ISSN 0004-3702. URL http://dx.doi.org/10. 1016/0004-3702(82)90020-0. Citado na pág. 5

Frantzi et al.(1998) Katerina Frantzi, Sophia Ananiadou e Junichi Tsujii. The C-value/NC-value: Method of automatic recognition for multi-word terms. Em Research and Advanced Technology for Digital Libraries, volume 1513 of Lecture Notes in Computer Science, páginas 520-520. Springer Berlin / Heidelberg. Citado na pág. 18

Freitas(2007) Maria Cláudia De Freitas. Elaboração Automática de Ontologias de Domínio. Discussão e Resultados. Tese de Doutorado, Pontificia Universidade Católica do Rio de Janeiro. Citado na pág. 41

Ganter(1984) Bernhard Ganter. Two basic algorithms in concept analysis. FB4-Preprint 831, TH Darmstadt. Citado na pág. 9

Ganter e Wille(1999) Bernhard Ganter e Rudolph Wille. Formal Concept Analysis: Mathematical foundations. Springer, Berlin-Heidelberg. Citado na pág. 9

Godin et al.(1991) R. Godin, R. Missaoui e H. Alaoui. Learning algorithms using a Galois lattice structure. Em Tools for Artificial Intelligence, 1991. TAI '91., Third International Conference on, páginas 22 -29. doi: 10.1109/TAI.1991.167072. Citado na pág. 2, 11

Grefenstette(1997) Gregory Grefenstette. SQLET: Short query linguistic expansion techniques, palliating one-word queries by providing intermediate structure to text. Em In Proceedings of the RIAO'97, páginas 500-509. Springer Verlag. Citado na pág. 21

Gruber(1993) Thomas R. Gruber. A translation approach to portable ontology specifications. Knowl. Acquis., 5(2):199-220. ISSN 1042-8143. doi: 10.1006/knac.1993.1008. URL http://dx. doi.org/10.1006/knac.1993.1008. Citado na pág. 3

Haav(2004) Hele-mai Haav. A semi-automatic method to ontology design by using fca. Em University of Ostrava, Department of Computer Science. Citado na pág. 12 
Harris(1968) Z.S. Harris. Mathematical Structures of Language. Wiley. Citado na pág. 22

Hearst(1992) Marti A. Hearst. Automatic acquisition of hyponyms from large text corpora. Em In Proceedings of the 14th International Conference on Computational Linguistics, páginas 539-545. Citado na pág. 21

Hitzler(2011) Pascal Hitzler. What's happening in semantic web: and what FCA could have to do with it. Em Proceedings of the 9th International Conference on Formal Concept Analysis, ICFCA'11, páginas 18-23, Berlin, Heidelberg. Springer-Verlag. ISBN 978-3-642-20513-2. URL http://dl.acm.org/citation.cfm?id=2008557.2008560. Citado na pág. 11

Ivan Kostial(2003) Jan Paralic Ivan Kostial. I.: Ontology-based information retrieval. Information and Intelligent Systems, Croatia, páginas 23-28. Citado na pág. 3

Jean-Pierre et al.(1997) Salah Ayt-Mokhtar Jean-Pierre, Salah Ait-mokhtar e Jean pierre Chanod. Subject and object dependency extraction using finite-state transducers. Em In Proceedings of the ACL/EACL'97 Workshop on Automatic Information Extraction and Building of Lexical Semantic Resources, páginas 71-77. Citado na pág. 47

Karlsson(1995) F. Karlsson. Constraint Grammar: A Language-Independent System for Parsing Unrestricted Text. Natural Language Processing. Mouton De Gruyter. ISBN 9783110141795. URL http://books.google.com.br/books?id=70IvVPlH63cC. Citado na pág. 23

Kinoshita et al.(2007) Jorge Kinoshita, Lais N. Salvador e Carlos E. D. Menezes. Cogroo an openoffice grammar checker. Em Proceedings of the Seventh International Conference on Intelligent Systems Design and Applications, páginas 525-530, Washington, DC, USA. IEEE Computer Society. ISBN 0-7695-2976-3. URL http://portal.acm.org/citation.cfm?id=1317534. 1318289. Citado na pág. 17

Lacerda-Dias(2004) Maria Abadia Lacerda-Dias. Extração automática de palavras-chave na língua portuguesa aplicada a dissertações e teses da área das engenharias. Dissertação de Mestrado, Universidade Estadual de Campinas - UNICAMP. Citado na pág. 16

Lagunilla e Rebollo(2004) Mariana Fernández Lagunilla e Alberto Anula Rebollo. Sintaxis y Cognición: Introducción a la gramática generativa. Citado na pág. 25, 30

Lopez et al.(1997) Mariano F. Lopez, Asuncion G. Perez e Natalia Juristo. METHONTOLOGY: from Ontological Art towards Ontological Engineering. Em Proceedings of the AAAI97 Spring Symposium, páginas 33-40, Stanford, USA. Citado na pág. 41

Lozano-Tello(2002) Adolfo Lozano-Tello. Métrica de Idoneidad de Ontologías. Tese de Doutorado, Universidad de Extremadura, Escuela Politécnica de Cáceres, Departamento de Informática. Citado na pág. 41

Maedche e Staab(2001) Alexander Maedche e Steffen Staab. Ontology learning for the semantic web. IEEE Intelligent Systems, 16(2):72-79. ISSN 1541-1672. doi: http://dx.doi.org/10.1109/ 5254.920602. Citado na pág. 6

Maria da Graça Krieger(2004) Maria José Bocorny Finatto Maria da Graça Krieger. Introdução a Terminologia: teoria EJ prática. Citado na pág. 15

Mizoguchi(2003) Riichiro Mizoguchi. Part 1: Introduction to ontological engineering. New Gen. Comput., 21(4):365-384. ISSN 0288-3635. doi: http://dx.doi.org/10.1007/BF03037311. Citado na pág. 3

Noy e Mcguinness(2001) Natalya F. Noy e Deborah L. Mcguinness. Ontology development 101: A guide to creating your first ontology. Online, 2001. URL http://www.ksl.stanford.edu/people/ $\mathrm{dlm} /$ papers/ontology101/ontology101-noy-mcguinness.html. Citado na pág. 3 
Pantel e Lin(2001) Patrick Pantel e Dekang Lin. A statistical corpus-based term extractor. Em AI '01: Proceedings of the 14th Biennial Conference of the Canadian Society on Computational Studies of Intelligence, páginas 36-46, London, UK. Springer-Verlag. ISBN 3-540-42144-0. Citado na pág. 16

Peng e Zhao(2007) Xin Peng e Wenyun Zhao. An incremental and FCA-based ontology construction method for semantics-based component retrieval. Em QSIC, Seventh Quality Software International Conference, páginas 309-315. Citado na pág. 11

Perini(1976) Mário A. Perini. A Gramática Gerativa; Introdução ao Estudo da Sintaxe Portuguesa. Belo Horizonte. Citado na pág. 30, 31

Ribeiro-Junior(2008) Luiz Carlos Ribeiro-Junior. OntoLP: Construção Semi-Automática de Ontologias a partir de Textos da Língua Portuguesa. Dissertação de Mestrado, Universidade do Vale do Rio dos Sinos, São Leopoldo. Citado na pág. 1, 7, 17, 35

Ruwet(1975) Nicolas Ruwet. Introdução à Gramática Gerativa. Universidade de São Paulo. Citado na pág. 30

Sag et al.(2001) Ivan A. Sag, Timothy Baldwin, Francis Bond, Ann Copestake e Dan Flickinger. Multiword expressions: A pain in the neck for NLP. Em In Proc. of the 3rd International Conference on Intelligent Text Processing and Computational Linguistics (CICLing-2002, páginas 1-15. Citado na pág. 15

Sánchez(2009) David Sánchez. Domain ontology learning from the web. The Knowledge Engineering Review, 24(04):413. URL http://www.journals.cambridge.org/abstract_ S0269888909990300. Citado na pág. 21, 22

Schutz e Buitelaar(2005) Er Schutz e Paul Buitelaar. Relext: A tool for relation extraction from text in ontology extension. Em In: Proceedings of the 4th International Semantic Web Conference (ISWC). (2005, página 05. Citado na pág. 23

Shamsfard e Abdollahzadeh Barforoush(2003) Mehrnoush Shamsfard e Ahmad Abdollahzadeh Barforoush. The state of the art in ontology learning: a framework for comparison. Knowl. Eng. Rev., 18(4):293-316. ISSN 0269-8889. doi: http://dx.doi.org/10.1017/S0269888903000687. Citado na pág. 21

Shearer et al.(2008) Rob Shearer, Boris Motik e Ian Horrocks. Hermit: A highly-efficient OWL reasoner. Em Alan Ruttenberg, Ulrile Sattler e Cathy Dolbear, editors, Proc. of the 5th Int. Workshop on OWL: Experiences and Directions (OWLED 2008 EU), Karlsruhe, Germany. Citado na pág. 5

Silva e Koch(2001) Maria Cecilia Perez De Souza E Silva e Ingedore Grunfeld Villaça Koch. Lingüistica Aplicada ao Português: Sintaxe. São Paulo. ISBN 85-249-0204-3. Citado na pág. 30

Sirin et al.(2007) Evren Sirin, Bijan Parsia, Bernardo Cuenca Grau, Aditya Kalyanpur e Yarden Katz. Pellet: A practical OWL-DL reasoner. J. Web Sem., 5(2):51-53. Citado na pág. 5

Staab e Studer(2004) Steffen Staab e Rudi Studer. Handbook on Ontologies, chapter 1, páginas 1-23. International Handbooks on Information Systems. Springer. ISBN 3-540-40834-7. Citado na pág. 4

Tomokiyo e Hurst(2003) Takashi Tomokiyo e Matthew Hurst. A language model approach to keyphrase extraction. Em Proceedings of the ACL 2003 workshop on Multiword expressions, páginas 33-40, Morristown, NJ, USA. Association for Computational Linguistics. doi: http: //dx.doi.org/10.3115/1119282.1119287. Citado na pág. 16 
Vrandečić(2010) Denny Vrandečić. Ontology Evaluation. Tese de Doutorado, KIT, Fakultät für Wirtschaftswissenschaften, Karlsruhe. Citado na pág. 41

Wang e He(2006) Jian Wang e Keqing He. Towards representing FCA-based ontologies in semantic web rule language. Em Proceedings of the Sixth IEEE International Conference on Computer and Information Technology, CIT '06, página 41, Washington, DC, USA. IEEE Computer Society. ISBN 0-7695-2687-X. doi: http://dx.doi.org/10.1109/CIT.2006.186. URL http://dx.doi.org/10.1109/CIT.2006.186. Citado na pág. 1, 12

Wille(1982) Rudolf Wille. Restructuring lattice theory: an approach based on hierarchies of concepts. Em Ivan Rival, editor, Ordered sets, páginas 445-470, Dordrecht-Boston. Reidel. Citado na pág. 1

Wray(2002) Alison Wray. Formulaic Language and the Lexicon. Cambridge University Press. Citado na pág. 15

Yang e Callan(2008) Hui Yang e Jamie Callan. Metric-based ontology learning. Em ONISW '08: Proceeding of the 2nd International Workshop on Ontologies and Information Systems for the Semantic Web, páginas 1-8, New York, NY, USA. ACM. ISBN 978-1-60558-255-9. doi: http://doi.acm.org/10.1145/1458484.1458486. Citado na pág. 6 